University of Louisville

ThinkIR: The University of Louisville's Institutional Repository

\title{
An examination of professional niche sport sponsorship : sponsors' objectives and selection criteria.
}

Greg P. Greenhalgh

University of Louisville

Follow this and additional works at: https://ir.library.louisville.edu/etd

\section{Recommended Citation}

Greenhalgh, Greg P., "An examination of professional niche sport sponsorship : sponsors' objectives and selection criteria." (2010). Electronic Theses and Dissertations. Paper 529.

https://doi.org/10.18297/etd/529

This Doctoral Dissertation is brought to you for free and open access by ThinkIR: The University of Louisville's Institutional Repository. It has been accepted for inclusion in Electronic Theses and Dissertations by an authorized administrator of ThinkIR: The University of Louisville's Institutional Repository. This title appears here courtesy of the author, who has retained all other copyrights. For more information, please contact thinkir@louisville.edu. 


\title{
AN EXAMINATION OF PROFESSIONAL NICHE SPORT SPONSORSHIP: SPONSORS' OBJECTIVES AND SELECTION CRITERIA
}

\author{
By
}

\author{
Greg P. Greenhalgh \\ B.S.M., Brock University, 2003 \\ M.A., Central Michigan University, 2007
}

\begin{abstract}
A Dissertation
Submitted to the Faculty of the

College of Education of the University of Louisville

in Partial Fulfillment of the Requirements

for the Degree of
\end{abstract}

Doctor of Philosophy

Department of Health and Sport Sciences

University of Louisville

Louisville, Kentucky

August 2010 
Copyright 2010 by Gregory P. Greenhalgh

All rights reserved 

AN EXAMINATION OF PROFESSIONAL NICHE SPORT SPONSORSHIP: SPONSORS' OBJECTIVES AND SELECTION CRITERIA

\section{By}

Gregory P. Greenhalgh

B.S.M., Brock University, 2003

M.A., Central Michigan University, 2007

A Dissertation Approved on

July 29,2010

by the following Dissertation Committee:

T. Christopher Greenwell, Chair

Mary A. Hums

Susan G. Lasky

Alexis Lyras

Anita M. Moorman 


\section{ACKNOWLEDGMENTS}

I would like to take this opportunity to thank the numerous people who assisted me through this dissertation journey. To my dissertation committee I am forever grateful. First, I would like to extend my sincerest gratitude to my dissertation chair Dr. Chris Greenwell. Your flexibility and availability outside the typical business hours made the completion of this project possible. I think I must also send many thanks to your family, as I am sure time with them was sacrificed through this project. I would also like to thank Dr. Mary Hums, your open door and giving nature were very much appreciated and well used throughout my journey. Professor Anita Moorman, I must thank you for always challenging me to look at problems from all angles and not be afraid to step outside of my comfort zone. I must also thank Dr. Sue Lasky, your kind words and insightful leadership was very much appreciated. Dr. Lyras thank you so much for your methodological support and willingness to assist from all reaches of the globe.

I must also thank my fellow doctoral students: Dr. Enzo Chen, Dr. Marion Hambrick, Katie Sime Mc Jury, Nick Stover, Dr. Sagatomo Tokuyama, Jason Simmons, and Dr. Dustin Thorn. Your willingness to discuss ideas and concerns anytime anywhere was instrumental in the completion of this journey. I would also like to thank my friends outside of school whose support and inspirational words kept me going some days. 


\section{DEDICATION}

This dissertation is dedicated to my loving family and loving girlfriend Liz. To my extended family, aunts, uncles and cousins: your continuous support, kind words, inspiration and motivation were instrumental pushing me to achieve this and shaping me into the man I am today. To my parents, Dave and Gail, I could never have asked for better role models. Your drive, ambition, and quest for the best was obviously passed down. Your support, in all aspects, made this happen. You made my dreams possible. To my brother Todd, thank you for supporting me, grounding me, and having faith in me. Finally, I would like to thank Liz. Your unwavering support and encouragement pushed me through many tough times. Your unselfish nature and confidence in my abilities were instrumental. I am forever indebted to you for all of your assistance throughout this whole journey as we maneuvered it together.

Thank you all, I love you all very much! 


\title{
ABSTRACT \\ NICHE SPORT SPONSORSHIP
}

\author{
Gregory P. Greenhalgh
}

July 29,2010

Sport organizations face tremendous pressure to secure sponsorship support (Copland et al., 1996). Professional niche sports face even greater pressure as sponsorship support often determines whether an event can even take place (Sutton, 2009). Kuzma et al. (1993) stated the number one principle in selling sponsorships is establishing a close match between sponsor objectives and event characteristics.

The purpose of the current study was to investigate the objectives sponsors aim to achieve through niche sport sponsorship as well as understand the selection criteria used to screen niche sport sponsorship opportunities.

A survey of 352 sport sponsorship decision-makers, yielding a response rate of $25.3 \%(N=89)$ with 32 usable professional niche sport sponsor responses revealed many interesting findings. Respondents indicated the most important objectives they aim to achieve through niche sport sponsorship include: (a) increase target market awareness, (b) increase sales/market share, (c) increase public awareness, (d) enhance company image, and (e) become involved in the community.

Niche sport sponsorship decision-makers within the current study also reported the most important selection criteria used to screen niche sport sponsorship opportunities to include: (a) cost effectiveness, (b) company image fit within the target market of the 
sport property, (c) flexibility of the sport property, (d) spectator demographics, and (e) company product/service image fit with the sport image.

Finally, findings suggested that different companies engaged in niche sport sponsorships for different reasons. Some companies placed a greater importance on target market awareness than others, while some were more concerned with spectator demographics.

In summary, niche sport properties must be well aware of their fan base and community reach and how these factors match the target market of potential sponsors. Findings from the current study indicated niche sport properties must be flexible in assisting sponsors achieve their sponsorship objectives. Finally, niche sport properties should demonstrate ways in which a potential sponsor can increase awareness within their target market while increasing sales/market share within their sponsorship proposals. 


\section{TABLE OF CONTENTS}

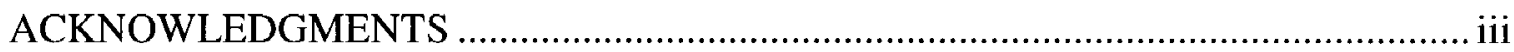

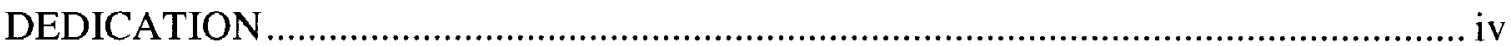

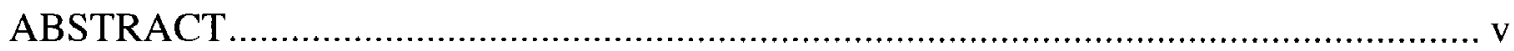

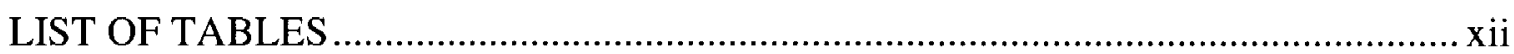

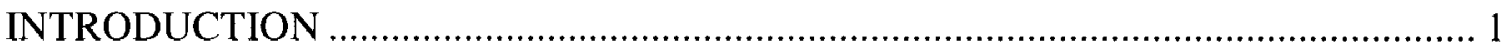

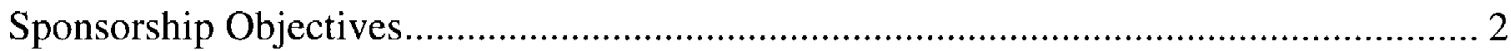

Sponsorship Selection Criteria.................................................................................. 3

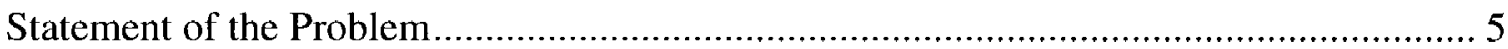

Unique Objectives and Selection Criteria................................................................. 5

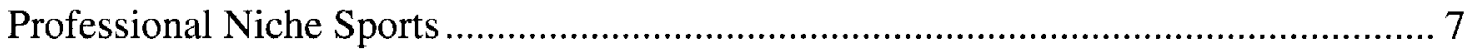

Benefits of Niche Sport Sponsorship....................................................................... 10

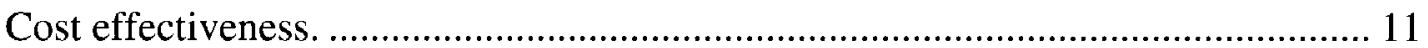

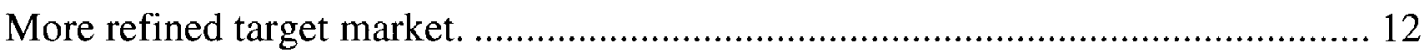

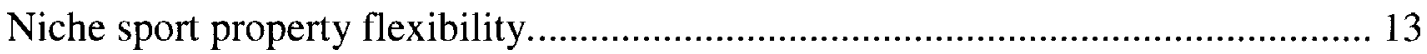

Decreased niche sponsor clutter......................................................................... 14

Professional Niche Sports' Need for Sponsorship..................................................... 14 
Purpose of the Study

Significance of the Study

Delimitations

Limitations

Definition of Terms.

REVIEW OF RELATED LITERATURE.

Sport Sponsorship Defined

Sponsorship Decision-Makers

Increase public corporate awareness.

Enhance corporate image

Alter public perception 34

Getting involved in the community . 34

Building business/trade goodwill. 34

Enhance employee relations/motivation 35

Increase target market awareness. 36

Identify/enhance image within target market (positioning).

Increase sales/market share

Summary 46

Sport Sponsorship Selection Criteria. 


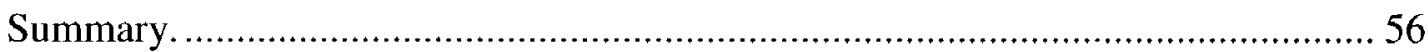

Sport Specific Sponsorship Selection Criteria ..........................................................58

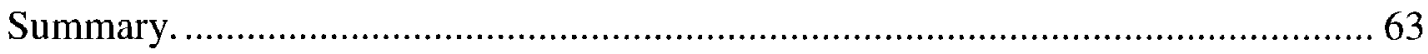

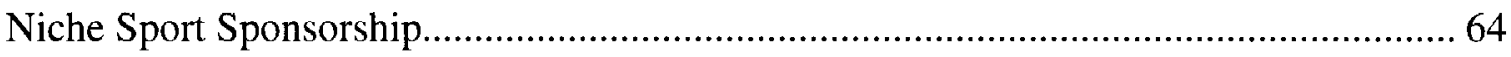

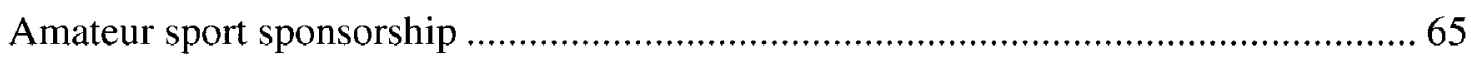

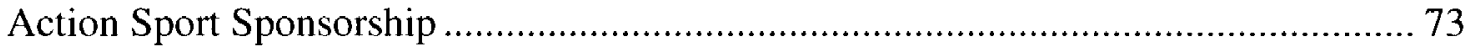

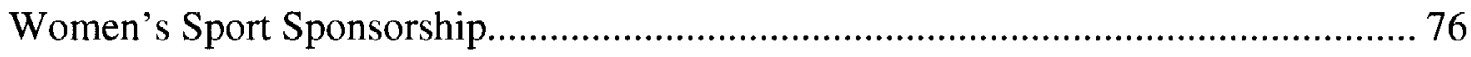

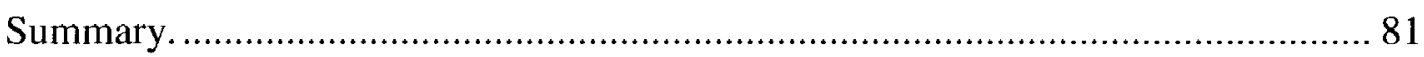

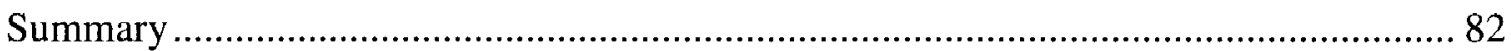

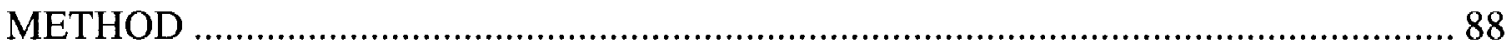

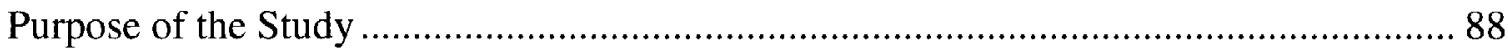

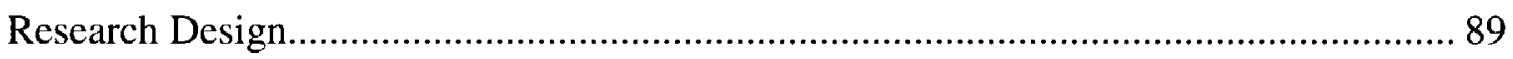

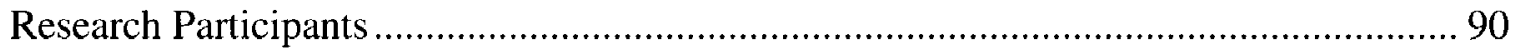

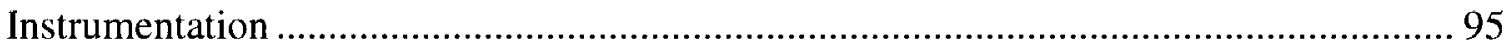

Professional Niche Sport Identification ................................................................. 96

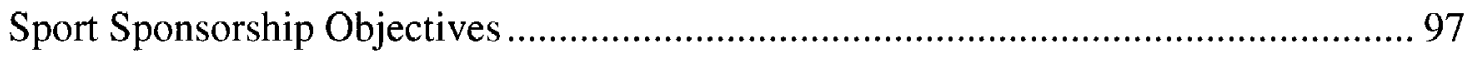

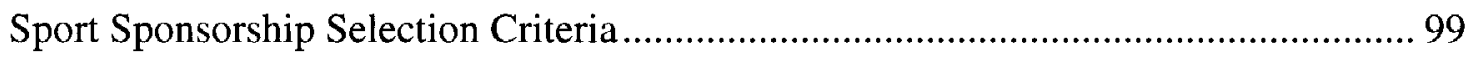

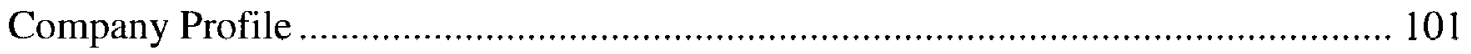

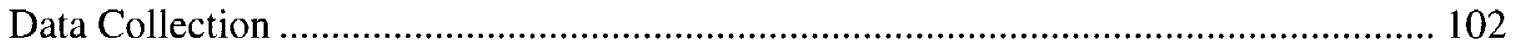


Data Analysis

Assumptions

Response Bias

RESULTS

Preliminary Analysis.

Response Rate. 108

Respondent Bias.

Descriptive Statistics

Procedures

Results for Research Question One

Results for Research Question Two.

Results for Research Questions Three

Statistical Power.

Assumptions......

Company Size

Company Scope

Frequency of Product/Service Purchase

Results for Research Question Four

Company Size.

Company Scope 
Summary

DISCUSSION

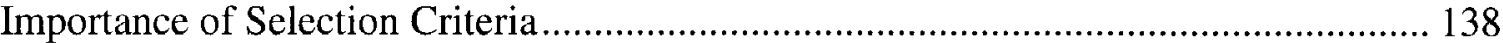

Most Important Niche Sport Sponsorship Selection Criteria ..................................... 139

Least Important Niche Sport Sponsorship Selection Criteria .................................. 145

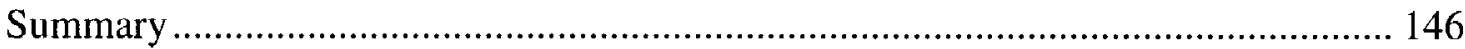

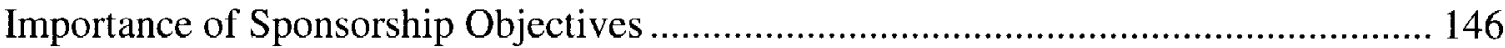

Most Important Niche Sport Sponsorship Objectives ............................................ 148

Least Important Niche Sport Sponsorship Objectives ............................................. 151

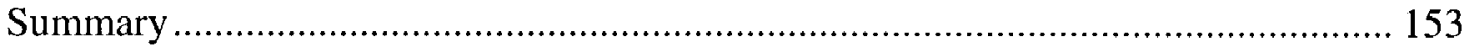

Variance by Company Demographics ...................................................................... 153

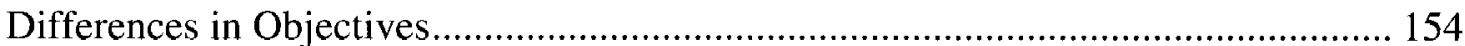

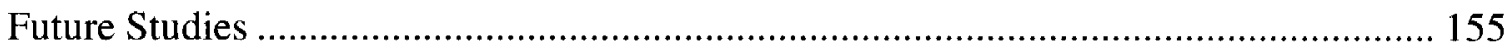

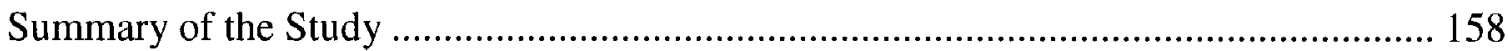

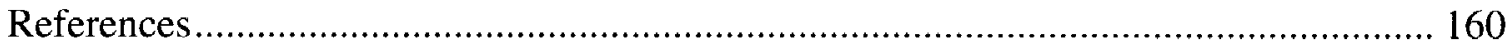

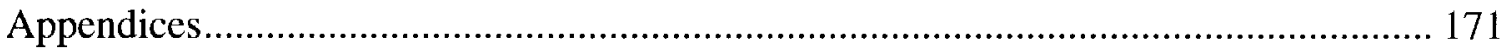

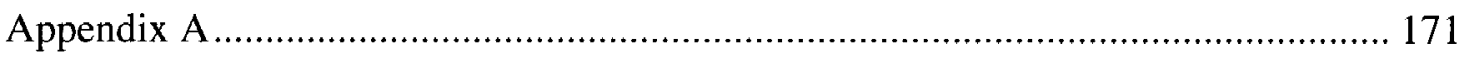

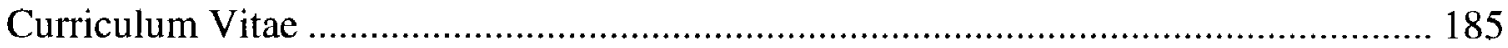




\section{LIST OF TABLES}

TABLE

PAGE

3.1. Sport Sponsors' Survey Response Rates.................................................95

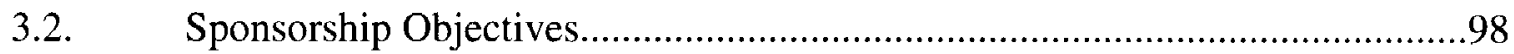

4.1. Professional Niche Sport Represented........................................................ 112

4.2. Professional Niche Sponsors Represented..........................................113

4.3. Company Demographic Frequencies....................................................... 115

4.4. Means and Standard Deviations of Sponsorship Selection Criteria..............117

4.5. Response Frequencies of Sponsorship Selection Criteria........................119

4.6. Top Five Ranked Sponsorship Selection Criteria.................................. 121

4.7. Means and Standard Deviations of Sponsorship Objectives........................123

4.8. Response Frequencies of Sponsorship Objectives.................................. 124

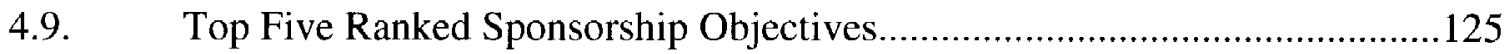

4.10. Comparison of Sponsorship Objectives Means by Company Size................129

4.11. Comparison of Sponsorship Objectives Means by Company Scope.............131

4.12. Comparison of Sponsorship Objectives by Industry Segment.....................132

4.13. Comparison of Sponsorship Selection Criteria Means by Company Size......134

4.14. Comparison of Sponsorship Selection Criteria Means by Company Scope...135

4.15. Comparison of Sponsorship Selection Criteria Means by Industry Segment.136 


\section{CHAPTER I}

\section{INTRODUCTION}

Sport organizations face tremendous pressure to seek out and secure sponsorship support (Copeland, Frisby, \& McCarville, 1996). Sponsorship was defined by Meenaghan (1991) as "an investment in cash or in-kind, in an activity, in return for the exploitable commercial potential associated with that activity" (p.36) and has been described as the 'financial backbone' for many sport properties and can be the central element in the image of an event. Within North American society, an unsponsored event is often viewed as second rate and of little significance (Lamont \& Dowell, 2007). Therefore, the attainment of sponsorship support is among the most critical tasks of any sport manager. Hence, it is very important for sport mangers to have a firm understanding of the sponsorship decision-making process. The sponsorship decision-making process includes all the factors that affect the sponsorship decision-maker (the person(s) within a corporation whom selects which sponsorship opportunities their company will support and which they will not support). These factors include the sponsorship decision-maker themselves as well as the corporate sponsorship objectives and specific selection criteria.

Central to most sport sponsorships is the exchange between the sponsor (company providing assistance to the sport property) and the sport property (sport team, league, tour, event, or individual athlete). McCarville and Copeland (1994) noted successful sponsorships are based on the assumption each party (sponsor and sport property) will provide a resource valued by the partnering organization and reciprocated. Clearly, in 
order to attract sponsors, sport properties must identify benefits they can provide a potential sponsor, which the sponsor will value. These benefits may be exchanged for money, or goods or services, provided by the sponsor to the sport property. Benefits provided by sponsorship can often mean the difference between a successful or unsuccessful sporting event, team, league, or tour.

\section{SPONSORSHIP OBJECTIVES}

Sport properties fundamentally require a firm understanding of the rationale for sponsors to engage sponsorship relationships. Sponsorship objectives have been defined as overarching corporate marketing, communications, or public relations goals aimed to be achieve through sponsorship (Abratt, Clayton, \& Pitt, 1987). According to Kuzma, Shanklin, and McCalley (1993), the number one principle in selling sponsorships is exhibiting a close match between corporate objectives and event characteristics. Abratt et al., (1987) reported that sport sponsorship was a viable vehicle corporations could utilize to achieve corporate marketing, communications, and public relations objectives.

Due to the immense importance placed on sport properties to understand the goals and expectations of potential sponsors, there has been an abundance of research on corporate sport sponsorship objectives. Yet, it is difficult to classify corporate sponsorship objectives in a clear-cut way because companies frequently have a number of overlapping and interacting objectives within one sponsorship relationship (Mullin, Hardy, \& Sutton, 2007). For example, MCI Corporation uses its sponsorship of the Heritage Golf Classic to increase awareness, build their relationship with their customers, and prospect new customers. Even after a thorough review of academic writing and 
empirical research combined with practical findings, Mullin et al. (2007) found no specific single corporate objective dominated the decision-making process concerning whether or what sport property to sponsor.

Some of the most commonly cited sport sponsorship objectives include increasing corporate awareness, enhancing company image, becoming involved in the community, building trade relations, enhancing employee relations, and increasing sales/market share (Ferreira, Hall, \& Bennett, 2008; Irwin, Sutton, \& McCarthy, 2008; Stotlar, 2009). Whereas sponsorship objectives are intrinsic to the sponsoring company, many other factors influence the decision-making process. Sponsorship selection criteria are also part of the sponsorship decision-making process and were defined as 'sport property specific factors potential sponsors also utilize to in the sponsorship decision-making process' within the current study.

\section{SPONSORSHIP SELECTION CRITERIA}

Once sponsors clearly define sponsorship objectives, those objectives help guide the sponsorship decision-making process (Irwin et al., 2008). However, sponsorship decision-making is not based exclusively on the ability of the relationship to achieve corporate objectives. To screen sponsorship opportunities, corporations use a variety of selection criteria such as the cost of the sponsorship opportunity, the demographics of the sport property's fan base, and hospitality opportunities. Sponsorship selection criteria may be linked to a specific sponsorship objective or may be a standalone criterion. An example of a standalone criterion is the cost of the sponsorship. This factor is not directly linked to a corporate marketing, communications, or public relations objective but certainly influences the decision to embark on a given sponsorship opportunity. 
Opportunities for corporate signage at an event would be an example of a selection criterion associated with a sponsorship objective. Alternatively, signage opportunities would not likely be a stand-alone marketing, communications, or public relations objective of an organization. However, a company may be looking to increase awareness as one of its marketing objectives and signage at an event would certainly assist in achieving of this objective. Sponsorship selection criteria is an area of growing importance, and sport managers able to understand the key influences in the selection process will increase their probability of creating a successful sponsorship proposal (Aguilar-Manjarrez, Thwaites, \& Maule, 1997). Fullerton (2010) noted thousands of companies sponsor sport properties but do not all want the same set of components within their sponsorship. By understanding the prospect's goals and expectations, sport managers can create a sponsorship proposal more closely aligned with the needs and wants of the prospective company, subsequently enhancing the value of the sponsorship proposal (Copeland et al., 1996; Fullerton, 2010; Jowdy \& McDonald, 2002; Lamont \& Dowell, 2007; Lough, Irwin, \& Short, 2000; Mueller \& Roberts, 2008; Sam, Batty, \& Dean, 2005; Stotlar, 2009).

Commonly cited selection criteria include: media coverage at the local, regional, and national level (Abratt et al., 1987; Crowley, 1991; Irwin, Asimakopoulos, \& Sutton, 1994; Scott \& Suchard, 1992; Thwaites, Aguilar-Manjarrez, \& Kidd, 1998; Witcher, Craigen, Culligan, \& Harvey, 1991); ability to reach a specific audience, including demographics and/or psychographics (Irwin et al., 1994; Mack, 1999; Meenaghan, 1991; Thwaites et al., 1998); hospitality opportunities (Crowley, 1991; Irwin et al., 1994; McCarthy \& Irwin, 2000; Meenaghan, 1991; Scott \& Suchard, 1992); audience size, both 
on-site and off-site (Irwin et al., 1994; Meenaghan, 1991); sport/sponsor product fit

(Irwin et al., 1994; Thwaites et al., 1998); and cost of the sponsorship opportunity (Irwin et al., 1994; Meenaghan, 1991).

\section{STATEMENT OF THE PROBLEM}

Current issues within sport sponsorship are discussed below. A brief insight into the unique sport sponsorship objectives and selection criteria corporations consider when engaging in sport sponsorship relationships is presented. The remainder of the section is dedicated to an introduction of professional niche sport and the potential benefits these types of sport properties may offer a prospective sponsor. Finally, a discussion concerning the importance of sponsorship funding for professional niche sport is presented.

\section{Unique Objectives and Selection Criteria}

Numerous researchers have indicated sponsors do not evaluate all sponsorship opportunities using identical guidelines (Copeland et al., 1996; Irwin \& Sutton, 1994; Kuzma et al., 1993; Lough, Irwin, \& Short, 2000; Lough \& Irwin, 2001). In fact, different companies sponsoring the same event may do so for entirely different reasons (Irwin \& Sutton, 1994).

Lough and Irwin (2001) proposed the sponsorship lifecycle theory. Lough and Irwin (2001) argued mainstream professional sport properties within the United States has reached a level of maturation and sponsors of these types of sport properties have set sponsorship objectives based on quantifiable results such as increasing sales and market share. Lough and Irwin (2001) based the maturity of a sport property on sponsor's awareness of a sport property and the growth rate of sponsorship sales. Sport properties 
considered to be less mature or still in the growth stage have very rapid sponsorship sales increases. Sport properties within the mature stage may still have sponsorship growth, but at a much slower pace.

Furthermore, Lough and Irwin argued sport properties relatively 'new' to corporate sponsorship, such as women's sports, may have sponsors who delay expectations of quantifiable outcomes until the sport property has had sufficient time to sustain market affiliation (Lough \& Irwin, 2001). During the less mature phase, sponsors may be more focused on achieving a combination of less tangible goals such as awareness and image based objectives as well as market-driven goals such as increased sales and market share.

Several researchers have produced findings in support of this theory. Lough, Irwin, and Short (2000) reported Canadian companies engaged in sport sponsorship ranked social responsibility and community involvement significantly higher than sport sponsors in the United States. Corporate sport sponsorship has been much more prevalent within the United States as compared to Canada. Therefore, the Canadian sport sponsorship landscape may be considered less mature, much like the women's sport properties analyzed in Lough and Irwin's (2001) study. Similar findings were reported by Thjomoe, Olson, and Bronn (2002) in their study on Norwegian sport sponsors' objectives. Lough and Irwin (2001) found sponsors engaged in a sponsorship relationship with both a women's only sport and a 'traditional' sport (co-ed or male only) were more interested in achieving sales and market share objectives for the 'traditional' sport sponsorship and image and awareness objectives within the women's sport sponsorship. 
Interestingly, the majority of research conducted on corporate sponsorship objectives and selection criteria within North America has been conducted at the mainstream, major professional, Division I college, or Olympic levels (Wartella, 2009). Yet, an entire subsection of profession sports, termed professional niche sports, exists in relative abundance within North America. However, it is not understood whether the sponsorship lifecycle applies equally to any sport event utilizing sponsorship activities.

Of particular not is North American professional niche sport. Understanding corporations view sport properties as unique ventures capable of achieving distinct objectives and corporations assess sponsorship opportunities distinctly from each other, professional niche sports would be well served to understand how they are being evaluated by potential sponsors. In addition, niche sports may be able to offer unique opportunities not provided by other sport properties.

\section{Professional Niche Sports}

Commonly, the term professional sport conjures visions of major league, elite level sport played in front of tens of thousands of fans and broadcast to millions of fans nationally or internationally. However, the North American professional sport landscape includes a variety of niche, non-mainstream, fringe, minor league, non-traditional, or emerging professional sports. Several researchers have provided examples of niche sports including the National Lacrosse League (NLL)(Hanas,2007; Livingstone, 2009; Tedesco, 2009), Professional Bull Riders (PBR)(Livingstone, 2009; McCarthy, 2006; Tedesco, 2009), Association of Volleyball Professionals (AVP)(Tedesco, 2009), Extreme/Action Sports (Hochman, 1999; Mickle, 2010), Women’s National Basketball Association (WNBA)(Livingstone, 2009; Tedesco, 2009), and Women's Professional Soccer 
league(WPS)(Livingstone, 2009; Tedesco, 2009). While this is but a small sampling of North American professional niche sports it demonstrates a variety of professional sports sometimes forgotten, or at least not top of mind, when most people envision professional sports in North America. For the remainder of the current study, this collection of sports will be referred to as professional niche sports. The current study views niche sport through a North American lens. Niche sports vary based on region and culture and therefore the current study is limited to the North American sport sponsorship cultural lens.

Miloch and Lambrecht (2006) stated niche sports could best be classified as sports that are not mainstream and do not appeal to a mass audience. Rather, participants and supporters of these niche sports usually represent a niche demographic or sub-segment of sport consumers. Miloch and Lambrecht (2006) also provided some examples of niche sports, including tennis, lacrosse, bowling, fishing, curling, horse racing, action/extreme sports, archery, cycling, mountaineering, and snow sports. In the most comprehensive description of niche sports, Rosner and Shropshire (2004) classified niche sports into four distinctive categories. The first of the categories is minor leagues. These leagues do not represent the top level of professional competition within the given sport. An example would include minor league baseball team such as the Louisville Bats. The second category is emerging sports that represent the top level of competition in their respective sport. However, these sports lack the financial success and media coverage to make them mainstream. Examples of these sport properties would be Major League Soccer (MLS), or Major League Lacrosse (MLL). A third category of niche sports is indoor variations of traditionally outdoor sports. This would include the Arena Football League (AFL), or the 
Professional Arena Soccer League (PASL). Finally, the fourth niche sport category includes gender specific leagues, which offer women the opportunity to participate in their own league. Examples include World Team Tennis, and the Women's National Basketball Association (WNBA) (Rosner \& Shropshire, 2004). These four categories, while not necessarily exhaustive or mutually exclusive of all niche sports, provide insight into the fact the term niche sports encompasses a vast array of eclectic sports. For the purposes of this study, professional niche sports were operationally defined as all North American professional sports not including the NFL, NBA, NHL, MLB (collectively referred to as the 'Big 4'), NASCAR, or the Professional Golfers Association Tour (PGA).

Some of these niche sports have recently attracted major crowds. The PBR hosted nearly 33,000 fans during a three-day tour stop in New York City in 2009 (Livingstone, 2009). PBR officials noticed an increase in fan interest nationwide as their tour has expanded from eight tour stops to 29 tour stops from 1994 through 2009 (Livingstone, 2009). The PBR is not the only niche sport drawing a substantial number of fans. The WNBA and NLL have both witnessed sustained growth over the last several years with the WNBA averaging 8,000 fans per game league-wide and the NLL averaging 10,000 fans per game across the league (Tedesco, 2009). When Sports Business Journal asked some of the largest brands and marketing agencies in the United States what sport properties they believed to be 'on the rise' their answers included the Ladies Professional Golf Association (LPGA), NLL, and mixed martial arts (A futile search, 2008), all of which qualify as professional niche sports according to the operational definition of niche sports for the current study. While professional niche sports have demonstrated 
attendance growth, they still fall far short of the number of fans attracted by mainstream professional sports.

Corporate sponsors have also paid heed to the increasing popularity and opportunities afforded by sponsoring these professional niche sports. According to Kojima (2010), major companies in non-lacrosse categories have shown great interest in the NLL. This has been demonstrated through their league wide sponsorship deals with Vonage, Hummer, Edge shave gel, (Kojima, 2010) and Reebok (Tedesco, 2009). Similarly, the WNBA signed more than 20 sponsors, including Adidas, McDonald's, Nike, and Toyota (Tedesco, 2009). Tedesco (2009) also noted the AVP and WPS have been able to attract major sponsors. The WPS signed a $\$ 10 \mathrm{M}$ multiyear deal with shoe and apparel manufacturer Puma. The PBR has also signed major corporate sponsors including Enterprise Rent-A-Car, Jack Daniels, Las Vegas, Wrangler, and the U.S. Border Patrol (Livingstone, 2009). Sponsors have demonstrated an interest in niche sports, however, niche sports still do not attract the sponsorship funding realized by their mainstream counterparts. Furthermore, little empirical evidence is available to understand why these corporations are attracted to professional niche sports. Some analysts have anecdotally provided their opinion as to the reasons sponsors choose to support professional niche sports which are discussed below.

\section{Benefits of Niche Sport Sponsorship}

While professional niche sports may not receive the mainstream media attention, or large-scale crowds realized by the NFL, NBA, and MLB major corporations have engaged in sponsorship relationships with these pro niche sports. Interestingly, Brenner (2003) noted the Core Tour, Long Drivers of America, Wal-Mart FLW Outdoors Tour, 
and the International Mountain Bike Association have been able to draw many major corporate sponsors including Re/Max International, Fuji Film U.S.A., Nokia, and Subaru of America. The lack of empirical research on niche sport sponsorship has led to anecdotal claims, by both academics and practitioners, as to the rationale for corporation's engagement in niche sport sponsorship relationships. The literature has identified four main reasons sponsors engage in niche sport sponsorship relationship. These reasons include cost effectiveness (Fullerton, 2010; Hanas, 2007; Williams, 2001), more refined target market (Brenner, 2003; Greenwald \& Fernandez-Balboa, 1998; Milne, McDonald, Sutton, \& Kashyap, 1996; Stotlar, 2009; Tripodi, 2001), niche sport property flexibility (Hanas, 2007; Jones, 2008; Livingstone, 2009; Rovell, 2009; Williams, 2001), and decreased niche sponsorship clutter (Amis, Slack, \& Berrett, 1999; Greenwald \& Fernandez-Balboa, 1998; Lough, 1996; Lough \& Irwin, 2001; Maxwell \& Lough, 2009; Shank, 2005; Tripodi, 2001). Each of these factors are discussed more thoroughly below.

Cost effectiveness. In order to be a corporate partner of the Super Bowl, the NBA, or the New York Mets, corporations must pay several thousands, possibly even millions of dollars. This fact alone eliminates a number of companies that simply lack the financial wherewithal to take on such an endeavor. Many companies that do not have multi-million dollar marketing or public relations budgets may still see value in sport sponsorship. For these companies, professional niche sports provide a viable alternative to the highly priced sponsorship packages offered by mainstream professional sport properties. As opposed to the million dollar sponsorship deals found within mainstream sports, Hanas (2007) determined for about $\$ 10,000$ a company could sponsor an entire 
season of the National Dodgeball League, World Kickball Association, Professional Beach Tennis, or Pro Sand Soccer. According to Fullerton (2010), many marketers use extreme sports or the WNBA as a cost-effective alternative to mainstream sports and are still able to reach their target markets. Niche sport properties have become aware of this gap and have realized they can offer more value for less cost when compared to their mainstream sport competitors (Williams, 2001).

Also, the economic crisis starting with the collapse of the United States financial sector in 2008 profoundly affected sport sponsorship. The year 2009 marked a historic point in recent sponsorship history as sponsorship spending receded from the previous year's spending for this first time in 25 years (IEG, 2010). Sport sponsorship spending within North America declined one per cent from $\$ 11.4$ billion in 2008 to $\$ 11.28$ billion in 2009 (IEG, 2010). However, according to Livingstone (2009) professional niche sport such as the WNBA and PBR view this economic downturn as an opportunity rather than a threat, as they believe their organizations are able to provide sponsors more value for their dollar compared to other sport properties.

More refined target market. Although niche sports often lack the mass media appeal of mainstream sports, they offer sponsors the opportunity to be more targeted with their sponsorship message (Greenwald \& Fernandez-Balboa, 1998; Tripodi, 2001). Niche sports often attract more homogeneous fans with respect to demographics (age, gender, education, socio-economic class, and ethnicity) and psychographics (attitudes, beliefs, and feelings) (Stotlar, 2009) as opposed to the more popular mainstream sports (Milne et al., 1996). Many marketers believe they do not need to reach the masses via a sponsorship with a mainstream sport. Subaru stated the reason it does not advertise 
during the Super Bowl is due to the fact only $10 \%$ of the Super Bowl viewership match the demographics and psychographics which align with its brand. Rather, Subaru would prefer to sponsor the International Mountain Bike Association, whose 32,000 members nearly all fit the demographics and psychographics of Subaru customers (Brenner, 2003). Numerous marketers have indicated the more tightly targeted audience of niche sports is a substantial lure for sponsors (Brenner, 2003; Fullerton, 2010; Hanas, 2007; Kojima, 2010; Milne et al., 1996).

Niche sport property flexibility. Another reported benefit to sponsoring niche sports is the flexibility afforded to sponsors. Flexibility breeds creativity and marketers have long been respected for their creativity. Most niche sport properties are willing to work with sponsors to help attain their sponsorship objectives (Jones, 2008). Some niche sports such as the NLL have overtly stated they are more flexible than the big four sports (NFL, NBA, MLB, and NHL) (Hanas, 2007). Sponsors would not be permitted to display logo on an NFL game jersey. It was big news when the NFL allowed one small corporate logo on teams' practice jerseys (Rovell, 2009). However, the NLL and WNBA have both incorporated relatively large corporate logos on their game jerseys (Hanas, 2007; Rovell, 2009). Niche sports also offer sponsor perks many mainstream sport properties are not willing to offer. The Arena Football League was open to allowing sponsors to take their employees, friends, and families onto the field after the game to play touch football (Williams, 2001). The NLL mandates all players must attend an informal post-game reception at a local restaurant (usually a sponsor of the team) after all home and away games. Fans are also encouraged, via the public address system at the game, to attend the post-game reception and interact with the players (Livingstone, 2009). 
Decreased niche sponsor clutter. Sport sponsorship was originally believed to be a form of uncluttered advertising (Stotlar, 2009). However, the increasing number of corporations involved in sport sponsorship has lead to a sport marketing landscape which has replicated the cluttered advertising environment sponsors were trying to escape (Maxwell \& Lough, 2009). Many academics have noted that mainstream sports are so cluttered with sponsors they are reaching a point of sponsorship saturation (Amis et al., 1999; Greenwald \& Fernandez-Balboa, 1998; Shank, 2005; Tripodi, 2001). Parallels have been drawn between the corporate shifts from traditional advertising to mainstream sport sponsorship in a quest for relief from advertising clutter to the current shift of many sponsors from mainstream sport sponsorship to niche sport sponsorship to escape the same clutter, which is now pervading numerous mainstream sports (Lough, 1996; Lough \& Irwin, 2001; Shank, 2005; Tripodi, 2001). The contemporary realization is that niche sports may offer sponsors a safe harbor clean from the sponsor clutter found in traditional advertising and more recently found in mainstream sport sponsorship.

\section{Professional Niche Sports' Need for Sponsorship}

Funding from sponsorships within niche sports is viewed as vital capital for operations (Lough \& Irwin, 2001) as they do not received the revenues from media contracts and gate receipts found in their more affluent mainstream sport counterparts. Stotlar (2009) noted three examples of professional niche sports canceling events due purely to a lack of sponsorship funding. An international badminton tournament, the Chicago stop on the Women's Tennis Association (WTA) tour, and the Women's World Doubles Championship in Fort Lauderdale were all canceled due to a lack of sponsorship support. Combining this essential need for sponsorship revenues to remain financially 
viable and sustainable with the fact all sport properties are competing for the same pool of sponsorship money creates a sense of urgency for niche sport properties to create proposals with the greatest chance of acceptance. This urgency is exacerbated due to the vast number of sponsorship proposals many companies receive on a regular basis. According to Shank (2005), Pepsi receives approximately 500 sponsorship proposals each year, and Pennzoil receives 200 requests annually.

This innate need for sponsorship support in order to produce a viable sport product forces sport managers to pay heed to the reasons why companies engage in sport sponsorship. As outlined earlier, sport sponsorship provides benefits to both the sponsor as well as the sport property. The vast number of sport sponsorship proposals submitted to many corporations provides these companies the ability to intensely scrutinize each potential sport sponsorship opportunity.

Practitioners and academics have anecdotally claimed professional niche sports have the capabilities to provide sponsors with assets not found within mainstream sport sponsorship (cost effectiveness, more refined target market, flexibility, and decreased clutter) however, there is a lack of empirical knowledge as to what sponsors look for when assessing professional niche sport sponsorship opportunities. Considering sponsorship funding is crucial for the very existence of most niche sports, there exists a fundamental need to determine why companies choose to support these types of sports, what the companies aim to achieve from this relationship, and how these companies go about screening and selecting which sport properties they are going to support. From this, niche sport properties will be capable of refining their sponsorship proposals to better 
address these issues, significantly enhancing the probability a company will choose to support their sport property.

\section{PURPOSE OF THE STUDY}

Given the exceptionally competitive nature of sport sponsorship, the unique attributes provided to sponsors by professional niche sports, and professional niche sports reliance on sponsorship funding for financial sustainability, the need exists for a study to investigate what companies aim to achieve from a niche sport sponsorship and how companies screen niche sport sponsorship opportunities. Numerous researchers have indicated there is a fundamental need for sport properties to have a firm understanding of potential sponsors' objectives and selection criteria (Abratt et al., 1987; Kuzma et al., 1993; Mullin et al., 2007). By understanding a potential sponsor's objectives and selection criteria niche sports managers can create sponsorship proposals more closely aligned with the needs and wants of the prospective company, subsequently enhancing the value of the sponsorship proposal (Copeland et al., 1996; Fullerton, 2010; Jowdy \& McDonald, 2002; Lamont \& Dowell, 2007; Lough, Irwin, \& Short, 2000; Mueller \& Roberts, 2008; Sam, Batty, \& Dean, 2005; Stotlar, 2009). Therefore, the primary purposes of this study were to (a) identify which criteria sponsors deem important when evaluating professional niche sport sponsorship opportunities and (b) investigate the objectives sponsors seek to achieve by engaging in a sponsorship relationship with a professional niche sport. To accomplish these purposes the following research questions anchored the study. 
RQ 1: What is the relative importance of each of the sponsorship selection criteria corporations use when evaluating professional niche sport sponsorship opportunities?

RQ 2: What is the relative importance of each of the sponsorship objectives corporations aim to achieve when engaging in professional niche sport sponsorship relationships?

As noted by Irwin and Sutton (1994) the literature indicates that different corporations involved in sport sponsorship may vary with respect to anticipated sponsorship objectives as well as the selection criteria they deem important. The current study also examined the different industry affiliations and corporate characteristics of professional niche sport sponsors. To accomplish this purpose the following research questions were used.

RQ 3: How do important sponsorship objectives of niche sport sponsor vary by company industry segment, company size, or company scope?

RQ 4: How do the selection criteria used to evaluate professional niche sport sponsorship opportunities vary by industry segment, company size, or company scope?

\section{SIGNIFICANCE OF THE STUDY}

Results of the present study could provide professional niche sport managers with vital information and insight into the types of organizations sponsoring niche sports, their most sought after sponsorship objectives and the selection criteria used to make sponsorship decisions. From this, professional niche sport managers should be able to create more focused and better-suited sponsorship proposals aimed at highlighting the 
sponsorship objectives they can deliver and emphasizing their strengths with regard to the selection criteria deemed important.

Results of the current study may also provide professional niche sport managers with a better understanding of the types of companies currently engaged in professional niche sport sponsorship. From this, professional niche sport managers may be able to focus their energy and limited resources towards industries which appear to be more receptive to engaging in professional niche sport sponsorship. Conversely, this study may reveal industries which are considered to be untapped resources and potentially ripe for a focused well-constructed niche sport sponsorship proposal. Finally, the results of this study could educate corporations not currently engaged in niche sport sponsorship on the objectives other companies attempt to achieve through professional niche sport sponsorship.

The sponsorship literature has identified that sponsors evaluate sponsorship proposals as unique requests (Copeland et al., 1996; Irwin \& Sutton, 1994; Kuzma et al., 1993; Lough, Irwin, \& Short, 2000; Lough \& Irwin, 2001). Yet, the sport sponsorship literature has focused primarily on professional mainstream sport, Olympic focused sponsorships, and intercollegiate sponsorship (Wartella, 2009). Considering professional niche sports have been able to attract major corporate sponsors, a logical extension of the literature would entail an exploration into the sponsorship decision-making process within professional niche sports. The present study fills a gap in the literature and provides guidance for niche sport properties, companies interested in sponsoring professional niche sports, and future studies seeking to better understand the sponsorship phenomenon within the realm of professional niche sports. 


\section{DELIMITATIONS}

The present study contained the following delimitations:

1. The current study focused on the sponsorship decision-making process of professional niche sport sponsors. The actual or perceived outcomes, or the ability of the sport property to achieve corporate sponsorship objectives, were not investigated within the current study.

2. Respondents were limited to those companies listed within the 2010 edition of the Sport Business Journal Resource Guide and Fact Book (Sports Business Journal RGFB). Therefore, niche sport sponsors not included on this list had a $0 \%$ chance of inclusion within the current study. Only companies within the 2010 Sports Business Journal RGFB for which an accurate email address could be ascertained were eligible for inclusion.

3. Due to the lack of a generally accepted definition of professional niche sports, respondents were allowed to include any professional sport within North America other than the NFL, NBA, MLB, NHL, NASCAR, or PGA. In essence, the current study allowed respondents to provide their own definition of professional niche sports with very limited constraints.

4. The different types of niche sports included in this study were not controlled for, as respondents were self selected based solely on their current or previous sponsorship of any professional niche sport property.

5. Only professional sports were looked at within the current study. While collegiate and amateur sports could be separated into mainstream and niche, many confounding factors prevented their inclusion within this study. Collegiate sport 
sponsorship investigation would have created many more variables as sponsors may engage in a blanket sponsorship of the entire athletic department: mainstream (revenue generating) and niche (Olympic) sports collectively. Further, sponsors may be influenced by their personal educational background when selecting a collegiate sponsorship. While future research may look at collegiate or amateur niche sports, the current study focused solely professional niche sports. Collectively, these delimitations indicate the results of the current study should not be over generalized. Generalization to the accessible sample of 352 seems appropriate as respondents appeared to be representative of the accessible population.

\section{LIMITATIONS}

As with all research, certain limitations existed within the current study. A review of the current study revealed eight specific limitations that must be addressed. Limitations of the current study included:

1. Respondent company policies may have precluded them from engaging in the current study. Some companies may have specific company policies preventing sponsorship decision-makers from providing proprietary information. Other companies may prevent all employees from engaging in surveys of any kind.

2. The lack of research on professional niche sport sponsorship may prevent substantial post study comparisons. Also, the lack of research on niche sport sponsorship meant no survey instrument was available for this specific sport segment. While sport sponsorship objectives have been deemed intrinsic to the sponsoring corporation, sponsorship selection criteria are directly related to the sport property in question. Hence, 
a modified version of the SSPEM was required to address the purpose of the current study.

3. Sponsorship of professional niche sports has grown exponentially in the recent past. However, this study provides only a snapshot in time. North American professional niche sport sponsor objectives and selection criteria may shift over time. According to the sponsorship lifecycle (Lough \& Irwin, 2001), sponsorship objectives are expected to shift towards market-driven goals as the sport property matures. Many social, economical, and environmental factors may have influenced results. Therefore, findings should not be generalized to past or future North American niche sport sponsorships. Hence, findings of the current study should not be inferred to any past or future sponsorship scenarios.

4. Respondents were self-selected based on their understanding of the operational definition of professional niche sports. While every attempt was made to mitigate any confusion within this definition, respondents may not have paid close enough attention to the definition potentially affecting the results.

5. Respondents may have refrained from responding as they regularly receive requests for participation in these types of studies. Furthermore, respondents may have refrained from responding, as they may be afraid the study is could be a cover created by a competitor to receive proprietary information (T. Kuiken, personal communication, June 24, 2010).

6. Overall, the companies represented within the current study were relatively homogeneous with respect to size and scope. Most companies conducted business as the national or international and had gross annual revenues of $\$ 500 \mathrm{M}$ or more. The lack of small companies within the current study may have affected results. 
7. Responses to many of the selection criteria and objectives were found to be nonnormal. The disproportionately high level of importance reported on many of the objectives and selection created negatively skewed results. Non-normality caused a violation of one of the MANOVA assumptions and typically decreases the reliability of the results.

8. Another limitation found within two of the MANOVAs indicated a violation of the equality of variance covariance matrices assumption. The MANOVA analysis also demonstrated low power. Therefore, results of insignificance must be applied with caution.

9. A number of respondents who began the survey failed to complete the instrument. Perhaps, the instrument needs to be adjusted to enhance the usable number of responses.

\section{DEFINITION OF TERMS}

Professional Sport: events and exhibitions in which athletes compete individually or on teams and are paid for their performance (Masteralexis, 2009).

Professional Niche Sports: all professional sports not Including the NFL, NBA, NHL, MLB (collectively referred to as the 'Big 4'), NASCAR, and the Professional Golfers Association Tour (PGA).

Sport Sponsorship: "an investment in cash or in-kind, in an activity, in return for the exploitable commercial potential associated with that activity" (Meenaghan, 1991, p. 36). 
Exchange Theory: exchange and reciprocation of valued resources between two parties (McCarville \& Copeland, 1994).

Sponsor Objectives: overarching corporate marketing, communications, or public relations goals aimed to be achieved through sponsorship (Abratt et al., 1987).

Sponsorship Selection Criteria: sport property specific factors potential sponsors may utilize to in the sponsorship decision-making process.

Sponsorship Decision-Makers: the person(s) within a corporation whom selects which sponsorship opportunities their company will or will not support. 


\section{CHAPTER II}

\section{REVIEW OF RELATED LITERATURE}

The purpose of this literature review is to provide a comprehensive discussion of the sport sponsorship decision-making process. This is a multifaceted process encompassing decision-makers, sometimes gatekeepers, corporate sponsorship objectives and sport property specific selection criteria. Holistically, these facets all contribute to a corporation's decision to sponsor, or not sponsor, a particular sport property.

The focus of this review is grounded in the literature based on influential factors within the sport sponsorship decision-making process. While there is an abundance of literature discussing the outcomes of sport sponsorship relationships the following review only analyzes studies looking at the antecedents (decision-maker, sponsorship objectives, and sponsorship selection criteria) of sport sponsorships. Considering the focus of this study is professional niche sports, where the literature is scarce, antecedents appeared to be the logical starting point for this study. From a pragmatic perspective, those sport properties unable to attract and secure sponsors have little need for a study focused on the outcomes of sponsorship relationships. The following review was divided into five main sections. First, sport sponsorship is discussed generally and the operational definition of sport sponsorship is put forth. The second section reviews studies focused specifically on sport sponsorship decision-makers, that is, the individual(s) responsible for making the decision as to which sponsorship proposals their corporation will, or will not support. 
Thirdly, a thorough review of the research on sport sponsorship objectives is presented. These studies are specifically focused on the overarching corporate objectives, most often marketing, communications, promotions, and/or public relations objectives organizations try to achieve through sport sponsorship. Only those studies that purely investigated these overarching corporate objectives are presented in the Sport Sponsorship Objectives section. The fourth section, Sport Sponsorship Selection Criteria, presents studies focused on the specific aspects of the sport property, or specific sponsorship opportunity which corporations evaluate when determining which sponsorship opportunities to support. This section also includes any studies which may have combined sponsorship objectives and sponsorship selection criteria. As many of these studies provide a hierarchical list of objectives or selection criteria as rated by corporate sponsors, studies combining selection criteria and objectives were holistically included in the Sport Sponsorship Selection Criteria section to maintain the integrity of the research results. The final section investigates all aspects of niche sport sponsorship. As opposed to the rest of the review focused solely on the sponsorship decision-making process, the Niche Sport Sponsorship section reviewed all studies focused on any aspect of niche sport sponsorship.

\section{SPORT SPONSORSHIP DEFINED}

Several researchers have defined sport sponsorship. One of the earliest definitions of sport sponsorship was constructed by Abratt et al. (1987) when they stated: "sponsorship is an agreement in terms of which a sponsor provides some aid to a beneficiary, which may be an association, a team, or an individual, to enable the latter to pursue some activity and thereby derives the benefits contemplated in terms of its promotion strategy" (p. 300). Abratt et al. (1987) went on to state the aid provided may 
be financial, a service, or provision of expertise. The benefits contemplated could include TV or other media exposure, creating corporate or brand awareness, promoting the public relations of the sponsor, or publicity (Abratt et al., 1987). However, the most commonly cited and accepted definition of sponsorship, and the operational definition used within the current study was provided by Meenaghan (1991) when he stated sponsorship to be "an investment in cash or in-kind, in an activity, in return for the exploitable commercial potential associated with that activity" (p. 36). Briefly, in-kind investments occur when the sponsor provides the sport property with a good or service as opposed to cash. An example of this is illustrated through Under Armour's sponsorship of The University of Maryland's athletic department. Within the five year $\$ 520000$ sponsorship agreement, Under Armour provided The University of Maryland with $\$ 200000$ in cash, $\$ 195000$ in apparel and footwear allowances, and $\$ 125000$ in marketing support for Maryland football (Shank, 2005). While a number of sport sponsorship definitions exist, each stresses the exchange of resources on behalf of the sponsor for the right to associate with and be given access to the fans/participants of the sport property (Irwin et al., 2008;

Mullin et al., 2007; Tripodi, 2001). Simplistically, sport sponsorship involves an exchange between two parties, in which each side gains something of value. Typically, the sponsor provides the sport property with cash or in-kind products or services, in exchange for the ability to reach the fans and participants of said sport property through some form of communication.

\section{SPONSORSHIP DECISION-MAKERS}

Much of the early research on sport sponsorship focused on determining who, within a sponsoring organization, was responsible for making sponsorship decisions. The 
literature has analyzed sponsorship decision-making from a variety of perspectives including decision-making autonomy within franchises (Cousens \& Slack, 1996), roles within the decision-making process (Aguilar-Manjarrez et al., 1997; McCook, Turco, \& Riley, 1997), company departments responsible for sponsorship decision-making (Thwaites et at., 1998) and the influence of decision-makers' educational background on sponsorship selection (Berrett, \& Slack, 1999). As noted by Cousens and Slack (1996), from the sport property's standpoint, an understanding of the decision-making process of a potential sponsor can drastically enhance its preparation and subsequent success of securing the sponsorship. The following research provides insight into the 'who' aspect of the sport sponsorship decision-making process.

Cousens and Slack (1996) examined the sport sponsorship decision-making process of fast food franchisees within the restaurants' local markets. Sixteen in-depth interviews were conducted with 11 franchisees, four regional managers, and a national representative. While many fast food restaurants gain global visibility through major national/international sponsorships which are handled by their respective head offices, local chains also engage in sport sponsorship at the community or grassroots level. It was at this local level where Cousens and Slack (1996) found three distinctive decisionmaking models implemented by these fast food restaurants. Some franchisees were given complete autonomy to evaluate and select the types of local sport sponsorships they would like to support. Examples of grassroots sponsorship provided by the respondents included minor league youth hockey and beer league softball. The second category presented by Cousens and Slack (1996) was that of a communal approach where local franchisees would pool their sponsorship budgets and make group decisions on which 
properties to support based on the collective regional needs. Finally, some franchisees were shackled in the sense that all sponsorship decisions were made by the head office no matter the size or geographic scope of the proposed sponsorship (Cousens \& Slack, 1996).

Similar to Cousens and Slack (1996), Aguilar-Manjarrez et al. (1997) utilized qualitative research methods when they interviewed representatives of 10 companies involved in sport sponsorship. However, their sample included corporations engaged in sponsorship within the United Kingdom. Aguilar-Manjarrez et al. (1997) asked the sponsors to reconstruct and explain the sponsorship selection process of a particular sponsorship relationship. Respondents within the study conducted by Aguilar-Manjarrez et al. (1997) more specifically laid out the specific organizational or group roles which influenced the sponsorship decision-making process including the influence and power of gatekeepers and decision-makers. Gatekeepers are individuals within an organization who act as a first screen or buffer between the sponsorship proposals submitted to an organization and the sponsorship decision-makers. Aguilar-Manjarrez et al. (1997) noted sport properties must be cognizant of the organizational structure of the potential sponsor. A key understanding of the gatekeepers and decision makers within the potential sponsoring organization can drastically enhance the probability of a sponsorship proposal being accepted. Typically, gatekeepers have the authority to reject a sponsorship proposal or prevent the proposal from reaching a decision-maker. Yet the same gatekeeper does not have the authority to accept a proposal; s/he can only pass it along to the decisionmakers. 
From an U.S. collegiate perspective, McCook et al. (1997) conducted case studies of four sponsors of the Illinois State University Athletics Department for the 1995-1996 school year. McCook et al. (1997) found large, national companies employed the use of a gatekeeper as the initial sponsorship screen. The ultimate sponsorship decision-makers depended on the level and cost of the sponsorship. Local managers executed smaller sponsorships while larger sponsorships were the responsibility of vice-presidents and sponsorship committees.

Moving beyond describing the different individual roles involved within sport sponsorship selection, Thwaites et al. (1998) wanted to better understand which department was responsible for making sponsorship decisions. Where did these gatekeepers and decision-makers reside within these organizations? Through a series of 10 interviews with leading Canadian sponsorship authorities and surveying Canada's 500 largest companies, Thwaites et al. (1998) produced some general findings surrounding the practice and management of sponsorship within Canada. The majority of the 102 respondents indicated they were involved in some sort of sponsorship, which was predominantly managed by the company's marketing department. Companies indicated the marketing manager, advertising manager, or sponsorship manager tended to bear most of sponsorship decision-making responsibilities. Interestingly, Thwaites et al. (1998) noted the lack of senior executive input as indicative of the lack of strategic planning involved in sponsorship selection. In addition, this lack of executive influence may demonstrate the move away from sponsorships selected based on the personal preferences of corporate senior executives. 
Maintaining the theme of investigating the internal influences of sponsorship decision-making as found in the previous four studies, Berrett and Slack (1999) conducted semi-structured interviews with sponsorship decision-makers from 28 Canadian-based corporations currently or recently committed to sport sponsorships (Berrett \& Slack, 1999).

Findings indicated the educational training of the sponsorship decision-maker played a significant impact on the sport sponsorship decision-making outcome. Decisionmakers holding a marketing background were more focused on sport sponsorship which could demonstrate a return on investment. Decision-makers with public relations training were more focused on goodwill and social responsibility. The authors also determined personal relationship between the executives of the sport entity and the corporation held significant value when determining sponsorship direction (Berrett \& Slack, 1999).

The research presented on the sponsorship decision-makers demonstrated that many factors influence who makes the decision and how the decision is made. As sponsorship requests grow with respect to the size, scope, and cost, the decision-making process becomes more centralized within the corporate headquarters. Also, as sponsorship proposals increased in support requested so did the screening process. Gatekeepers were found to be a first screen for larger sponsorship requests as more local and regional requests were generally handled only by the decision-maker. Research has also indicated most sponsorships are handled within the marketing, advertising, or sponsorship department of the sponsoring organization. Clearly, the sponsorship decision-maker is a key piece of the overall sponsorship decision-making process. However, most often sponsorship decisions are not solely based on the personal opinions 
of the decision-maker. Several other key factors influence the sponsorship decisionmaking process. The sponsorship decision-maker assesses a sponsorship opportunity based on its ability to achieve corporate sponsorship objectives as well as the specific assets a particular sport property can provide. These specific assets are considered to be sponsorship selection criteria. Sport sponsorship objectives and then selection criteria are discussed below.

\section{SPORT SPONSORSHIP OBJECTIVES}

As noted earlier, sport sponsorship objectives are broad corporate objectives which could potentially be achieved through a sport sponsorship or some other advertising, marketing, or promotional vehicle. The realization sport sponsorships could achieve corporate promotional, marketing, and/or public relations objectives is far from a new phenomenon. Abratt et al. (1987) were among the first researchers to investigate the corporate objectives of sport sponsors. Sport was identified as being a popular sponsorship choice as it provided two potential markets: the participants and the spectators. A number of corporate objectives were identified from the general marketing and advertising literature which Abratt et al. (1987) believed were salient sport sponsorship objectives. These objectives included community involvement, increase public corporate awareness, alter corporate image, build goodwill, reassure policyholders and stockholders, counter adverse publicity, aid staff relations, assist in staff recruitment, identify with a target market, facilitate prospecting for the sales force (Abratt et al., 1987).

Five years later, in arguably the seminal article on sport sponsorship decisionmaking, Irwin and Asimakopoulos (1992) presented the Sport Sponsorship Proposal 
Evaluation Model (SSPEM). The SSPEM was integrated within the larger Six-Step Approach to Sport Sponsorship Management. The SSPEM provided potential sponsors with an extensive checklist of objectives and selection criteria to be used when evaluating a sponsorship opportunity. Looking specifically at sponsorship objectives within the SSPEM, Irwin and Asimakopoulos (1992) identified a number of sport sponsorship objectives, which they suggested, were used to guide the sponsorship decision-making process "similar to the objectives employed regarding any advertising decision"(p. 46). Irwin and Asimakopoulos (1992) divided sponsors objectives into corporate-related objectives and product/brand-related objectives. Corporate-related objectives included increasing public corporate awareness, enhancing corporate image, altering public perception, getting involved in the community, building business/trade goodwill, and enhancing employee relations/motivation. The product/brand-related objectives were increasing target market awareness, identifying/building image within target market (positioning), and increasing sales/market share (Irwin \& Asimakopoulos, 1992).

An investigation of the current sport sponsorship literate revealed each of the sport sponsorship objectives put forth by Irwin and Asimakopoulos (1992) have been utilized by numerous researchers. Each objective is discussed more thoroughly below.

\section{Increase public corporate awareness}

Sponsorship has been used in an effort to increase the awareness, or educate the public regarding the capabilities of a company (Mullin et al., 2007). Marketers have realized consumers must first be aware of their company's existence before they can possibly purchase corporate goods or services. Sport sponsorship has been deemed an effective way to gain public awareness (Fullerton, 2010; Irwin et al., 2008; Mullin et al., 
2007; Shank, 2005). A number of sport sponsorship researchers have also found sponsors to value the ability of sponsorship in achieving this objective, making 'increase public corporate awareness' arguably the most commonly cited objective within the sport sponsorship literature (e.g. Apostolopoulou \& Papadimitriou, 2004; Chadwick \& Thwaites, 2004; Greenwald \& Fernandez-Balboa, 1998; Lamont \& Dowell, 2007; Lough \& Irwin, 2001; Ludwig \& Karabetsos, 1999; McCarthy \& Irwin, 2000; Meenaghan, 1991; Papadimitriou, Apostolopoulou, \& Theofanis, 2008; Seguin, Teed, \& O’Reilly, 2005; Thjomoe et al., 2002; Witcher et al., 1991).

\section{Enhance corporate image}

A slightly more complex objective than increasing corporate awareness is trying to enhance a corporation's image through sport sponsorship. Every company strives to portray a particular image to customers, stakeholders, and the general public (Irwin \& Asimakopoulos, 1992; Irwin et al., 2008). Through sport sponsorship, the sponsoring corporation is able to associate itself with the sport property in the hopes the positive image fans associate with the sport property is transferred to the sponsor (Mullin et al., 2007; Shank, 2005). This phenomenon, sometimes called a 'halo of goodwill' occurs when the meanings consumers/fans associate with a sport entity are transferred to the sponsoring company (Irwin et al., 2008). The literature has demonstrated an abundance of sponsors who indicated image enhancement was one of their most revered objectives (e.g. Apostolopoulou \& Papadimitriou, 2004; Chadwick \& Thwaites, 2004; Jarvis, 2002; Lough, 1996; Lough \& Irwin, 2001; Ludwig \& Karabetsos, 1999; Mack, 1999; Meenaghan, 1991; Papadimitriou et al., 2008; Slack \& Benz, 1996; Thjomoe et al., 2002; Witcher et al., 1991). 


\section{Alter public perception}

Similar to enhancing corporate image, altering public perception is quite contingent upon the view of the company and sponsored sport property by the consumer/fan. Once a perception has been created about a company, it becomes very difficult to change that perception. Altering public perception of a company is possible through long-term sport sponsorships. Key to altering this perception is finding properties or events which are part of the consumer's lifestyle (Irwin \& Asimakopoulos, 1992; Irwin et al., 2008).

\section{Getting involved in the community}

Some sponsors have tried to use sport sponsorship to demonstrate their commitment to a given community. According to Mullin et al. (2007), sport sponsorship has more potential than any other promotional tool to have a direct impact on the community. Sport sponsorship is often thought to be a part of corporate 'good citizenship' or community relations (Irwin \& Asimakopoulos, 1992; Irwin et al., 2008; Mullin et al., 2007). Companies engaged in the sponsorship of community-based events are often seen to be in touch with their community and their community's needs.

Researchers have identified community involvement as a salient objective of numerous sport sponsors (Apostolopoulou \& Papadimitriou, 2004; Lough \& Irwin, 2001; Mack, 1999; McCarthy \& Irwin, 2000; Seguin et al., 2005).

\section{Building business/trade goodwill}

"Sport offers an opportunity for building relationships with other businesses, affiliates, and trade customers beyond daily business operations" (Irwin et al., 2008, p. 166). Sponsorship has been used as a tool to improve corporate relations with a variety of 
stakeholders (Irwin \& Asimakopoulos, 1992; Irwin et al., 2008). Sport sponsorship provides sponsors with unique opportunities such as event tickets and hospitality areas for key clients, which can go a long way in harvesting a fruitful business relationship (Mullin et al., 2007). This idea of using sport sponsorship for building goodwill, especially hospitality of key stakeholders, has been well documented as a viable sponsor objective throughout the sponsorship literature (e.g. Crowley, 1991; Jarvis, 2002; Ludwig \& Karabetsos, 1999; Mack, 1999; McCarthy \& Irwin, 2000; Meenaghan, 1991; Thjomoe et al., 2002).

\section{Enhance employee relations/motivation}

Much like utilizing sport sponsorship to host customers and suppliers, sport sponsorship can also be used as entertainment and rewards for sponsors' employees (Fullerton, 2010). Sport sponsorship has the capability of increasing staff motivation and corporate pride (Irwin et al., 2008). Increased pride can be invoked though sport sponsorship in different ways. First, corporations sponsoring a sport property in which their staff has a vested interest are more likely to increase corporate identification: positive feelings towards the company (Irwin et al., 2008). Second, corporations sponsoring events that have a humanitarian overtone can evoke a sense of pride and involvement for the employees who appreciate working for a company which cares about others (Fullerton, 2010). Both of these sport sponsorship methods have been successfully implemented to enhance corporate commitment, motivation, and pride within employees. A number of researchers have identified employee relations as an important sponsorship objective (e.g. Apostolopoulou \& Papadimitriou, 2004; Lough, 1996; Lough \& Irwin, 2001; Ludwig \& Karabetsos, 1999; Papadimitriou et al., 2008; Seguin et al., 2005). 
The previously discussed objectives have all been focused on influencing the sponsoring company as a whole. However, some companies have many different brands which fall beneath an overarching umbrella company. Sport sponsorship has also been identified as a vehicle capable of attaining objectives designated to specific products or brands. The most commonly cited product/brand-related sport sponsorship objectives are discussed below.

\section{Increase target market awareness}

As noted earlier, sport sponsorship has been used to increase the overall awareness of a company. Numerous sport sponsors have also indicated they use sport sponsorship to increase the awareness of a particular brand within the sponsor's target market. A number of researchers have identified increasing target market awareness as a popular sport sponsorship objective (e.g. Lough, 1996; Lough \& Irwin, 2001; Mack, 1999; Meenaghan, 1991).

\section{Identify/enhance image within target market (positioning)}

Sport sponsorship has been found to be a primary alternative to mass marketing. "Companies today are most interested in tailoring specific messages to small, targeted segments"(Irwin et al., 2008, p. 168). Sport sponsorship can be a very effective vehicle for more individualized communication as people who are attracted to sport properties often share common interests (Irwin et al., 2008; Mullin et al., 2007; Shank, 2005). Therefore, sporting events provide a natural forum for segmenting consumers based on psychographics (activities, interests, and opinions) (Shank, 2005). Sport sponsorship sometimes allows companies to target a niche market with very little waste on spectators outside of their target market (Irwin et al., 2008). The sponsorship literature has reflected 
the prevalence of this objective (e.g. Lough, 1996; Lough \& Irwin, 2001; Mack, 1999; Meenaghan, 1991).

\section{Increase sales/market share}

The ultimate objective of nearly all sponsors is to increase sales and/or increase market share (Fullerton, 2010; Irwin \& Asimakopoulos, 1992; Mullin et al., 2007; Shank, 2005). According to Shank (2005) and Irwin et al., (2008) sales and market share objectives are the most popular within sport sponsorship. One may be so inclined to argue all previously discussed objectives, are antecedents to increasing sales and market share. Increasing sales and market share can be attained in several different ways through sport sponsorship. First, studies have shown fans of many sports and sporting events are more prone to purchase products of brands that sponsor activities they value than competing non-sponsor products (Fullerton, 2010; Irwin et al., 2008). Second, considering so many buying decisions are made in-store, brands have used sport featured point-of-purchase displays to draw attention to their product and influence consumer decisions (Irwin et al., 2008). Finally, sponsorship agreements can include on-site product distribution, trials, or the exclusive concessions rights for a given product category (i.e. Pepsi has exclusive pouring rights for all home Colorado Avalanche, Colorado Mammoth, and Denver Nugget events through their naming rights sponsorship of the Pepsi Center)(Irwin \& Asimakopoulos, 1992; Irwin et al., 2008). Many researchers have discovered corporations have recently shifted objectives from increasing awareness and enhancing corporate or brand image to more market-driven objectives with a vast number of sponsors indicating sales and market share to be the most important of all corporate sponsorship objectives (e.g. Apostolopoulou \& Papadimitriou, 2004; Jarvis, 
2002; Lamont \& Dowell, 2007; Lough \& Irwin, 2001; Ludwig \& Karabetsos, 1999;

McCarthy \& Irwin, 2000; Papadimitriou et al., 2008; Seguin et al., 2005; Witcher et al., 1991).

The relative importance placed on the different sport sponsorship objectives has gone through a transformation over the past few decades. At the inception stage of sport sponsorship, during the 1970s and early 1980s, many companies looked at sponsorship as a form of philanthropy (Cornwell, Roy, \& Steinard, (2001); Crompton, 2004; Kuzma et al., 1993). During this era many sponsorship decisions were based on the sport preferences of top executives in the sponsoring corporations. Today, corporations around the world view sponsorship as a commercial practice rather than a philanthropic venture. Many companies recognizing sport sponsorship provides a cost-effective opportunity, compared to traditional advertising and marketing, to promote their products as a part of their promotional/marketing mix (Lyberger et al., 2008). Sponsorship fits naturally alongside advertising, public relations, personal selling, and sales promotion; in that sponsorship's basic purpose is achieving marketing, promotions, public relations and/or communications objectives (Abratt et al., 1987; Meenaghan, 1991).The remainder of the Sport Sponsorship Objectives section reviews a number of studies which have examined the sport sponsorship objectives identified by Irwin and Asimakopoulos (1992).

Following up on the theoretically based creation of the SSPEM by Irwin and Asimakopoulos (1992), Irwin and Sutton (1994) empirically tested the items included within the SSPEM and investigated their relative importance as viewed by sponsorship decision-makers within major corporate sponsors. Usable survey instruments collected from 78 corporate sport sponsorship decision-makers determined sponsors placed the 
most importance on increasing sales, followed by (in order of importance): increasing target market awareness, enhancing general public awareness, enhancing general company image, enhancing trade relations, enhancing trade goodwill, achieving community involvement, altering public perceptions, enhancing employee relations, blocking competition, being socially responsible, and demonstrating corporate philanthropy. Sales objectives and objectives oriented towards specific markets were found to be the most important.

Irwin and Sutton (1994) determined these 12 objectives could be classified within four distinct factors as a result of a principle component factor analysis. The four factors included position enhancement (alter public perception, increase target market awareness, increase sales/market share, block competition, and enhance general public awareness), public service (community involvement, corporate philanthropy, and social responsibility), trade networking (enhance trade relations, enhance trade goodwill) and corporate relations (enhance general company image, and employee relations).

Irwin and Sutton (1994) also hoped to determine if there were any significant differences in objectives based on the industry segment in which the sponsors conducted business. However, due to the small sample size the proposed four by four factorial Analysis of Variance (ANOVA) could not be conducted. Yet, the researchers noted different corporations sponsoring the same sport property may do so with entirely different sponsorship objectives in mind (Irwin \& Sutton, 1994).

Slack and Benz (1996) provided a much different view when they interviewed 11 small businesses (7-250 employees) known to be involved in local sport initiatives within a large western Canadian city. Slack and Benz (1996) reported the sponsorship decision 
was primarily a one-person decision with personal contacts at the sport property playing a significant factor in decision-making. The researchers noted none of the 11 respondents used a formalized sponsorship decision-making procedure. Some of the respondents indicated they averaged five sponsorship requests per day from walk-in traffic alone. The most commonly cited sponsorship objectives of these small businesses were social responsibility and enhancing company image. Virtually all sponsorships were local in nature, making social responsibility and image enhancement very suitable and attainable objectives. Finally, Slack and Benz (1996) noted many of the sponsors hoped to be seen as good corporate citizens to customers as well as local politicians. Some of the small businesses admitted their actions were in response to similar sponsorship actions conducted by their competitors.

Lough, et al. (2000) blended the samples presented in the previous two studies when they conducted an international study which investigated the relative importance of corporate sponsorship objectives within North America. Lough et al. (2000) sent surveys to 300 sponsorship decision-makers identified in the 1995 Sports Marketplace, within the United States $(\mathrm{N}=250)$ and Canada $(\mathrm{N}=50)$. The researchers utilized a derivative of the questionnaire developed by Irwin, Asimakopoulos \& Sutton (1994) which employed a 7 point Likert scale to ascertain the relative importance of 12 objectives presented to the sponsorship decision-makers.

A principal component factor analysis of the data collected from the 186 usable surveys (U.S.A. $=151$, Canada=35) determined the 12 objectives loaded on to four distinct factors. Very similar to the findings of Irwin and Sutton (1994), trade networking included enhance trade relations and enhance trade goodwill. The public service factor 
had three items philanthropy, social responsibility, and employee relations. Position enhancement included increase awareness, increase sales/market share, increase target market awareness, block competition, and community involvement. The fourth and final factor, status enhancement, was a two-item factor consisting of altering public perception and enhancing corporate image. Corporate sport sponsorship objectives associated with sales and marketing were found to be of greatest importance for both groups. These findings indicated a trend towards more market driven objectives was consistent with this sample. An ANOVA analysis found significant differences between the Canadian and U.S. respondents for community involvement and social responsibility, with the Canadian firms rating these objectives more highly than their U.S. counterparts. These findings may be partially explained by the fact sport sponsorship has a longer history within the United States. As sport sponsorship matures within Canada, objectives focused on social responsibility and community involvement may be overwhelmed by the sales and market focused objects so prevalent within the U.S. based corporations.

In another study designed to compare the sponsorship objectives of two different groups, Lough and Irwin (2001) aimed to determine whether sponsors of U.S. women's sports resembled "traditional" sport sponsors, with respect to sponsorship objectives. The researchers also investigated whether the objective-driven focus of "traditional" sport sponsorship would hold true for women's sport sponsorship, with an emphasis on demonstrating return on sponsorship investment.

Lough and Irwin (2001) randomly selected 74 corporate executives involved in sport sponsorship identified within Sports Marketplace (1997). Qualifying corporations had to be actively involved in sport sponsorship relationships with one or more sport 
property whose competitors were comprised exclusively of female athletes, as well as one or more other sport properties whose competitors were not comprised exclusively of female athletes. A seven-point Likert scale was employed in an effort to ascertain the importance attributed to the sport sponsorship objectives categorized by Lough et al. (2000).

Sixteen corporations provided adequate responses for analysis within this study. Results were reported using descriptive statistic and paired sample t tests (Lough \& Irwin, 2001). Lough and Irwin (2001) reported "traditional" sport sponsors ranked the objectives in the following order: (a) increase sales/market share, (b) increase target market awareness, (c) enhance corporate image, (d) increase corporate awareness, (e) community involvement, (f) build trade relations, (g) build trade goodwill, (h) social responsibility, (i) block competition, (j) enhance employee relations, and (k) philanthropy. The same sponsor ranked their objectives for the sponsorship of women's sports as: (a) enhance corporate image, (b) increase target market awareness, (c) increase sale/market share, (d) increase corporate awareness, (e) community involvement, (f) social responsibility, (g) build trade relations, (h) build trade goodwill, (i) block competition, (j) enhance employee relations, and (k) philanthropy. For data analysis purposes, Lough and Irwin (2001) collapsed the 11 objectives into the four dimensions described by Lough et al. (2000). The four factors were trade networking (enhance trade relations and enhance trade goodwill), public service (philanthropy, social responsibility, and employee relations), position enhancement (increase awareness, increase sales/market share, increase target market awareness, block competition, and community involvement), and status enhancement (alter public perception and enhance corporate 
image). Subsequent statistical analysis indicated the dimension public service was reported to be the least important to all respondents, however, a significant difference was found between “traditional” and women's sport sponsors on this dimension. Even though this dimension was of least importance, women's sport sponsors reported these criteria to be significantly more important than their "traditional" sport counterparts. Hence, women's sport properties could use public service objectives as a point of differentiation from "traditional" sport sponsorship proposals. Lough and Irwin (2001) also found a statistically significant difference within both "traditional" and women's sponsorship objectives, between the position enhancement and trade networking dimensions as well as between the position enhancement and public service dimensions. These findings revealed sponsors of both types of sport properties found the position enhancement objectives to be significantly more important than the trade networking or public service objectives. This is a clear demonstration that sponsors of both types of sport properties focus on market driven objectives.

Lough and Irwin (2001) noted that for more mature sport properties ('traditional sports'), the sponsors focused on more quantifiable results, such as sales. In less mature sports (women's sports) sponsors tended to focus on a combination of quantifiable and qualitative expectations such as increase awareness and image. As noted previously, Lough and Irwin (2001) presented the idea of a sport sponsorship lifecycle, where sponsor objectives progress towards more quantifiable sales-driven objectives as the sport property matures and becomes more established.

Thjomoe et al. (2002) provided a unique perspective on sponsorship objectives as they surveyed, via telephone, 400 of the largest companies within Norway. This sample 
provided a unique perspective as large-scale sponsorship is a relatively new phenomenon within Norway. From the 144 usable responses, Thjomoe et al. (2002) found the most important sponsorship objectives to be: (a) increase awareness, (b) improve image, and (c) improve customer and supplier relations.

Apostolopoulou and Papadimitriou (2004) explored the motivations behind the 2004 Athens Olympic Games Grand National Sponsors decision to become Olympic sponsors and examined the objectives each company sought to achieve through their sponsorship. Semi-structured interviews were conducted with the marketing director, or other staff member responsible for the sponsorship, from seven of the ten Grand National Sponsors of the 2004 Olympic Games in Greece.

Four major motivational themes presented themselves from the interviews. Those themes included (a) help the country [Greece] in a national effort; (b) be part of the most important sporting event within the modern history of the country and develop an association with the Olympic Games; (c) fulfill an obligation fitting the history, size, and strength of the company; and/or (d) support a major development in the company. Surprisingly, there was little evidence to indicate companies viewed this sponsorship as an opportunity to gain a competitive advantage. With respect to the companies' objectives, the majority were concerned with sales/market share objectives and image enhancement, while about half of the companies interviewed were seeking to increase brand recognition and increase community involvement. Finally, only two of the sponsors indicated they hoped to enhance employee relations through their sponsorship. Interestingly, even those organizations which had set commercial objectives provided no evidence their objectives were measurable or could be used in the future to track the 
effectiveness of their sponsorship (Apostolopoulou \& Papadimitriou, 2004).

Apostolopoulou and Papadimitriou (2004) noted a better understanding of sponsors' motivations and objectives can assist both companies and sport properties in the fulfillment of successful partnerships.

In a study published four years later, Papadimitriou and Apostolopoulou teamed up with Theofanis in 2008 when they explored the adoption (or not) of a strategic approach to the sponsorship process on the part of large companies involved in Olympic sponsorship. Specifically, Papadimitriou et al. (2008) interviewed seven of the ten marketing directors or other corporate executives responsible for coordinating their company's Grand National Sponsorship of the 2004 Athens Olympic Games.

Semi-structured interviews were guided by probing questions incorporating the following key themes: reason for entering the sponsorship agreement, ways in which the sponsorship was integrated into the firms' overall corporate strategy, marketing strategy, and brand management efforts, amount of resources designated to the sponsorship, initiatives introduced to leverage the sponsorship, and plans to evaluate the effectiveness of the sponsorship.

Papadimitriou et al. (2008) found some of the Grand National sponsors of the 2004 Athens Olympic Games entered expensive sponsorship agreements with only moderate considerations to strategic brand-building elements of sponsorship. While all of the companies seemed to have some stated goals for the sponsorship, with the exception of two, the goals were not specific or measureable. The majority of sponsors indicated they were looking to increase sales. However, one sponsor stated it was simply hoping to recoup the sponsorship fee invested in the relationship. The most prevalent sponsor 
priorities were increasing brand awareness, recognition, and image enhancement. Finally, two of the companies surveyed stated they hoped to enhance employee relations through their Olympic sponsorship.

\section{Summary}

Sport sponsorship objectives were described to be corporate marketing, communications, public relations, and/or promotional objectives (Abratt et al., 1987; Meenaghan, 1991) deemed to be attainable through sport sponsorship. In essence, the sport sponsorship relationship is used as a vehicle to achieve these overarching corporate objectives. Sponsorship objectives are intrinsic to the corporate sponsor.

The literature revealed 12 consistently salient sport sponsorship objectives. However, not all objectives are equally important for all sponsors of a particular sport property. Likewise, the relative importance of each objective can vary for a given company based on a particular sport sponsorship relationship.

Lough and Irwin (2001) presented the idea of a sport sponsorship lifecycle where sponsor objectives move from awareness through image enhancement on their way to sales/market share as the sport property matures. This theory appears to hold value when compared against the current sport sponsorship objectives literature. This theory could be expanded to encompass the sport sponsorship experience of both the sport property, as suggested by Lough and Irwin (2001), as well as the sponsorship experience of the sponsoring company. The review of sport sponsorship objectives literature revealed those studies which surveyed large corporations or companies involved in sponsorship of a large scale event such as the Olympic Games all reported market drive objectives as most important (e.g. Apostolopoulou \& Papadimitriou, 2004; Irwin \& Sutton, 1994; 
Papadimitriou, Apostolopoulou, \& Theofanis, 2008). Conversely, the literature has demonstrated within countries with a less mature sponsorship lineage than the United States, such as Canada or Norway, small business sponsors, and sponsors of less traditional spectator sports, typically have sponsorship objectives more focused on increasing awareness, enhancing the corporate image, or engaging in social responsibility or community involvement (e.g. Lough \& Irwin, 1994; Lough \& Irwin, 2001; Slack \& Benz, 1999; Thjomoe et al., 2008).

\section{SPORT SPONSORSHIP SELECTION CRITERIA}

The Sport Sponsorship Objectives section discussed several overarching corporate objectives companies have often attempted to achieve through sport sponsorship. Sport sponsorship selection criteria are related to sponsorship objectives yet distinctly different. Sponsorship objectives are ingrained within the corporation and the corporation could use several different methods, or vehicles, to attempt to achieve such objectives. Conversely, sponsorship selection criteria are specific to a given sponsorship opportunity. Selection criteria represent the inventory a sport property is able and/or willing to provide a sponsor to assist in the achievement of corporate sponsorship objectives. An example of a sponsorship selection criterion includes sponsor signage at an event, television coverage, and hospitality opportunities. While it is quite unlikely any corporation would have a corporate objective of increasing its signage opportunities, as discussed above many companies are looking to increase corporate awareness. Signage at a sport event may assist in increasing corporate awareness as those in attendance (fans and participants) will view the sign. In addition, if the event is televised the off-site viewing audience will also view the signage, hopefully increasing corporate awareness exponentially. However, not 
all sponsorship selection criteria are directly related to a sponsorship objective. For example, cost effectiveness or the overall cost of the sponsorship will certainly be taken into consideration when a company is evaluating a sponsorship opportunity. Yet, none of the sponsorship objectives contained this very vital component of any sponsorship evaluation.

The following review of sport sponsorship selection criteria research is divided into two categories: General Sponsorship Selection Criteria and Sport Specific Sponsorship Selection Criteria. The first section presents studies which investigated corporations' sponsorship selection criteria but did not specify the type of sport property the corporate sponsors were referring to when they provided their responses. The second section, Sport Specific Sponsorship Selection Criteria, presents studies in which the sport property is identified and results of these studies are specific to a given sport property or genre.

Two types of studies are found within both subsections: (a) studies focused exclusively on sport sponsorship selection criteria, and (b) studies which mixed selection criteria with a variety of sponsorship objectives. Those studies mixing selection criteria and objectives are presented wholly within the Sport Sponsorship Selection Criteria section rather than dividing results and placing the results of the objectives in the above section and the results pertaining to selection criteria in the section to follow. This organizational decision was strategically based in an effort to keep the integrity of the ranking based results of these mixed studies. 


\section{General Sponsorship Selection Criteria}

Abratt et al. (1987) were some of the first researchers to investigate sport sponsorship selection criteria. Sport was identified as a popular sponsorship choice as it provided two potential markets the participants and the spectators. Sponsors wanted their message transmitted to their consumers through the sponsorship, no matter what the message was, even if their message was to simply draw attention to the fact they were sponsors of a given event (Abratt et al., 1987).

Abratt et al. (1987) revealed many corporate objectives and selection criteria through the survey of 45 sport sponsors within popular South African media, from November 1984 to May 1985, followed by interviews with 10 respondents. Respondents identified TV coverage, on-site signage and jersey sponsorship as their most essential promotional activities within sport sponsorship (Abratt et al., 1987). From these findings, Abratt et al. (1987) produced three categories of, what they termed, sport sponsorship objectives. The first category, the 'most important' objectives, included potential TV coverage, enhancing corporate image, other media coverage (press \& radio), increasing corporate awareness, potential of spectators as consumers/customers, promoting public relations with customers and potential customers. The second group of objectives were classified as 'important' and included such objectives as the sport's natural link with sponsor's product/service, participants in the sport as potential users of product/service, number of spectators at the venue, and cost of the sponsorship relative to other forms of promotion. Finally, the third category of sport sponsorship objectives was classified 'less important' and included concern for public interest, promotion of staff morale, previous 
involvement in sport sponsorship, competitors' involvement in sponsorship, and CEO's personal interest (Abratt et al., 1987).

In another early study Meenaghan (1991) determined the ability to fulfill sponsorship objectives, including awareness and image at both the corporate and brand level, as well as coverage of the defined target audience, including demographic and geographic concerns were all deemed important selection criteria. Meenaghan (1991) also indicated the ability of the sponsorship to reflect the lifestyle of the target audience, audience size (both on-site and media coverage), the cost of the sponsorship, and potential hospitality opportunities were instrumental sponsorship selection criteria.

Looking at sport sponsorship selection criteria from a European perspective, Witcher, et al. (1991) investigated the links among the sponsorship selection criteria, categories of sponsored activities, and organizational functions. Witcher et al. (1991) surveyed (54 usable responses) large commercial organizations known to be involved in sponsorship within the United Kingdom. While the number of arts and sport sponsorships were about equal, only the sport sponsorship results are discussed.

Professional sport was the most supported activity while amateur sport was more often supported by organizations at the local level. Enhancing corporate image was deemed the most important reason for sponsorship engagement. Other important reasons for sponsorship involvement were (a) brand awareness, (b) television, radio, and press exposure, and (c) increasing sales (Witcher et al., 1991). While Witcher et al. (1991) determined differences between the types of sponsorship expectations (national vs. local) between professional and amateur sports, they failed to keep these categories segregated 
for any subsequent analysis, providing only aggregate data with respect to sponsorship selection criteria.

In another European based study, Crowley (1991) investigated the sponsorship selection criteria deemed important by sport sponsors in Ireland. Crowley's (1991) analysis of 70 surveys returned by senior marketing personnel involved in sponsorship within the Republic of Ireland determined important sponsorship selection criteria to include (a) media coverage, (b) event title, (c) entertain guests (hospitality), (d) exposure to attendance, (e) perimeter advertising (f) heart of the action identification (ability to put corporate logo on participants' equipment), (g) exposure to participants, and (h) advertising theme (ability to create promotional campaign around sponsorship).

Scott and Suchard (1992) collected surveys from 108 companies engaged in sponsorship in Australia. From their factor analysis of 23 selection criteria, 10 items significantly loaded on four salient factors media coverage, performance (improve company/product awareness and market share), client relationships (hospitality), and promotional extensions (complement advertising and public relations). Interestingly, Scott and Suchard (1992) determined only performance (improve company/product awareness and market share) and client relationships (hospitality) were significant motivators for Australian businesses to spend a proportion of their advertising budget on sponsorship. Even though media coverage was not found to be a significant motivator for businesses to allocate monies toward sponsorship, the researchers stressed media coverage was found to be a motivating factor for engaging in sponsorship. Scott and Suchard (1992) concluded the major purposes for sponsorship were brand awareness, market share improvement, and client hospitality. 
Within the United States, Irwin et al. (1994) followed up on the theoretical creation of the Sport Sponsorship Proposal Evaluation Model (SSPEM) by Irwin and Asimakopoulos (1992) and sought to empirically test the inclusion of the 47 sponsorship selection criteria on the SSPEM and their seven respective constructs: budget considerations, event management, positioning/image, targeting of market, integration of communications, competition considerations, and strategies.

Irwin et al. (1994) utilized a 7-point Likert Scale to assess the importance of each criterion for inclusion in a sport sponsorship proposal. Respondents were also asked to provide and rate any criteria not included in the SSPEM. Surveys were forwarded to 200 U.S. corporations identified as active sport sponsors, yielding 78 usable surveys.

Irwin et al. (1994) performed a principle components factor analysis for each dimension. Findings indicated sponsors were most concerned with matching images between the sport property and the sponsor. Four of the top 10 most important criteria related to the demographic and psychographic profiles of the sport property's audience.

The factor analysis determined 42 selection criteria, as opposed to the original 47 , fit better onto the following 11 constructs: (a) budgetary considerations (affordability, cost effectiveness), (b) management issues (event profile, organizing committee status, media guarantees, legal status, regulatory policy, athletes cooperation, governing body status, marketing agency profile), (c) positioning/image (product-sport image fit, product utility fit, image-target market fit), (d) targeting of market (demographic fit, size, fan association strength, national media coverage, local media coverage), (e) extended audience profile (demographic fit, size), (f) public relations (hospitality accommodations, community leader presence, customers presence, staff sport knowledge, event sales/retail 
tie-in, new account opportunities), (g) promotional opportunities (promotional licensing, complementary advertising, signage opportunities), (h) competition considerations (competition's interest, ambush market avoidance), (i) sponsorship status (title sponsor, major sponsor, exclusivity, established, long term involvement), (j) alternative sponsorships (co-sponsor, in-kind supplier), and (k) sponsorship type (team, league/championship, event, facility) (Irwin et al., 1994). The factor 'integration' was removed from the original SSPEM and replaced with extended audience profile, public relations, sponsorship status, alternative sponsorship, and sponsorship type. All of these revisions were reflected in the Revised SSPEM, presented at the conclusion of the study conducted by Irwin et al. (1994). These changes reflect the need to base models on both theory and empirical testing. The Revised SSPEM provides future researchers with an instrument more psychometrically sound than the purely theoretical original SSPEM.

Four years later, Thwaites et al. (1998) investigated the sponsorship selection criteria of Canadian corporate sponsors by interviewing 10 leading Canadian sponsorship decision-makers and then surveyed 500 of the largest companies in Canada. The findings indicated hockey, baseball, golf, and football were the most frequently supported sports, which is easily conceivable considering the prevalence of hockey within Canada and overall popularity of the other sports within North America (Thwaites et al., 1998). Thwaites et al. (1998) determined the top selection criteria used by sponsors when selecting sponsorship proposals included (a) event has a clean image, (b) sponsor's name can be linked to event, (c) good fit with product/corporate positioning, (d) audience profile can be determined, (e) audience size can be measured, (f) sponsorship can be incorporated within mainstream advertising and sales promotions, (g) sole sponsorship 
available (exclusivity), (h) television coverage, (i) duration of contract is three years or greater, (j) sponsorship represents a new event rather than an existing one, and (k) little dialogue necessary with organizers. The most notable finding concerning selection criteria was the fact television coverage was ranked eighth, surprisingly lower than reported in previous research. This result could be partially due to the decreased emphasis and lower level of commercialization of many sports in Canada compared to the United States. This information is critically important to the large number of sport properties seeking funding. Thwaites et al. (1998) stated, due to the fact too many sports are chasing too few sponsorship dollars, sport organizers need to be able to identify and satisfy the needs of potential sponsors.

While the previous researchers focused on large companies involved in sport sponsorship, Mack (1999) provided insight into the interworking of small business sponsorship of community focused events. A focus group was held with small business owners to better understand their opinions of, involvement in, and objectives for sponsorship (Mack, 1999). From this activity, the researcher learned many of the small businesses were most concerned about community support, employee involvement, and reaching target markets through their sponsorship relationships.

The second stage of Mack's (1999) study included mailing questionnaires to 800 small businesses within a Southeastern state whose consumer sales were between $\$ 5 \mathrm{M}$ and \$20M annually. Mack (1999) received 212 usable surveys. From those responses, the author determined approximately $70 \%$ of the companies engaged in sponsorship activities. The majority of these companies supported between one and ten events annually. Most sponsorships involved charitable associations while sport sponsorship was 
the second most frequently supported segment of sponsorship as indicated by Mack (1999). Interestingly, approximately $30 \%$ of the respondents indicated they were increasing their marketing focus with respect to sponsorship. The results of the study demonstrated the most important reasons for engaging in sponsorship by these small business were (a) giving back to the community, (b) increase company image/goodwill, (c) interest/concern about event, (d) employee involvement in the event (e) reach target market, (f) prior participation in event type (g) service group promotion, and (h) status associated with the event. These findings demonstrate a lack of marketing initiatives compared to some of the previous studies. The ability to reach the company's target market was the highest ranked marketing focused objective and it was ranked fifth of eight objectives reported. Also, when asked to respond to statements about their involvement in sponsorship, most sponsors agreed that sponsorship provides for community assistance. Using sponsorship as a marketing tool was ranked sixth of eleven and the use of sponsorship to improve sales was ranked ninth of eleven reasons for sponsorship involvement. Overall, the sponsors appeared to be happy with their investments as the vast majority indicated they planned on continuing or increasing their involvement in sponsorship (Mack, 1999).

An alternative explanation to the sponsorship lifecycle for the community focus of smaller businesses may be related to the corporate mission and vision. Smaller businesses may have a corporate mission and/or vision more focused on the local community, whereas larger corporations may have a mission/vision focused on the generation of revenue in an effort to appease shareholders. 
McCarthy and Irwin (2000) provided yet another perspective on sponsorship selection with their investigation into the motives of corporations seeking facility sponsorship/facility naming rights, the intended implementation of these arrangements, entitlements sought by naming rights purchasers, and assessment procedures utilized to determine sponsorship effectiveness.

Surveys adapted from Irwin et al. (1994) were sent to eight sponsorship/marketing directors or corporate communication directors involved in a sport facility naming rights purchase. Executives were then interviewed over the phone as a follow-up to their survey responses. Respondents were strategically selected, two airlines, two communications companies, two breweries, a utilities company, and a financial services firm, from those industries most commonly involved in sport facility naming rights.

McCarthy and Irwin (2000) found the most popular motive for corporations engaging in naming right agreements were community citizenship, followed by an effort to increase sales and market share. Interestingly, only four of the eight respondents indicated specific objectives were identified prior to sponsorship engagement. The corporate executives indentified a number of selection criteria considered valuable including: extended sales opportunities, corporate hospitality, ticket packages, luxury suites, enhancing brand awareness, on-site product usage, product display opportunities, and local marketing opportunities.

Summary. The previous section presented literature revealing a number of general sport sponsorship selection criteria. Some of the most commonly cited selection criteria included media coverage at the local, regional, and national level (Abratt et al., 1987; Crowley, 1991; Irwin et al., 1994; Scott \& Suchard, 1992; Thwaites et al., 1998; 
Witcher et al., 1991); ability to reach a specific audience including demographics and/or psychographics (Irwin et al., 1994; Mack, 1999; Meenaghan, 1991; Thwaites et al., 1998); hospitality opportunities (Crowley, 1991; Irwin et al., 1994; McCarthy \& Irwin, 2000; Meenaghan, 1991; Scott \& Suchard, 1992); audience size, both on-site and off-site (Irwin et al., 1994; Meenaghan, 1991); sport/sponsor product fit (Irwin et al., 1994; Thwaites et al., 1998); and cost of the sponsorship opportunity (Irwin et al., 1994; Meenaghan, 1991).

The study conducted by Mack (1999) on small businesses indicated there may be differences in the relative importance placed on different sponsorship selection criteria based on the size of the company. These differences may be reflected in the type of sport property support or possibly the differences in corporate philosophies between small and large businesses.

The criteria presented within this section reflected the findings of studies not specific to any particular sport, league, or organization. Therefore, the findings from these studies provide an overview of the criteria generally deemed important by sport sponsors. Furthermore, these studies do not provide any basis for understanding if sponsorship selection criteria vary due to the type of sport property sponsored. In an effort to fill this gap, the following section reviews studies which have identified a specific sport property sponsors have supported and gauge the importance sponsors placed on the specific selection criteria present when making the decision to support a given sport property. 


\section{Sport Specific Sponsorship Selection Criteria}

The sponsorship selection criteria studies reviewed above provide a good base for a general understanding of the criteria sponsors use when evaluating sport sponsorship opportunities. The studies within this section provide more specific insight into the selection criteria sponsors have used when evaluating certain sport sponsorship opportunities. Some studies have compared and contrasted the selection criteria sponsors used when evaluating different types of sport properties, other studies simply examined the most important selection criteria sponsors reported when evaluating a specific sport sponsorship opportunity. Collectively these studies provide a firm foundation to stake the claim sponsors do not view all sport properties as a homogeneous group but rather diverse opportunities to achieve distinctive goals.

Through their mixed method study, Kuzma et al. (1993) surveyed 180 advertising, marketing, public relations, and/or communications vice presidents in Fortune 1000 companies, each of which had sport sponsorship experience. The researchers also surveyed event representatives from the 30 corporate sponsors of the 1991 International Special Olympics. Sponsorship representatives from the 51 sponsors of the 1990 U.S. Olympic Festival were also surveyed. The researchers followed up the written questionnaire with personal and telephone interviews. Kuzma et al. (1993) aimed to produce a set of research-based guidelines sporting event organizers could use in formulating plans for gaining corporate sponsorships.

Kuzma et al. (1993) found companies evaluating sponsorship proposals tended to categorize the proposals as either commercial or philanthropic, emphasizing different selection criteria based on this categorization. All companies were most concerned about 
a demographic and psychographic match between the sport property's fans and the company's target market. Once this match is established potential sponsors are more likely to evaluate the proposal against corporate objectives. Fortune 1000 companies reported their primary sponsorship objective to be increasing corporate awareness. Awareness was followed by improving company image, community responsibility, increasing brand awareness, hospitality opportunities, increase short-term sales, increase long-term revenues, and enhance employee relations Kuzma et al. (1993).

Sponsors of the U.S. Olympic Festival and the International Special Olympics were most concerned with demonstrating community responsibility while increasing company awareness and improving company image. Sponsors of the 1990 U.S. Olympic Festival and 1991 International Special Olympics were also concerned with increasing brand awareness, short-term sales, and enhancing employee relations. Some of the most important findings indicated the Olympic Festival and International Special Olympics sponsors reported customer entertainment and long-term revenue generation were considered to be of negligible importance. From these findings it is quite obvious sponsors do not paint all sport entities with the same broad brush.

Copeland et al. (1996) provided a Canadian perspective through their investigation of 112 large Canadian companies engaged in sponsorship. Copeland et al. (1996) investigated the selection criteria these companies deemed important when sponsoring grassroots, elite amateur, and professional sports.

Findings indicated most sponsors were involved in sponsorship at all levels (community-based grassroots sport, elite amateur, and professional). Results demonstrated the top 10 criteria reported by sponsors were, in order: (a) exclusivity, (b) 
increase awareness, (c) reinforce image, (d) signage at event, (e) spectator targeted, (f) increase sales/trial, (g) ability to quantify results, (h) national television coverage, (i) community relations, and (j) regional print coverage (Copeland et al., 1996). The researchers determined only three of 37 sponsorship selection criteria differed significantly based on the type of sport property being sponsored: national television coverage, national print coverage, and community relations. The two criteria concerning national media coverage were most valued by sponsors of elite amateur and professional sports, while community relations was most valued by grassroots sport sponsors. These findings are not too surprising. Companies engaged in sponsorship with sport properties which attract greater media attention would rank this type of exposure as a more important selection criteria than sponsors of grassroots and amateur sport properties who rarely attract even local media attention. Overall, firms seemed to implement consistent selection criteria regardless of the level of sport they were sponsoring (Copeland et al., 1996). These findings may be partially explained by the sponsorship life cycle presented by Lough and Irwin (2001). Professional sport sponsors in Canada may not have evolved to sales or market share sponsorship goals at the time of the study conducted by Copeland et al. (1996).

Ludwig and Karabetsos (1999) investigated, among other things, the goals and selection criteria of the corporate partners of the 1996 Atlanta Olympic Games. The researchers received usable surveys from 11 of the 19 TOP sponsors and Centennial Games Partners of the 1996 Olympic Games in Atlanta. Ludwig and Karabetsos (1999) indicated sponsors ranked the most important selection criteria in the following order: (a) exclusivity, (b) increase public awareness, (c) increase sales, (d) create or alter image, (e) 
generate media benefits, (f) unique hospitality opportunity, (g) increase market share, (h) reach specific market segments, (i) build goodwill, (j) enhance employee relations, and (k) continue Olympic tradition. Responses were analyzed collectively; hence, no differences were analyzed between TOP Sponsors and Centennial Games Partners.

Chadwick and Thwaites (2004) reviewed the progression of sponsorship management within English professional soccer. Thirty-seven English professional soccer jersey sponsors provided usable survey responses. Findings of this study were compared against the findings of Thwaites (1995) to determine if the management of sport sponsorship in English professional soccer had progressed over this time period. Overall, findings suggested the management of sport sponsorships had become more professional. However, Chadwick and Thwaites (2004) noted the major concern surrounding sponsorship, found in both the 1995 and 2004 studies, concerned the lack of objective setting and evaluation.

Responses were on par with the findings of Thwaites (1995), having corporations ranking the ability of a sponsorship to generate public awareness as most important, followed by: media attention, enhancing corporate image, and creating product/service display opportunities (Chadwick \& Thwiates, 2004).

Tomasini, Frye, and Stotlar (2004) analyzed the knowledge base of U.S. collegiate athletic department senior marketing administrators regarding their corporate sponsors' goals and selection criteria. The researchers also examined the differences between Division I-A, I-AA, and I-AAA senior marketing administrators' perspectives of the objectives and selection criteria of their sponsors and compared their results to sport sponsorship industry standards reported by IEG's Sponsorship Report and Hot Buttons. 
The results provided by Tomasini et al. (2004) from their analysis of 116 questionnaires completed by senior marketing administrators at the, then defined, NCAA Division, I-A, I-AA, and I-AAA, determined there we many similarities and some differences among the different divisions represented in the study. Only descriptive statistics were provided, so no statistically significant differences were established among the three respondent groups. While a vast majority $(85.2 \%)$ of administrators indicated sponsors had overtly expressed their objectives for the sponsorship, the remaining $14.8 \%$ were misinformed as to the magnitude of marketing and sales focused selection criteria driving most corporations to sponsor sport properties. The most notable findings indicated athletic department administrators informed of their sponsors' objectives reported the sponsorship selection criteria used by their current sponsors to be (a) increase visibility/awareness, (b) increase sales, (c) advertising, (d) promotion/sampling opportunities, (e) create a positive image, (f) enhance business-to-business relationships, (g) increase loyalty, (h) to be associated with a successful program, (i) to have tickets to events, (j) alumni, (k) philanthropy, and (l) social event. While these selection criteria were not ranked in this exact order for all three divisions, the top four were consistent across all divisions and the deviation for subsequent selection criteria were not too dramatic (Tomasini et al., 2004). The researchers noted the respondents' sponsorship selection criteria reported by the executives were very much in line with the most current industry reports.

Daniels, Baker, Backman, and Backman (2007) analyzed the important sponsorship selection criteria of 28 sponsors at a 35-year-old PGA tournament, held in the southeastern United States. Daniels et al. (2007) found sponsors were highly 
concerned about hospitality opportunities with their key clients as opposed to objectives focused on the general public or fans in attendance of the event, very similar to the earlier findings of Crowley (1991). The top 10 sponsorship objectives were identified to be (a) opportunities to entertain business associations, (b) location of hospitality tents, (c) location of skyboxes, (d) communication with tournament/event staff, (e) return on sponsorship expenditures, (f) opportunity to watch professional golf, (g) sponsorship signage, (h) quality of skybox packages, and (i) transportation system at the tournament. One very interesting finding indicated the opportunity for on-site signage was ranked in the bottom five of all sponsorship objectives (Daniels et al., 2007).

Summary. While many of the same selection criteria unveiled within the General Sport Sponsorship Selection Criteria section were reiterated within this section (media coverage, ability to reach specific demographics/psychographics, hospitality opportunities, and sport/sponsor product fit), the review of sport specific sponsorship selection criteria revealed several nuances not presented within the General Sport Sponsorship Selection Criteria section. First, the study conducted by Kuzma et al. (1993) demonstrated that sponsors do not place the same level of importance on all selection criteria for all sport properties. Clear differences were found between Fortune 1000 companies engaged in sport sponsorship and the sponsors of the Olympic Festival and International Special Olympics. The Fortune 1000 companies focused more on selection criteria aimed to achieve marketing and sales goals, while the Olympic Festival and International Special Olympic sponsors noted they were concerned with enhancing employee relations and marketing and sales goals were of negligible importance. Similarly, Copeland et al. (1996) found sponsors of professional and elite level amateur 
Canadian sports were more concerned about national media coverage than sponsors of grassroots sports. Interestingly Daniels et al. (2007) found sponsors of a PGA event were most concerned about hospitality opportunities. Of the nine selection criteria/objectives presented by Daniels et al. (2007), five were focused on hospitality opportunities associated with the golf event.

\section{NICHE SPORT SPONSORSHIP}

Academic investigation into the sponsorship of niche sports has been relatively sparse. Considering the field of sport sponsorship has been empirically studied since the 1980s and so few studies have focused on niche sports, a gap in the literature is clearly present. The remainder of this section provides insight into the current knowledge base regarding niche sport sponsorship.

In an effort to ensure all relevant studies were uncovered, all academic databases known to contain sport or sponsorship related research were searched. This list of databases included ABI/Inform, Business Source Premier, EBSCO Academic Search Premier, ERIC, Google Scholar, ProQuest Direct, ProQuest Research Library, Social Sciences Index, Sport Discus, and Sport Business Research Network. Each database was searched using the terms niche, non-mainstream, nonmainstream, second tier, second-tier, secondtier, fringe, grass roots, grassroots, grass-roots, semi-professional, semi professional, semiprofessional, emerging, non-traditional, non traditional, nontraditional, and untraditional along with the term sport. All relevant research was reviewed and is discussed below.

The following review of niche sport sponsorship literature is broken into three categories: amateur sport sponsorship, action sport sponsorship, and women's sport 
sponsorship. While the current study focuses on professional niche sport sponsors' objectives and selection criteria, the following review of niche sport literature takes a more global approach including all forms of sponsorship research on niche sports, as only Lough and Irwin (2001) specifically investigated sponsorship objectives of a niche sport (women's sport). The amateur sport sponsorship literature represents a large variety of sporting events including, among others, 3-on-3 basketball, senior games, state games, recreation center activities, the Gay Softball World Series, triathlon, national sport organizations (synchronized swimming), and horseracing. When the increasingly popular action sports and women's sports are added, a very large sport industry segment is revealed. However, there still exists very little empirical research to unveil trends or guidance to either niche sport properties or potential niche sport sponsors.

\section{Amateur sport sponsorship}

While the literature on amateur sport sponsorship is sparse, it has managed to cover a vast array of sporting activities. Due to the diversity of the literature, it may be difficult to draw any conclusions concerning the sponsorship of these types of sports. However, it should be noted even with the fragmentation of amateur sports, this area has received far more attention from academics when compared to professional niche sports.

One of the first inquires into the sponsorship of niche sports was conducted by Greenwald and Fernandez-Balboa (1998) when they analyzed the role of grassroots sport sponsorship in U.S. Corporations. The researchers defined grassroots sports to be sporting events, in contrast to professional sports, which attract local community members as participants as well as spectators (Greenwald \& Fernandez-Balboa, 1998). Activities encompassed within this definition included 3-on-3 basketball tournaments, 
activities within a recreation center, as well as senior, women's, and club sport.

Greenwald and Fernandez-Balboa (1998) identified several market and demographic trends believed to be responsible for the increase in grassroots sport sponsorship. These trends included (a) increased clutter in mainstream sport sponsorship, (b) escalating bigtime sport sponsorship costs, (c) increasing merchandise and sales focus, (d) increasing sponsorship integration within the corporate marketing mix, (e) increasing consumermarket fragmentation, (f) decreased interest of mainstream sports by senior citizens, $(\mathrm{g})$ Generation Xers shifting interest from big-time sports to "fringe/second-tier" sports, and (h) increase in women's sport sponsorship. Fourteen key informants, knowledgeable about grassroots sports were interviewed. Snowball sampling was implemented to reach the 14 respondents. Respondents represented marketing/sponsorship departments of athletic apparel companies, grassroots sports organizations, sport marketers/consultants, and a sport publishing company representative.

Results indicated sponsorship of grassroots sports had significantly increased over the preceding decade. The researchers also noted several companies had even created departments specifically designed to handle grassroots sponsorships. Greenwald and Fernandez-Balboa (1998) determined those trends identified previously were all present within the grassroots sponsorship industry as well as four additional trends effecting grassroots sport sponsorship: (a) increased cable network television coverage of grassroots sport, (b) corporations' increasing attempts to reach customers at the national level through grassroots sport sponsorship, (c) increased corporate ownership of events, and (d) increased sponsorship measurability. Findings also indicated corporate exposure and increasing awareness were deemed as important objectives in grassroots sport 
sponsorships (Greenwald, \& Fernandez-Balboa, 1998). These findings demonstrate niche sports are able to provide sponsors with a cost-effective, less cluttered alternative to mainstream sport sponsorship while providing a more targeted demographic.

Opposed to grassroots amateur sports, Seguin et al. (2005) looked at elite level amateur sport in Canada. Seguin et al. (2005) conducted semi-structured interviews with key individuals responsible for the marketing of three Canadian National Sport Organizations (NSOs) and key individuals responsible for sponsorship decision-making activities for three Canadian corporations, partnered with each of the NSOs respectively. Through their investigation, Seguin et al. (2005) aimed to provide a list of best practices to assist the 33 Canadian NSOs who struggle the most to secure corporate sponsorships. The researchers intentionally selected NSOs outside of the sports they deemed the 'Big Six' Canadian NSOs, specifically Figure Skating, Hockey, Alpine Skiing, Tennis, Rugby, and Soccer (Seguin et al., 2005). These 'Big Six' sports generated enough sponsorship dollars to be considered well supported. Seguin et al. (2005) hoped to provide these less well-funded NSOs with the knowledge and capabilities to secure and develop successful sponsorships.

Through their interviews, Seguin et al. (2005) found corporate sponsors had distinctive yet related sponsorship motives, sponsorship objectives, corporate objectives, and general marketing approaches. Motives for entering the sponsorship varied for each company, and included personal interest of $\mathrm{CEO} /$ philanthropy, adding to the marketing mix, playing a leadership role, long-term marketing, leveraging existing Olympic sponsorship, internal marketing, and image association. Two of the three respondents indicated one of their sponsorship objectives was to increase brand awareness (Seguin et 
al., 2005). Other sponsorship objectives included increasing sales, building reputation of financial strength, building relationships, and creating good corporate citizenship.

Miloch and Lambrecht (2006) also investigated what they classified as grassroots or niche sports defined as sports "that are not mainstream and do not appeal to a mass audience"(p. 147). The researchers went on to note participants and fans of these sports usually represent a niche or sub-segment of sport consumers. Some examples of grassroots sports provided by Miloch and Lambrecht (2006) included tennis, lacrosse, bowling, fishing, curling, horseracing, and action or extreme sports.

When discussing the benefits niche sports provide to sponsors, Miloch and Lambrecht (2006) indicated niche sport participants and fans are typically more identified and passionate about their sport than mainstream sport participants and fans. This higher level of identification has been demonstrated in the mainstream sport sponsorship literature to be an antecedent of sponsorship awareness and subsequently intent to purchase a sponsors product or service. Miloch and Lambrecht (2006) also determined that while niche sports may draw fewer participants and spectators, the homogeneous nature of the group, with respect to demographics and psychographics, lends favorably to providing sponsors with a highly targeted market to which they can relay their corporate marketing message.

Miloch and Lambrecht (2006) assessed consumer awareness of sponsors at a Midwestern State games through the examination of recall and recognition rates and purchase intentions. A total of 492 respondents completed usable self-administered surveys. Findings indicated recall and recognition rates were slightly lower but comparable to sponsorship awareness studies focused in mainstream sports. The 
researchers also found those sponsors who engaged in product giveaways or product sampling had significantly higher levels of awareness. Indicating corporate sponsors of niche sports should be using these opportunities within their sponsorship selection criteria and niche sport properties should be including this as a valuable piece of inventory when soliciting sponsorships.

Rather than investigating a variety of sports, as the previously discussed amateur sport investigations, Jarvis (2002) investigated the nature, motivations, effectiveness, and trends within the sponsorship of the 2000 Gay Softball World Series hosted in Toronto, Ontario, Canada. More specifically, Jarvis (2002) hoped to better understand how different the motives for sponsors involved in this event were from mainstream sports events. Semi-structured interviews were conducted with event organizers (2), executive board members (2), event sponsor representatives (15), and event participants (21). Jarvis (2002) found the majority of sponsors were companies or organizations within the gay and lesbian community (bars and restaurants mostly). However, major corporations were also involved in the event.

Similar to much of the research on mainstream sport sponsorship, sponsors within Jarvis' (2002) study reported increasing sales as the most important factor for engaging in the sponsorship. A sense of community responsibility or community goodwill, increasing market share, and enhancing the company image were the other commonly cited rationales for supporting the event. Unlike mainstream sport sponsorship objectives, exclusivity, media awareness, and hospitality were not reflected in the reasons sponsors support Gay Softball World Series (Jarvis, 2002). Jarvis (2002) indicated mainstream sponsors were more focused on the sales, market share and brand loyalty objectives, 
while the gay and lesbian oriented companies were more focused on community relations, sales, and image. One of the most transferrable findings of this study was the fact mainstream companies have started engaging in non-mainstream sport sponsorship, legitimizing this new medium as a viable sponsorship alternative to the commonly supported mainstream sports.

Similar to both Greenwald and Fernandez-Balboa (1998), and Miloch and Lambrecht (2006), Lamont and Dowell (2007) focused on grassroots sports. However, unlike the previous grassroots studies, the study by Lamont and Dowell (2007) was located in Australia as opposed to the United States. Noting the heavy focus of mainstream sport sponsorship research Lamont and Dowell (2007) were inspired to investigate the sponsorship objectives, leveraging strategies, and evaluations of small and medium sized enterprises (1-200 employees) sponsorships of regional sport tourism events.

Ten semi-structured interviews were conducted with event managers of five regional sport tourism events and five sponsors of the corresponding events. All events were located in Northern New South Wales, Australia and included an ocean swim, two triathlons, a Masters' Games, and a horseracing event. Their findings indicated sponsors rated their objectives for engaging in these events as follows: give back to the community, gain media exposure, increase awareness, increase sales, and attract visitors to the host community (Lamont, \& Dowell, 2007). These finding are similar to other nonmainstream sport sponsor studies (e.g. Lough \& Irwin, 2001) with sales objectives ranked noticeably lower than reported in many of the mainstream sport studies. From their 10 interviews, Lamont and Dowell (2007) also found two of the sponsorship agreements 
were initiated with a formal proposal brought forth by the sport property. Another two sponsorship relationships were developed stemming from existing personal relationships between individuals in the sponsoring organization and individuals organizing the event. The final relationship was initiated when the sponsor approached the sport property and proposed they would be the presenting sponsor of an event if the sport property was willing to host said event. Lamont and Dowell (2007) concluded contemporary sport properties must be aware of the processes and objectives which underpin sponsorship agreements. The researchers also suggest additional research is required to better understand the rationale behind small and medium sized enterprises' engagement in sponsorship as their research identified philanthropic motives still existed for the respondents in their study. While the contemporary sponsorship literature has determined philanthropy to be all but dead, this finding may present an argument that Lough and Irwin's (2001) sponsorship lifecycle may also be applicable to the size of the sponsoring company. Perhaps there is an interaction effect as well, where small and medium sized companies are more likely to support smaller sporting events, and according to Lough and Irwin's (2001) sponsorship lifecycle theory, sponsors of these less mature properties typically have awareness and image focused objectives.

Similar to Jarvis' (2002) investigation of the Gay Softball World Series, Doherty and Murray (2007) also focused on a single niche sport when they conducted a case study of the sponsorship process within Synchro Canada. Synchro Canada is the non-profit National Sport Organization (NSO) which oversees synchronized swimming within Canada. Information was collected via interviews with the Marketing Director of Synchro Canada. In Canada, synchronized swimmers were 99\% female. Due to substantial cuts in 
public funding Synchro Canada decided it would need to increase corporate sponsorship to obtain the funding needed to continue to operate the organization.

In order to be successful in obtaining sponsorships, Doherty and Murray (2007) determined sport organizations must identify what qualities and assets make Synchro Canada attractive to a corporation. One of the most important findings by Doherty and Murray (2007) was the fact sponsors felt Synchro Canada had very few risks for its corporate partners as sponsors believed they could control ambush marketing, variable media coverage, uncertainty of athlete performance, and most importantly sponsorship clutter. Finally, Synchro Canada attempted to assess the objectives of each potential sponsor prior to their first formal meeting. However, Doherty and Murray (2007) reported there was very little information available to Synchro Canada.

The amateur sport sponsorship literature revealed many benefits to sponsoring amateur sports as compared to mainstream sports. Some of the most interesting findings indicated amateur sports have the ability to provide a cost effective alternative to mainstream professional sport sponsorship (Greenwald \& Fernandez-Balboa, 1998) with less sponsorship clutter (Doherty \& Murray, 2007; Greenwald \& Fernandez-Balboa, 1998), and a more targeted fan base of potential consumers (Doherty \& Murray, 2007; Greenwald \& Fernandez-Balboa, 1998; Miloch \& Lambrecht, 2006). These studies also indicated many amateur sport sponsors have varying selection criteria compared to mainstream sport sponsors. Most studies determined sponsors have a need to increase sales and they feel sport sponsorship can help achieve this objective. This was demonstrated in the mainstream sport sponsorship literature as well as the amateur sport sponsorship literature (Greenwald \& Fernandez-Balboa, 1998; Jarvis, 2002; Lamont \& 
Dowell, 2007). However, amateur sport sponsors were more prone to utilizing sport sponsorship to give back to the community (Jarvis, 2002; Lamont, \& Dowell, 2007).

\section{Action Sport Sponsorship}

Bennett, collaborating with several other researchers, initiated an entire line of research investigating action sports. As defined by Bennett, Henson, and Zhang (2002) "action sports is a label placed on sports that are not mainstream or traditional and often include risk, danger, or unconventional rules and/or techniques" (p. 175). These sports have also been given the moniker 'extreme sports'. Several U.S. based tour events have taken place over the past decade including both winter and summer X Games, Gravity Games, Gorge Games (Bennett et al., 2002), and Dew Action Sports Tour (Bennett, Ferreira, Lee \& Polite, 2009). The common theme Bennett stressed throughout this line of research is the fact action sports are burgeoning sports, or series of sports, explicitly attractive to Generation Y. In each of his studies, Bennett stresses the massive purchasing power this segment of the population controls. Hence, according to Bennett, goods and service manufacturers are keenly in tune with Generation $\mathrm{Y}$ interests.

The first study in this line of research occurred when Bennett et al. (2002) analyzed action sport sponsorship and athlete recognition between two segments of Generation Y (Generation Y was defined as those individuals born between 1977 and 1994): high school and college students. The researchers also investigated the perceptions of action sports advertisements and sponsorship, as well as perceived effects on purchasing behavior through the two segments of Generation Y. Bennett et al. (2002) surveyed 1327 high school and undergraduate students within a Southeastern city in the United States. Bennett et al. (2002) found overall recognition rates for sponsors and 
athletes were relatively low, with the exception of Mountain Dew. A partial rationale for the low recognition rates could have been due to the fact the survey was not administered at an event nor had an action sports event taken place recently before the survey was distributed. The researchers noted Mountain Dew and ESPN had recognition rates near the levels realized by previous studies conducted at sporting events. However, all other sponsors had low levels of recognition. Often, sponsors competitors were identified as official sponsors at a higher rate than actual sponsors.

Bennett, along with Sagas and Dees (2006) aimed to determine media preferences and consumption patterns of attendees at the 2002 Gravity Games in Cleveland, Ohio. The researchers surveyed 665 Generation X attendees and 1497 Generation Y attendees. Attendees $21-41$ years of age were considered Generation $X$ and those under 21 were considered Generation Y. Respondents indicated their preferred television stations were MTV, ESPN, Comedy Central and Nickelodeon. From this, marketers of action sports and sponsors of action sports can now know they can reach their target markets via television advertising on these channels. Bennett et al. (2006) also found respondents consumed the X Games and Gravity Games more than the Olympic Games, the NFL, and other traditional sporting events. However, the authors note before claiming action sports to be mainstream, respondents were only those in attendance at an action sports event.

When considering the differences between the Generation $\mathrm{X}$ and $\mathrm{Y}$ fans, the Generation Y respondents watch significantly more television and the Generation Xers were more likely to watch traditional sports on television compared to their generational counterparts. This study demonstrated action sports continue to increase in popularity and 
are starting to attract those in tune with popular culture as seen by the mainstream media consumption indicated by the fans at the event.

The final study in this line of inquiry specifically focused on omnipresent action sports sponsor Mountain Dew. This study aimed to better understand the factors leading to fans' use of a sponsor's product. Through their 552 surveys of attendees of the Dew Action Sports Tour held in Louisville, Kentucky in 2005, Bennett et al. (2009) found age, gender, and spectatorship were the only variables which had a significant impact on the attendees' use of a sponsor's product. The researchers found spectatorship, the amount a fan attended or watched action sports, was a mediator of brand use, while participation in action sports and video gaming were not directly related to brand use. Young men were found to be much more likely to consume Mountain Dew than either older male spectators or female spectators. Bennett et al. (2009) suggested these findings might lead sponsors of action sports to attempt to increase awareness through (a) advertising during events, (b) ensure the use of on-site signage, (c) utilize product placement in video games, (d) develop a contest or sweepstakes on-site or through media, and (e) have sales and promotions tied to event attendance.

From the work of Bennett and colleagues, action sports have demonstrated the ability to deliver a sponsor's message to the very difficult to reach young male audience who possess substantial buying power (Bennett et al., 2002; Bennett et al., 2009). Unlike many mainstream sports, action sports events still provide sponsors with the opportunity to own the naming rights to the event. This has been found to be very beneficial for sponsors looking to increase awareness within this demographic as demonstrated by ESPN and Mountain Dew (Bennett et al., 2009). 


\section{Women's Sport Sponsorship}

Much like amateur and action sports sponsorship, the research on women's sport sponsorship has been quite limited. As discussed earlier, a major objective of nearly every sport sponsor is to increase sales. In addition, it has been well-documented women make a majority of the purchasing decisions within North American society. Bradish and Lathrop (2001) indicated within the sporting goods industry, women purchased $94 \%$ of women's sports apparel, $89 \%$ of children's, and $45 \%$ of men's. Yet, very little attention has been paid to this segment of the sport sponsorship industry.

Lough (1996) indicated there has been significant growth in the sponsorship of women's sports as well as an increase in targeting women consumers through sport sponsorship. "With the level of competition continually rising for corporate sponsorship money and the development of a niche in today's market becoming increasingly complicated, the identification of this new market comprised of women would appear to be a positive option for companies interested in cutting-edge strategy"(Lough, 1996, p. 13).

Lough (1996) sought to determine the factors that influence corporate decisionmaking relative to sponsoring women's sports. Participants were companies identified as involved in the sponsorship of women's sport from the 1994 edition of Sports Marketplace. A modified version of the SSPEM (presented by Irwin et al., 1992) was sent to each of the 138 corporations. Fifty-six completed surveys were returned for analysis. Descriptive statistics were reported on the benefits realized by the sponsoring companies, influential factors in developing women's sport sponsorship, factors utilized 
in sponsorship decision-making, and the corporate characteristics of women's sport sponsors.

Lough (1996) reported women's sport sponsors ranked the benefits they realized due to their sponsorship as follows: (a) extended audience profile (demographic fit and size), (b) extended media coverage (national and local coverage), (c) public relations factors (customer presence, hospitality options, presence of community leaders), (d) promotional opportunities (signage, complimentary advertising, and promotional licensing), (e) sales objectives, and (f) corporate perks (exhibit space, and premier seating/parking).

Similar to Irwin et al. (1994), Lough (1996) indicated the factors women's sport sponsors deemed to be influential in developing the sponsorship were budget considerations, targeting of market, proposal considerations (sport property competency), sponsorship status (exclusivity, major/title sponsor), sponsorship type (event, championship, organization, facility or team), competition consideration (other interested corporations, ambush marketing avoidance), and alternative sponsorship (co-sponsor or in-kind/supplier) (Lough, 1996).

Finally, and most importantly, Lough (1996) provided the selection criteria utilized in sponsorship decision-making, which were ranked: (a) achievement of sponsorship goals (achievement of objectives, value/ROI, and execution of event organizers), (b) positioning/image (product/sport image fit, and image/target market fit), (c) targeting women, (d) attendance (on-site and TV), and (e) management issues (event profile, organizing committee status, and governing body status). 
Some of the most interesting findings indicated sponsors of women's sports were most interested in engaging in sponsorships, which were cost-effective and affordable. Unlike the results from studies conducted on mainstream men's sports, women's sport sponsors did not appear to be overly concerned with sales objectives.

As discussed in the previous section on sport sponsorship objectives, Lough teamed up with Irwin in 2001 to investigate the differences in relative importance sponsors placed on specific sponsorship objectives for women's sports compared to 'traditional' sports (those sports which are not composed of exclusively women participants). Lough and Irwin (2001) found sponsors were more focused on awareness and image enhancement objectives when sponsoring women's sports properties. Those same sponsors were more focused on sales and marketing objectives for 'traditional' sports. This is where Lough and Irwin (2001) proposed the sponsorship lifecycle discussed throughout this review of literature. As a point of reiteration, the sponsorship lifecycle theory proposes as sport properties mature their sponsors objectives will move from an increasing awareness and image enhancement focus to a more market-driven, sales and market share focus.

That same year, Shaw and Amis (2001) explored the reasons some corporations choose not to invest in women's sport while others see women's sport as a viable marketing opportunity. The authors point to a vast gap in the sponsorship literature with nearly all empirical work concentrating on male athletes, teams, and events as their rationale for carrying out such an investigation. Shaw and Amis (2001) theorized men's sports are "cluttered" with sponsorship and women's sports represent an avenue of sport properties which were clean, or uncluttered, with fewer sponsors than their male 
counterparts. Shaw and Amis (2001) conducted two case studies of two women's Olympic national teams. One team was British, and the other team was presumably from a North American country, although the nationality was not revealed. The sponsor of the team from the UK was a contemporary women's clothing store, while the sponsor of the North American team was multi-national telecommunications company. The case studies revealed two very different perspectives and approaches to women's sport sponsorship. Shaw and Amis (2001) found three predominant themes that appeared to be most influential in the selection and execution of the two women's sport sponsorship: (a) the values and beliefs of the sponsorship decision-maker, (b) media coverage, and (c) mimetic pressures. The two cases investigated by Shaw and Amis (2001) found disparate approaches by each sponsor on all three of the previously mentioned themes. One sponsor demonstrated a severe lack of anticipated value from the sponsorship of a women's sport. This was demonstrated through the complete lack of activation (associated additional marketing to draw awareness to the sponsorship relationship), even though the company had engaged in extensive activation, specifically utilizing hospitality opportunities in all of their high profile male sport sponsorships. The other sponsor viewed the women's sport sponsorship as an opportunity to align itself with one of the best teams in the world and portray the image of two industry leaders united through sponsorship. Both sponsors demonstrated an aspiration for a level of media coverage undeliverable from the women's sport property at the onset of their sponsorship. While the British sponsor simply abandoned the hopes of gaining any exposure through their sponsorship, the other worked extensively to assist the women's team to exponentially increase the media coverage for the team consequently increasing the exposure of the 
sponsor simultaneously. Finally, Shaw and Amis (2001) discussed the influence of mimetic pressures from which they determined sponsors falling into the mimetic cycle would never truly maximize the potential of niche sport sponsorship, as these will always be seen as philanthropic ventures. However, those sponsors, such as one of the respondents in their study, willing to put in the effort to assist the sport property grow and gain media attention will have the advantage of an uncluttered environment where their corporation can be directly and intimately intertwined with the sport property.

Looking more specifically at the effects of sponsorship signage, Maxwell and Lough (2009) wanted to better understand the effects of on-site signage on fans' recall of sport sponsors of women's college basketball. The researchers noted signage has nearly become synonymous with sport sponsorship. Numerous previous studies have investigated spectator recognition of sponsors with the underlying assumption that sponsor recognition leads to top of mind brand awareness and subsequently increased sales of the sponsor's good or service. However, no previous studies had focused on sponsor recognition at a women's sport event. Hence, Maxwell and Lough (2009) surveyed two samples of women's college basketball spectators to gauge their level of sponsorship recognition. One set of spectators attended a game in which there was no onsight sponsor signage while the other site had sponsor signage. Surprisingly, Maxwell and Lough (2009) found no significant difference between the two samples, indicating sponsor signage at an event did not influence sponsor recognition rates. Maxwell and Lough (2009) suggested in-game promotions appeared to have a more profound effect on recognition rates as those sponsors engaging in memorable unique in-game promotions appeared to have the highest levels of recognition. Finally, these findings indicated 
corporations may want to focus more on the in-game promotional opportunities rather than signage opportunities when selecting sponsorship proposals; at least within women's college basketball.

Similar to the amateur sport sponsorship literature, research on women's sport sponsors has yielded some significant findings, which differentiate these sports from their mainstream counterparts. Women's sport sponsors appear to place a diminished emphasis on sales objective when compared to mainstream sports (Lough \& Irwin, 2001).

Women's sport sponsors also demonstrated an elevated emphasis on image objectives. These findings were demonstrated by Lough (1996) as well as Lough and Irwin (2001), Shaw and Amis (2001) also indicated the level of respect, and capability of women's sports to achieve market driven objects is questionable, contingent upon the given sponsor. However, the use of sponsorship as a form of philanthropy was not realized in any of the studies on women's sports. Again, the sponsorship lifecycle concept put forth by Lough \& Irwin (2001) has demonstrated credibility with sponsors of more mature sport properties seeking quantifiable, market-driven sales and market share objective and less mature sport sponsors seeking awareness, image enhancement or other less quantifiable objectives.

Summary. Collectively, the niche sport sponsorship literature identified a number of differences between these sport properties and mainstream professional sports. From a sponsorship objectives perspective, the sponsorship lifecycle put forth by Lough and Irwin (2001) appeared to be supported, having niche sport sponsors more focused on less tangible objectives such as awareness (Bennett et al., 2009; Lough \& Irwin, 2001; Seguin et al., 2005) and less focus on the more measurable objectives such as increasing sales or 
market share (Lough \& Irwin, 2001). However, only Seguin et al. (2005) indicated sponsors were selected based on the personal preferences of an executive. More importantly, none of the research indicated any sponsor considered sponsorship to be a philanthropic endeavor. Seemingly, the floor or starting point of the sponsorship lifecycle begins with awareness, moving to image enhancement and eventually on to sales and market share objectives.

The niche sport literature also unveiled several selection criteria niche sports may use as points of differentiation from their mainstream counterparts. The most commonly cited selection criteria deemed to be a benefit attributed to niche sports was their ability to provide sponsors with a more targeted demographic than other sponsorship opportunities (Bennett et al., 2002; Bennett et al., 2009; Doherty \& Murray, 2007; Greenwald \& Fernandez-Balboa, 1998; Miloch \& Lambrecht, 2006). Niche sports were also found to provide sponsors with a cost effective alternative to professional mainstream sport sponsorships (Greenwald \& Fernandez-Balboa, 1998). Finally, the studies reviewed in the previous section revealed niche sports are typically less cluttered with sponsors than many other sport properties (Doherty \& Murray, 2007; Greenwald \& Fernanadez-Balboa, 1998; Miloch \& Lambrecht, 2006).

\section{SUMMARY}

The current review of sport sponsorship literature was strategically organized to not only provide a wide broad understanding of the factors which influence sport sponsorship decision-making process and also compare and contrast the sponsorship objectives and selection criteria associated with several different types of sport properties. Sponsorship was defined as "an investment in cash or in-kind, in an activity, in return for 
the exploitable commercial potential associated with that activity" (Meenaghan, 1991, p.36). Key to this concept is the understanding that this relationship hinges on an exchange of something of perceived value between two parties. In order for a sponsorship to transpire, each party must be able to provide the other with something of value. Once this is understood several other factors must be identified and addressed by a sport property to ensure their greatest likelihood of securing sponsorship funding from a corporation. The review of literature broke these remaining factors into three distinct groups: sponsorship decision-makers, sponsorship objectives and sponsorship selection criteria.

The literature on sponsorship decision-makers indicated sponsorship proposals are not all handled the same way across different companies or even within a single corporation. McCook et al. (1997) found as the cost of the sponsorship increased the decision-maker moved from local and regional management to vice presidents and sponsorship committees within the corporate head office. Similarly, Aguilar-Manjarrez et al. (1997) noted as the sponsorship request grew in value and scope, the prevalence of gatekeepers also increased. This portion of the literature review indicated the importance of sport properties understanding who the sponsorship decision-maker is within a company they are soliciting for sponsorship and how they can ensure their information makes it to this person in the most favorable light.

The second section of the literature review unveiled several sponsorship objectives omnipresent within the literature. These sponsorship objectives were identified as broad corporate objectives companies have attempted to achieve through sport sponsorship. Abratt et al. (1987) noted sport sponsorship was capable of achieving 
corporate promotional, marketing, and public relations objectives. Sponsorship objectives were divided into corporate related objectives and brand related objectives. Irwin and Asimakopoulos (1992) presented the SSPEM which proved to be the seminal piece in nearly all subsequent sport sponsorship objectives research. Corporate sponsorship objectives included increase public corporate awareness, enhance corporate image, alter public perception, community involvement, enhance business and trade goodwill, and enhance employee relations/employee morale (Irwin \& Asimakopoulos, 1992). Brand objectives included increase target market awareness, enhance image within a target market, and increase sales and market share (Irwin \& Asimakopoulos, 1992). While all of these objectives have been identified as salient sport sponsorship objective, sponsors may not attempt to achieve each of these objectives with each sport sponsorship. A company may use different sport sponsorship to achieve different objectives. Also, different companies sponsoring the same event may do so for very different reasons (Irwin \& Sutton, 1994).

One of the most significant contributions revealed within the review of sport sponsorship objectives was Lough \& Irwin's (2001) sport sponsorship lifecycle theory. This theory proposed as sport properties mature the corresponding sponsorship objectives will also mature from less tangible awareness and image focused objectives, to more measurable sales and market share objectives. This theory was supported by Lough et al. (2000) when they found Canadian sponsors to rank social responsibility and community involvement objectives significantly higher than American sponsors. Canadian sport sponsorship is much less mature compared to American sport sponsorship both in duration and amount of resources allocated. Thjomoe et al. (2002) also reported very 
similar findings about Norwegian companies who were most interested in increasing awareness, enhancing the corporate image and improving customer and supplier relations. Within the United States, Lough \& Irwin (2001) found sponsors of women's sports focused on the less tangible objectives when compared to their 'traditional' sport counterparts.

The third section focused on the sponsorship decision-making process reviewed sport sponsorship selection criteria studies. Whereas sponsorship objectives are unique or controlled by the sponsor, sponsorship selection criteria are housed more within the domain of the sport property. Sponsorship selection criteria are factors influencing the sponsorship decision-making process but are not overarching corporate objectives. Hence, this section was organized based on the sport property in question. The first subsection reviewed general sport sponsorship selection criteria studies. These studies did not indicate the sport property in question sponsors were referring to when reporting the relative importance of each of the selection criteria. Within these general studies, the most frequently reported selection criteria were media coverage, ability to reach a target market (demographics and psychographics specifically), hospitality opportunities, audience size, sport and sponsor product fit, and overall cost of the sponsorship opportunity (Abratt et al., 1987; Crowley, 1991; Irwin et al., 1994; Mack, 1999; McCarthy \& Irwin, 2000; Meenaghan, 1991; Scott \& Suchard, 1992; Thwaites et al., 1998; Witcher et al., 1991).

The second subsection presented specific sponsorship selection criteria studies. Much like the sport sponsorship objective literature, Kuzma et al. (1993) and Copeland et al. (1996) found sponsors do not place the same level of importance on each selection 
criteria for all sport sponsorship opportunities. For example, most of the literature indicated sponsors placed a very high level of importance on media and signage opportunities, however, Daniels et al. (2007) investigated the selection criteria of sponsors within a PGA event and found hospitality opportunities to be the most influential selection. These findings indicate sponsor do not paint all sport properties with the same broad brush but rather use different sport properties to achieve different objectives and consequently place varying degrees of importance on each selection criteria based on the given sport property.

The final section of the literature focused on niche sport sponsorship. While the previous sections had focused exclusively on the antecedents or decision-making process of sport sponsorship, the section on niche sport sponsorship encompasses all phases of the sponsorship phenomenon: antecedents, actual sponsorship, and results. The studies investigating niche sports indicated sponsors were attracted to this genre of sports for unique reasons compared to sponsors of mainstream sports. Within the sponsorship literature, niche sports were represented by studies focused on amateur sports, action sports, and women's sports. Collectively, this sub-segment of the sponsorship literature has revealed some unique characteristics of these types of sports properties which appear to be attractive to sponsors.

Sponsors of niche sports were most interested in engaging in cost-effective and affordable sponsorships (Greenwald \& Fernandez-Balboa, 1998). Unlike the results from studies conducted on mainstream sports, niche sport sponsors did not appear to be overly concerned with sales objectives. Mainstream sports have been theorized to be too "cluttered" with sponsorship and niche sports represent an avenue of sport properties that 
are clean, or uncluttered, with fewer sponsors than their mainstream counterparts

(Doherty \& Murray, 2007; Greenwald \& Fernandez-Balboa, 1998; Shaw \& Amis, 2001).

Niche sport sponsorship has been deemed a viable avenue to reach a targeted

demographic (Doherty \& Murray, 2007; Greenwald \& Fernandez-Balboa, 1998; Miloch

\& Lambrecht, 2006) including the very difficult to reach young male demographic

(Bennett et al., 2006). 


\section{CHAPTER III}

\section{METHOD}

The purpose of this chapter is to present the methodological procedures for examining the research questions presented in Chapter I. Essentially, this chapter discusses the execution of the current study. A brief discussion of the research design is followed by four extensive sections pertinent to the execution of the study. These four sections include (a) research participants, (b) instrumentation, (c) data collection procedures, and (d) data analysis procedures. First, a reiteration of the purpose of the study and research questions is provided to guide the subsequent sections.

\section{PURPOSE OF THE STUDY}

Given the exceptionally competitive nature of sport sponsorship, the unique attributes provided to sponsors by professional niche sports, and professional niche sports' reliance on sponsorship funding for financial sustainability, the need exists for a study to investigate what companies aim to achieve from a niche sport sponsorship and how companies screen niche sport sponsorship opportunities. Numerous researchers have indicated the fundamental need for sport properties to have a firm understanding of potential sponsors' objectives and selection criteria (Abratt et al., 1987; Kuzma et al., 1993; Mullin et al., 2007). By understanding a potential sponsor's objectives and selection criteria, niche sports managers can create sponsorship proposals more closely aligned with the needs and wants of the prospect company, subsequently enhancing the 
value of the sponsorship proposal (Copeland et al., 1996; Fullerton, 2010; Jowdy \& McDonald, 2002; Lamont \& Dowell, 2007; Lough et al., 2000; Mueller \& Roberts, 2008; Sam at al., 2005; Stotlar, 2009). Therefore, the primary purposes of this study were to (a) identify which criteria sponsors deem important when evaluating professional niche sport sponsorship opportunities and (b) investigate the objectives sponsors seek to achieve by engaging in a sponsorship relationship with a professional niche sport. To accomplish these purposes the following research questions anchored the study.

RQ 1: What is the relative importance of each of the sponsorship selection criteria corporations use when evaluating professional niche sport sponsorship opportunities?

RQ 2: What is the relative importance of each of the sponsorship objectives corporations aim to achieve when engaging in professional niche sport sponsorship relationships?

RQ 3: How do important sponsorship objectives of niche sport sponsor vary by company industry segment, company size, or company scope?

RQ 4: How do the selection criteria used to evaluate professional niche sport sponsorship opportunities vary by industry segment, company size, or company scope?

\section{RESEARCH DESIGN}

This study featured a survey design, with both closed and open-ended questions exploring the sponsorship objectives and sponsorship selection criteria employed by companies sponsoring North American professional niche sports. A purposive sample of corporate sponsorship decision-makers were surveyed to procure this information. Survey 
design allows for a relatively quick and economical snapshot of a phenomenon (Dillman, 2007). Compared to qualitative research, survey research is able to reach a large sample quickly and efficiently (Dillman, 2007). However, the use of surveys prevents the depth of knowledge often gained through qualitative research designs (Teddlie \& Tashakkori, 2009). A major limitation to survey research is the inability to ask follow-up questions or explain potentially ambiguous questions. The current research, while exploratory in nature, utilized a well-defined instrument which has been implemented and refined several times within similar samples. The use of a well-defined instrument mitigates many of the limitations associated with survey research. Also, open-ended questions were utilized to enrich the data collected from respondents.

\section{RESEARCH PARTICIPANTS}

According to Dillman (2007), the survey population represents "all of the units to which one desires to generalize survey results" (p. 196). In the current study, the survey population included professional niche sport sponsors within North America. The sampling frame, defined by Dillman (2007), is the "list from which a sample is to be drawn in order to represent the survey population" (p. 196). Cresswell (2002) clarified the sampling frame to include the list of individuals (or organizations) in a population a researcher can actually obtain. The current study utilized the 2010 Sports Business Journal RGFB. The Corporate Sponsors section of the directory included contact information for several decision-makers and key contacts within 689 organizations known to engage in sport sponsorship within the United States and internationally.

Considering the 2010 Sports Business Journal RGFB only includes companies known to engage in sport sponsorship, this sample is classified as a purposive sample. 
without email contact information. A personal email requesting contact information (name and email address) for the North American sponsorship decision-maker was sent to 341 organizations via the 'contact us' section of each company's website. Electronic correspondence was unavailable for 43 organizations. An additional 47 contacts were added to the sample via personal request. Email contacts were secured for 352 of the 689 companies listed on the 2010 Sports Business Journal RGFB. The 352 companies for which accurate email addresses were secured represented the accessible population of the current study. While researchers often would like to generalize their results to the target or survey population, in actuality "the population to which a researcher is able to generalize is the accessible population" (Frankel \& Wallen, 1996, p.93). Frankel and Wallen (1996) defined the accessible population as the "population from which the researcher can realistically select subjects for a sample" (p. 579). Therefore, results of the current study can be generalized to this same accessible population.

Cresswell (2002) indicated many survey studies aim to achieve a 50\% response rate or better. However, Baldauf, Reisinger, and Moncrief (1999) indicated a 15\% response rate is sometimes considered acceptable when surveying organizations. Unfortunately, respondent's refusal to co-operate in completing surveys within an industry setting has resulted in generally low response rates. Hagar, Wilson, Pollak, and Rooney (2003) extensively reviewed the response rates of survey based studies focused on non-profit organizations. Through their analysis of 17 different published non-profit organization focused studies, response rates ranged from $10 \%$ to $100 \%$ with $\mathrm{N}$ ranging from 31 to 480 . 
Several factors influence the response rate when surveying organizations. According to Baldauf et al. (1999) the ten most common reasons decision-makers within organizations refuse to respond to surveys include: (a) they are too busy, (b) they receive too many questionnaires, (c) the questionnaire is too long, (d) there is no benefit for the company, (e) survey was sent at an inconvenient time of the year, (f) working hours are too precious to spend completing a survey, (g) questions are too sensitive,(h) anonymity was not assured, (i) questions were not relevant to the company, and (j) refusal is part of the corporate culture. Of these ten reasons for refusal to participate five appear to be within the control of the researcher. The five reasons for refusal within the control of the researcher include: (a) the length of the questionnaire, (b) the perceived benefit to the company, (c) the time of year the survey is sent, (d) the level of sensitivity of the questions, and (e) assurance of anonymity. Four of these five barriers to organizational responses were addressed within the current study.

The only response barrier presented by Baldauf et al. (1999) not addressed in the current study pertained to the timing of the survey. Considering the completion of the current study was very time sensitive, the survey was distributed as soon as the instrument was finalized and Institutional Review Board approval was received. Respondents were provided five weeks to respond. The questionnaire was strategically created to gather as much data as possible while remaining sensitive to the time limitations of the sample. Respondents were assured the survey would only take approximately five minutes to complete. Each email sent to the sample provided insight into the purpose of the study as well as how the results could be beneficial to the sponsorship industry. Also, in the fourth reminder non-respondents were offered a 
technical report of the findings as an incentive for completing the survey. All questions requiring any sensitive information were formatted to allow respondents to skip the question and continue to complete the questionnaire. Also, the survey preamble informed respondents they did not have to answer any questions they did not feel comfortable answering. Finally, anonymity was assured to the entire sample in all email correspondence as well as within the preamble presented before commencing the survey.

Survey response rates of sport sponsorship decision-makers have also varied greatly as the previous studies demonstrated in Table 3.1. Clearly, response rates vary significantly within this line of research. Interestingly, the two studies focused on niche sport (Lough, 1996 (40\%) and Lough \& Irwin, 2001 (21.5\%) reported relatively low response rates in comparison to the group as a whole.

The accessible population for which findings can be inferred consisted of the 352 companies for which active email addresses were acquired. According to Dillman (2007), a sample of 153 responses would allow for estimates to a population of 400 with $95 \%$ confidence and accepting 5\% sampling error. 
Table 3.1

Sport Sponsors' Survey Response Rates

\begin{tabular}{lccc}
\hline & Sample & & \\
Author(s) & Size & Usable Responses & Response Rate \\
\hline Abratt et al. (1987) & 60 & 45 & $75 \%$ \\
Chadwick \& Thwaites (2004) & 43 & 37 & $84 \%$ \\
Copeland et al. (1996) & 112 & 75 & $68 \%$ \\
Daniels et al. (2007) & 46 & 32 & $70 \%$ \\
Irwin \& Sutton (1994) & 200 & 78 & $39 \%$ \\
Irwin et al. (1994) & 200 & 78 & $39 \%$ \\
Lough (1996) & 138 & 56 & $40 \%$ \\
Lough, Irwin, \& Short (2000) & 300 & 186 & $62 \%$ \\
Lough \& Irwin (2001) & 74 & 16 & $21.5 \%$ \\
Ludwig \& Karabetsos (1999) & 19 & 11 & $60 \%$ \\
Mack (1999) & 800 & 212 & $26.5 \%$ \\
McCarthy \& Irwin (2000) & 8 & 8 & $100 \%$ \\
Thwaites et al. (1998) & 500 & 102 & $20.5 \%$ \\
Thjomoe et al. (2002) & 400 & 144 & $36 \%$ \\
Witcher et al. (1991) & 140 & 54 & $39 \%$ \\
Scott \& Suchard (1992) & 512 & 102 & $21 \%$ \\
Tomasini et al. (2004) & 240 & 116 & $48.3 \%$ \\
\hline
\end{tabular}

\section{INSTRUMENTATION}

The instrument used in the current study is a derivative of the Revised Sport Sponsorship Proposal Evaluation Model (SSPEM) (Irwin et al., 1994). The Revised SSPEM was presented by Irwin et al. (1994) after empirically testing the purely theoretical original SSPEM created by Irwin and Asimakopoulos (1992). Derivatives of the Revised SSPEM have been used by a number of researchers investigating the objectives and/or selection criteria of sport sponsors (e.g. Irwin \& Sutton, 1994; Lough, 1996; Lough et al., 2000; Lough \& Irwin, 2001; McCarthy \& Irwin, 2000).

Content Validity

Content validity is the extent to which a specific set of items reflects a content domain (DeVellis, 2003). Content validity was assessed within the current study via an 
expert panel. This panel included two sport industry professionals, one currently involved within sport sponsorship and one recently removed from the practitioner's side of the industry currently working as an adjunct professor specializing in sport marketing. Prior to becoming involved in academia, this person had experience in the field of sport sponsorship as the General Sales manager at Clear Channel Radio, Vice President of Sales at Churchill Downs, and Director of Sponsorship Sales at Major League Baseball. The other industry professional currently holds the position of President and Chief Executive Officer at the International Sponsor Council. This person has also served as a Vice President for IMG, Vice President of Marketing for Octagon, and Vice President of Marketing for Home and Garden Television. This expert has also worked within the sport sponsorship industry from the sport property side specifically working with the FIFA World Cup, and the Olympic Games. The final member of the panel has a Ph.D. in Sport Administration and nine years of teaching experience at the University level. This person's teaching areas include sport marketing, event management, and promotion and publicity. The expert panel reviewed the instrument for clarity and to ensure the items best represented the decision-making criteria of professional niche sport sponsors. Instrument changes based on panel input are discussed in each the following sections.

The remainder of this section is divided into the four sub-categories found within the survey instrument (Appendix A): (a) professional niche sport identification, (b) sport sponsorship objectives, (c) sport sponsorship selection criteria, and (d) company profile. Professional Niche Sport Identification

The purpose of this section was to filter respondents. Companies were divided into two groups: (a) companies who have engaged in sponsorship relationship with a 
North American professional niche sport, and (b) companies who have not engaged in a sponsorship relationship with a North American professional niche sport. Respondents were provided with the operational definition of professional niche sports (any professional sport outside of the 'Big 4', NASCAR, or PGA Tour) and were asked if their company had engaged in a sponsorship relationship with a North America professional niche sport property. If yes, respondents were prompted via an open-ended question to identify the most recent North American professional niche sport their company had sponsored and indicate the level of the sponsorship (league, tour, team, event individual athlete, or other [open-ended]). Respondents were also provided the option of indicating they have never sponsored a professional niche sport property. Data were still collected for respondents indicating they had never engaged in a sponsorship relationship with a North American professional niche sport property. However, these respondents were not included in any subsequent analysis. At the end of the first section, respondents were instructed to refer to the sport property identified as their most recent professional niche sport sponsorship for all subsequent questions. Requiring respondents to reflect on one specific sponsorship relationship was intended to enhance the collection of actual sponsorship opportunity evaluation as opposed to hypothetical or ideal situations.

\section{Sport Sponsorship Objectives}

The second part of the survey was used to better understand the relative importance corporate sponsorship decision-makers placed on corporate sponsorship objectives when entering into their most recent North American professional niche sport sponsorship agreement. The data collected from this section were used to assess research question one (What is the relative importance of each of the sponsorship selection criteria 
corporations use when evaluating professional niche sport sponsorship opportunities?).

This portion of the instrument was adopted in whole from previous research. Objectives included in this section were first discussed by Irwin and Asimakopoulos (1992) within the SSPEM. Later, Irwin et al. (1994) refined those objectives through empirical testing, producing the Revised SSPEM. Several researchers since Irwin et al. (1994) have used these 12 objectives (e.g. Irwin \& Sutton, 1994; Lough et al., 2000; Lough \& Irwin, 2001) and full adoption of this section was encouraged by the expert panel. The twelve sport sponsorship objectives utilized in the current study are presented in Table 3.2.

Table 3.2

Sponsorship Objectives

1. Increase public awareness

7. Enhance employee relations

2. Enhance general company image

8. Increase target market awareness

3. Alter public perception

4. Involve with the community

5 . Build trade relations

9. Increase sales/market share

6. Build trade goodwill

10. Engage in corporate philanthropy

11. Block/pre-empt competition

12. Engage in social responsibility

Respondents were asked to rate the general importance of each of the twelve objectives with respect to their most recent North American professional niche sport sponsorship. Each of the items consisted of a statement of the objective followed by an eight-point Likert type scale ranging from 1 (not important) to 8 (extremely important). According to DeVellis (2003), Likert scales are widely used in instruments measuring opinions, beliefs, and attitudes. The sport sponsorship objectives section of the study was a measurement of the corporate sponsorship decision-makers opinions, and/or attitude concerning the importance of each of the 12 objectives with respect to a specific North American professional niche sport sponsorship relationship. An eight-point scale was considered appropriate as eight-points of differentiation across the items allowed for 
more meaningful discrimination within the data than a scale with fewer points. Also, an eight-point scale provides no mid-point, forcing respondents to make a commitment in the direction of one or the other extreme (DeVellis, 2003). Forcing an opinion was important as respondents were forced to put more time into their responses as they must commit to one direction or the other regarding the importance of each objective. The use of an even point scale may create more meaningful and accurate responses. Finally, respondents were asked to rank the five most important objectives in order of importance (one through five) their company aimed to achieve through their most recent North American professional niche sport sponsorship.

\section{Sport Sponsorship Selection Criteria}

While the section above, Sport Sponsorship Objectives utilized all items contained within the Revised SSPEM (Irwin et al., 1994), an adapted form of the selection criteria presented in the Revised SSPEM was deemed necessary for the current study. Each of the 42 items included in the Revised SSPEM was evaluated by the panel of experts for its appropriateness in the current study. The expert panel members were instrumental in the manipulation of this section of the survey as they provided critical insight on the items which needed to be added or removed.

Considering the Revised SSPEM was created to be a universal sport sponsorship evaluation tool, not all of the items were relevant for an analysis of professional sports, let alone professional niche sports. For example, the Revised SSPEM had an item which asked for sponsorship decision-makers to rate the level of importance their company placed on 'sport governing body regulatory policy (e.g. No signage)'. While this item may be appropriate for amateur or Olympic sports, clearly no professional sport property 
or league is going to implement a policy banishing sponsor signage. As noted in Chapter II, signage has become nearly synonymous with sponsorship. Upon the recommendation of the expert panel, this item was removed from the current study.

Items were also added to the instrument to accomplish one of two purposes (a) ensure the potentially unique benefits of professional niche sports were included, and (b) update the instrument. Items added to address the unique benefits of professional niche sports included sponsor clutter, ability to reach specific demographics and psychographics, and flexibility of the niche sport property/league to achieve sponsor objectives. Social media opportunities and the opportunity to implement unique leveraging platforms were also added as suggested by the expert panel, in an effort to update the instrument. A concerted effort was made to ensure the instrument captured enough data to conduct appropriate statistical analysis and provide practical significance while keeping the instrument as condensed as possible to minimize respondent fatigue and maximize the response rate. See Appendix A for the items within the Sport Sponsorship Selection Criteria section of the instrument.

Similar to the Sport Sponsorship Objectives section, respondents were asked to rate the level of importance of each selection criteria to the company entering into their most recent North American professional niche sport sponsorship relationship. Each item included a statement of the selection criteria, followed by an eight-point Likert type scale ranging from 1 (not important) to 8 (extremely important). Finally, respondents were asked to rank the five most important selection criteria in order of importance (one through five) which affected their decision to support their most recent North American professional niche sport sponsorship. At the conclusion of both the Sport Sponsorship 
Objectives and Sport Sponsorship Selection Criteria sections, an open-ended question was included to capture any new objectives or selection criteria not included in the current study, which respondents deemed important.

\section{Company Profile}

The final section of the instrument collected corporate demographic data. Previous literature had determined different types of companies engage in sport sponsorship for different reasons (Irwin \& Sutton, 1994). The purpose of this section of the instrument was to gather data on each of the respondents in an effort to analyze any trends that may be present with respect to the company profile and the importance placed on different niche sport sponsorship objectives or selection criteria. Respondents reported the size, scope, and industry segment in which their company operated.

Companies sponsoring professional niche sports were provided with 17 different industry segments and asked to indicate the segment in which their company operated. The 17 industry segments included all segments used by Wartella (2009) as well as two additional categories, Consumer Electronics, and Apparel, as suggested by the panel of experts. Respondents were also provided with an open-ended option to fill in their industry if their industry was omitted amongst the list of 17. Following Mack (1999), company size was measured using gross annual revenues. Respondents reported their company's approximate gross annual revenues ranging from less than one million to above $\$ 5$ million. Finally, company scope was assessed by respondents indicating whether their company would best be described as a local, statewide, regional, national, or international company. 


\section{DATA COLLECTION}

Surveys were distributed online to sponsorship decision-makers using SurveyMonkey. Several web-based and email survey distribution companies have been created in response to the substantial increase in the popularity of such data collection procedures. While self-administered pen and paper questionnaires have been widely accepted as a valuable tool for eliciting responses within the social sciences, this method has limitations. According to Ilivea, Baron, and Healey (2002), the pen and paper selfadministered questionnaire has a poor response rate, slow response time, and requires manual transcription of data from hard copy questionnaires to an appropriate statistical analysis tool. The most concerning of these weaknesses is the potential error incurred by the manual transcription of the data. From a very thorough analysis of the growing body of data collection literature, llivea et al. (2002) indicated online surveys provide several advantages, including very low financial resource implications, short response time, researcher's control of the sample and non-involvement in the survey, and direct data loading into the data analysis software, significantly decreasing transcription error. In addition, online surveys provide an environmentally friendly alternative to pen and paper survey administration.

The major concern with online surveys focuses on the technological requirements to complete such an instrument. Considering the current study population encompasses professional niche sport sponsorship decision-makers, the concern of technical ineptness is mitigated by the fact sponsorship decision-makers hold managerial or administrative positions within their organizations. These types of positions require moderate to advanced computer skills and access to the internet is a vital business function for this 
population. Therefore, this study's target population possesses the requisite technological skills to complete a survey administered online.

As noted in the sampling section, the eligible participants for this study are all self-identified North American professional niche sport sponsors within the 693 Corporate Sponsors in the 2010 Sports Business Journal RGFB. Email notifications were first sent to potential respondents alerting them to the fact a follow-up email would be provided in five days time which would include the survey. After the initial survey email, non-respondents were sent follow-up emails, including links to the survey. Follow-up reminders were sent to non-respondents four times. The first reminder was sent three days after initial survey distribution. The following three reminders were each separated by approximately five days.

All communication with participants was conducted through SurveyMonkey in an effort to prevent the messages from being detected as spam. SurveyMonkey allows researchers to employ a feature which automatically sends email communication out to a large sample one email address at a time to prevent the message from being considered spam or junk mail. This decreases sampling coverage error as more potential recipients are likely to receive the message as opposed to sending out a bulk message.

\section{DATA ANALYSIS}

As noted earlier, both descriptive and inferential statistics were utilized within the current study. For purposes of clarity, each research question provides the scaffolding for the remainder of the current section and the corresponding data analysis for each research question will be discussed. 
RQ 1: What is the relative importance of each of the sponsorship selection criteria corporations use when evaluating professional niche sport sponsorship opportunities?

The analysis of research question one required descriptive statistics only. Following the works of numerous previous researchers, (Irwin \& Sutton, 1994; Irwin, Asimakopoulos, \& Sutton, 1994; Lough et al., 2000; Lough \& Irwin, 2001) sponsorship selection criterion means and standard deviations were calculated and used to determine the most important criteria reported by the sample. Selection criteria importance was also assessed through frequencies of responses and respondent's ranking of their top five most important selection criteria with respect to their most recent North American professional niche sport sponsorship.

RQ 2: What is the relative importance of each of the sponsorship objectives corporations aim to achieve when engaging in professional niche sport sponsorship relationships?

Similar to the analysis implemented to address the first research question, descriptive statistics were also used to analyze research question two. Means, standard deviations, frequencies, and rankings of each objective were calculated and reported.

RQ 3: How do important sponsorship objectives of niche sport sponsor vary by company industry segment, company size, or company scope?

Three separate Multivariate Analysis of Variances (MANOVA) were used to analyze the effects of industry segment, company size, and company scope on the different objectives. The top five most important professional niche sport sponsorship objectives, as determined in the analysis of research question two, served as the 
dependent variables when assessing this research question. The constructs used to measure industry segment, company size and company scope were all categorical in nature. According to Garson (2010), MANOVA is used to determine the main and interaction effects of categorical variables on multiple dependent interval variables. The five sponsorship objectives were rated on an eight-point interval scale.

RQ 4: How does the selection criteria used to evaluate professional niche sport sponsorship opportunities vary by industry segment, company size, or company scope?

Research question four was also assessed using three separate MANOVAs. Industry segment, company size and company scope each served as the categorical independent variables in each of the three MANOVAs. The dependent variables in all three MANOVAs were the five most important selection criteria as determined from the analysis of researcher question one. Rather than using all 33 selection criteria as dependent variables, only the top five selection criteria were used. Using the top five selection criteria provided a more manageable data set to be analyzed and more importantly, from a practical stance, little value would have been derived by determining differences between company characteristics for those selection criteria sponsors place little importance on initially.

\section{Assumptions}

According to Stevens (2002), three assumptions must be met in order to confidently report the findings of a MANOVA. These assumptions include independence of observations, multivariate normality, and homogeneity of covariance matrix. 
Independence was addressed as only one executive from each company was sent an instrument ensuring respondents were not influenced by one another. According to Stevens (2002), each of the individual variables must be normally distributed for the variables to follow a multivariate normal distribution. Normality was tested by analyzing a histogram of the scores for each of the variables. Graphed frequencies forming a bell curve would provide evidence of normality. The homogeneity of variance-covariance was assessed using Box's test.

\section{Response Bias}

Respondents were compared to non-respondents based on company demographics as well as sponsorship selection criteria and objectives. Cresswell (2002) suggested that late respondents closely resemble non-respondents. Therefore, the importance placed on each of the selection criteria and objectives reported by early respondents were compared against responses from late respondents as a proxy to differences that may exist between respondents and non-respondent. Furthermore, a sampling of forty non-respondents (20 with accurate email addresses and 20 without accurate email contact information) were compared against the respondents with respect to the three corporate demographic variables: company size, company scope and industry segment. 


\section{CHAPTER IV}

\section{RESULTS}

The following section presents the results of the statistical analysis conducted in an effort to address each of the four research questions anchoring the current study. Descriptive and inferential statistical procedures were used to address the purpose of the study. Five main sections frame the current chapter. The first section presents the findings of the preliminary analysis before addressing the research questions. The preliminary analysis addresses the response rate, as well as the representativeness of the study. Descriptive statistics are reported revealing the types of companies represented in the current study as well as the types of niche sports those companies support. Finally, a description of the procedures used to transform data into a form best suited for statistical analysis is presented. The remaining four sections of the chapter address each of the four research questions individually. Finally, a brief summary of findings is presented.

\section{PRELIMINARY ANALYSIS}

The preliminary analysis stages the findings of the four research questions. A discussion on the response rate, respondent bias, descriptive statistics, and procedures are presented within this section. Following the preliminary analysis, findings from each research question are presented. 


\section{Response Rate}

The current study surveyed sport sponsorship decision-makers within national and international corporations. The 2010 Sports Business Journal RGFB provided a list of 689 corporations known to engage in sport sponsorship within North America. Accurate email contacts were provided for 305 sponsorship decision-makers within the 2010 Sports Business Journal RGFB. The researcher attempted to contact the remaining 384 organizations within the 2010 Sports Business Journal RGFB via the 'Contact Us' section of each company's website. This effort yielded an additional 47 accurate email contacts. Surveys were sent via email invitation to 352 corporate sponsorship decision-makers known to engage in sport sponsorship within North America. Surveys were sent to one representative from each company ensuring each company had an equal chance of being represented. Eighty-nine surveys were collected for a response rate of $25.3 \%$. Dillman (2007) suggested a sample of 153 was required to generalize findings to a population of 400. Thus, the 89 responses within the current study fell short of Dillman's suggestion. Sixty-seven percent $(n=60)$ of the respondents indicated they were a sponsor of a North American professional niche sport.

As discussed in Chapter III, response rates within the sport sponsorship literature are typically quite low. Baldauf et al. (1999) stated that response rates of $15 \%$ have been deemed acceptable when surveying organizations. A response rate of $25 \%$ could be considered typical of investigations of companies involved in sport sponsorship as previous studies within the sport sponsorship literature have yielded similar response rates (e.g. Lough and Irwin (2001) 21.5\%, Mack (1999) 20.5\%, Thwaites et al. (1998) $20.5 \%$, and Scott and Suchard (1992) 21\%). 
Of the 60 responses, 32 were deemed usable for analyzing the importance placed on sponsorship objectives and sponsorship selection criteria (Research Questions one and two), and 31 were deemed usable for analyzing differences within company demographics (Research Questions three and four). The number of completed questionnaires decayed as respondents progressed through the survey instrument. Questions pertaining to company demographics (size, scope, industry segment) were placed near the end of the survey, hence the fewer usable responses for questions pertaining to company demographics. One respondent provided responses to the first three sections of the study (niche sport identification, sponsorship objectives, and selection criteria) but failed to complete the Company Demographic section.

Previous sport sponsorship researchers have also had usable sample sizes similar to the 31 obtained within the current study. Chadwick and Thwaites (2004) obtained 37 usable responses, Daniels et al. (2007) analyzed 32 usable responses, Lough and Irwin (2001) had 16 usable responses, and Ludwig and Karabetsos (1999) completed a study with 11 usable responses. Therefore, the $25 \%$ response rate and 31 usable responses attained within the current study appear to be reasonable of this type of research. However, results of the current study still must be viewed with caution and not overly generalized.

The 31 usable responses were also considered adequate for conducting the requisite statistical analysis required to answer each of the four research questions within the current study. According to Garson (2010), the minimum sample size needed to conduct a MANOVA requires each cell size to be greater than the number of dependent variables. This requirement was met within the current study as all each MANOVA 
contained five dependent variables and the smallest cell size equaled 13. Yet the relatively small sample size may present issues relating to the power of statistical analysis within the current study. Field (2005) reported that statistical power indicates a test's ability to detect statistical significance when significance exists. Larger sample sizes are "intrinsically linked with statistical significance and power" (Field, 2005, p. 33).

Conversely, smaller sample sizes restrict the ability to find small statistically significant differences in the data. Hence, results gleaned from the current study should be interpreted with caution.

\section{Respondent Bias}

Cresswell (2002) indicated late respondents closely resemble non-respondents. Therefore, an analysis of early versus late respondents was conducted to determine if the sample was representative of the population for the current study. Siebert (2006) suggested researchers could confidently presume respondents to be representative of nonrespondents so long as there were no significant differences between early and late respondents. Within the present study, early respondents were identified as respondents completing the survey prior to the administration of the second reminder email notification. Late respondents were identified as respondents completing the survey after the second reminder email notification. The second reminder was sent to all nonrespondents approximately one week after the original survey disbursement.

As suggested by Siebert (2006) a series of one-way analyses of variance (ANOVA) were conducted to determine if early and late respondents differed significantly. No statistically significant differences were found between early and late respondents for any sponsor objectives $(\mathrm{p}=.100-.992)$ or selection criteria $(\mathrm{p}=.051$ - 
.943). Respondent and non-respondent companies were also compared on each of the three company demographic variables (industry segment, company size, and company scope). Forty non-respondent companies were randomly selected and company demographics were collected and compared against reported company demographics of respondent companies via Chi-Square analysis. Results of the Chi-Square analysis indicated no statistically significant difference between respondents and non-respondents with respect to industry segment $\left(\chi^{2}(1)=1.97, p=.160\right)$ or company size $\left(\chi^{2}(1)=.012, p\right.$ $=.912$ ). However, there was a statistically significant difference between respondents and non-respondents based on company scope $\left(\chi^{2}(1)=5.46, p=.019\right)$. There were significantly more National Level companies in the respondent group compared to the non-respondents. Overall, these results indicate the sample within this study appears to be relatively representative of the population for the current study.

\section{Descriptive Statistics}

The majority of respondents, $(67 \%)$ indicated they had sponsored a North American professional niche sport. Of the 32 usable niche sport sponsor responses, 14 $(44 \%)$ sponsored professional niche teams, $10(31.5 \%)$ sponsored at the league level, 4 $(12.5 \%)$ sponsored niche sport tours, 4 (12.5\%) sponsored niche sporting events, no respondent companies sponsored individual niche sport athletes. Additionally, four $(12.5 \%)$ of these respondents indicated they sponsored multiple levels of niche sports (i.e. team and league).

Emerging niche sports, those representing the top level of competition within their given sport but lacking the media and fan attention found within mainstream sports, as defined by Rosner and Shropshire (2004), were represented by 19 (60\%) of the niche 
sports identified within the current study. The remaining $40 \%$ of niche sports represented within the current study were classified as minor league sports (6), and semi-professional (7) (i.e. Canadian Hockey League, USA Swimming). See Table 4.1 for a complete breakdown of all professional niche sports represented within the current study.

Table 4.1

Professional Niche Sports Represented $(N=32)$

\begin{tabular}{|c|c|c|}
\hline $\begin{array}{l}\text { Minor League } \\
\text { Professional Sports } \\
(n=6)\end{array}$ & $\begin{array}{l}\text { Semi-Professional Sports } \\
(n=7)\end{array}$ & $\begin{array}{l}\text { Emerging Professional } \\
\text { Sports } \\
(n=19)\end{array}$ \\
\hline $\begin{array}{l}\text { Minor League Baseball } \\
\text { (6) }\end{array}$ & $\begin{array}{l}\text { Canadian Curling Assn. } \\
\text { Canadian Hockey League (2) } \\
\text { USA Ski \& Snowboard Assn. } \\
\text { (2) } \\
\text { USA Swimming } \\
\text { Western Hockey League }\end{array}$ & $\begin{array}{l}\text { AVP } \\
\text { Biking } \\
\text { CART Racing } \\
\text { Extreme Sports } \\
\text { Fast Pitch } \\
\text { Indy Racing (2) } \\
\text { LPGA (2) } \\
\text { MLS } \\
\text { Mountain Biking } \\
\text { Muddy Buddy Racing } \\
\text { National Hot Rod } \\
\text { Association } \\
\text { Rodeo } \\
\text { Softball } \\
\text { Tennis } \\
\text { WNBA } \\
\text { Women's Professional } \\
\text { Soccer } \\
\text { Women's Tennis } \\
\text { Association }\end{array}$ \\
\hline
\end{tabular}

An investigation of corporate demographics revealed the majority of respondents $14(46.7 \%)$ were international corporations with $11(33.3 \%)$ national level companies, 4 (13.3\%) regional, and $2(6.5 \%)$ statewide companies also represented in the current study. No companies claimed to be local in scope. Overall, respondents represented quite large corporations as $18(56 \%)$ reported having gross annual revenues in excess of $\$ 500 \mathrm{M}, 5$ 
$(15.5 \%) \$ 251 \mathrm{M}-\$ 500 \mathrm{M}, 3(9.7 \%) \$ 101 \mathrm{M}-\$ 250 \mathrm{M}, 3(6.5 \%) \$ 51 \mathrm{M}-\$ 100 \mathrm{M}$, and $2(6.5 \%)$

$\$ 11 \mathrm{M}-\$ 20 \mathrm{M}$. No companies reported gross annual revenues less than one million, $\$ 5 \mathrm{M}$ $\$ 10 \mathrm{M}$, or $\$ 21 \mathrm{M}-\$ 50 \mathrm{M}$.

A variety of industry segments were represented in the current study. Respondents in the current study represented the following industries: an airline, auto dealers, banking/financial/investments firms, beverage companies, a communications company, a health care provider, a print media organization, several companies in the retail trade industry, sporting goods companies, an apparel company, companies within the energy industry, a real estate firm, and several retail focused companies (see Table 4.2).

Table 4.2

Professional Niche Sport Sponsors Represented $(N=32)$

\begin{tabular}{ll}
$\begin{array}{l}\text { Frequently Purchased Products/Services } \\
(\mathrm{n}=17)\end{array}$ & $\begin{array}{l}\text { Infrequently Purchased Products/Services } \\
(\mathrm{n}=14)\end{array}$ \\
\hline Restaurants (5) & Real Estate \\
Food & Banking/Finance/Investments (3) \\
Beverage (3) & Print Media \\
Apparel & Communications \\
Retail (3) & Auto Dealer (2) \\
Sporting Goods (4) & Energy (3) \\
& Airline \\
& Retail (2) \\
\hline
\end{tabular}

\section{Procedures}

The independent variables (industry segment, company size, and company scope) were condensed into dichotomous groups for several reasons. First, due to the relatively low number of responses, statistical analysis of the multi-level groups would have created vastly unequal group sizes and violated numerous assumptions required to conduct a MANOVA. Practically, levels containing only one data point are not representative of a particular industry segment or representative of companies of a particular size or scope 
either. A level with only one data point only reflects the opinion of that single company and cannot be generalized beyond that single company. Hence, the consolidation of groups allowed for a more meaningful statistical analysis.

Company scope was converted from a five level variable to a two level variable. Local (0), statewide (2), regional (3), and nationally (12) based companies were condensed into one group labeled National Companies (17). The second level of company scope encompassed corporations with an international scope (14). This level retained the label International Companies.

Company size was measured using approximate gross annual revenues. Originally, an eight level variable company size was collapsed into two distinct groups. Companies indicating gross annual revenues ranging from less than $\$ 1$ million to $\$ 500$ million (Less than $\$ 1 \mathrm{M}(0), \$ 1 \mathrm{M}-\$ 4 \mathrm{M}(0), \$ 5 \mathrm{M}-\$ 10 \mathrm{M}(0), \$ 11 \mathrm{M}-\$ 20 \mathrm{M}(2), \$ 21 \mathrm{M}-$ \$50M (0), \$51M - \$100M (3), \$101M - \$250M (3), \$251M - \$500M (5)) were collapsed into a single level, labeled Less than $\$ 500 \mathrm{M}(12)$. The second level was retained as the original \$500M+ (18) group.

Company industry segment, originally an 18 level variable, including an openended option of 'other' was collapsed into two level variable. Segmenting companies based on the frequency their product/service is purchased by the typical consumer has been used extensively over the last 40 year (Sharma, \& Lambert, 1994). Hence, companies were grouped based on the frequency at which consumers purchase their goods or services. The first group, Frequently Purchased Products/Services (17), includes such companies as restaurants, sporting goods manufacturers, beverage companies, and gas stations. These companies produce relatively inexpensive goods/services that have a 
relatively high level of turnover. Consumers shop for these types of goods/services multiple times per year. Alternatively, the Infrequently Purchased Products/Services (14) group includes companies such as: airlines, banks and investment companies, real estate companies, and energy producers. These companies produce relatively expensive goods/services that consumers shop for quite infrequently. This divide represents a meaningful segmentation within the current study as organizational marketing, communications, and/or public relations objectives could significantly differ based on this divide. A complete presentation of company demographics and cell sizes can be found in Table 4.3.

Even after data manipulation, cell sizes were not exactly equal. However, Stevens (2002) suggested cell sizes are considered relatively equal so long as the largest cell divided by the smallest cell equals 1.5 or less. According to Stevens (2002), all cells within the current study can be considered of equal size.

Table 4.3

Company Demographic Frequencies

\begin{tabular}{llrr}
\hline & Level & \multicolumn{2}{c}{$\%$ of } \\
Demographic & $<\$ 500 \mathrm{M}$ & \multicolumn{1}{c}{ Total } \\
\hline Size & $\$ 500 \mathrm{M}+$ & 13 & $41.9 \%$ \\
& Total & 18 & $58.1 \%$ \\
& National & 31 & $100 \%$ \\
\hline Scope & International & 17 & $54.8 \%$ \\
& Total & 14 & $45.2 \%$ \\
& Frequently Purchased Products/Services & 31 & $100 \%$ \\
\hline Industry Segment & 17 & $54.8 \%$ \\
& Infrequently Purchased Products/Services & 14 & $45.2 \%$ \\
& Total & 31 & $100 \%$ \\
\hline
\end{tabular}




\section{RESULTS FOR RESEARCH QUESTION ONE}

The first research question aimed to assess the relative importance of each of the sponsorship selection criteria corporations used when evaluating professional niche sport sponsorship opportunities. Respondents reported the relative importance of each sponsorship selection criteria on an eight-point scale $(1=$ Not Important and $8=$ Extremely Important). Therefore, those selection criteria with a mean value greater than 4.5 represent selection criteria respondents deemed to be closer to extremely important than not important. Likewise, those selection criteria with a mean value less than 4.5 represent selection criteria respondents deemed to be closer to not important than extremely important. Descriptive statistics revealed cost effectiveness $(M=7.56, S D=$ 0.87 ) to be the most important selection criteria in the current study. Along with cost effectiveness, company image fit within the sports target market $(M=7.31, S D=0.96)$, the flexibility of the sport property in helping achieve sponsor's objectives $(M=7.25, S D$ $=1.02)$, spectator demographics $(M=7.21, S D=1.24)$, and company product/service image fit with the sport's image $(M=7.19, S D=1.21)$ formed the top five selection criteria reported. Table 4.4 provides a comprehensive report of the relative importance respondents placed on each selection criteria. 
Table 4.4

Means and Standard Deviations of Sponsorship Selection Criteria $(N=31)$

\begin{tabular}{|c|c|c|}
\hline Selection Criteria & Mean & $\begin{array}{l}\text { Standard } \\
\text { Deviation }\end{array}$ \\
\hline Cost Effectiveness (audience reach) & 7.55 & 0.88 \\
\hline Company Image Fit within Target Market & 7.29 & 0.97 \\
\hline Flexibility of Sport Property & 7.22 & 1.02 \\
\hline Spectator Demographics & 7.19 & 1.24 \\
\hline $\begin{array}{l}\text { Company Product/Service Image Fit with Sport } \\
\text { Image }\end{array}$ & 7.16 & 1.21 \\
\hline Potential Presence of New Customers & 6.93 & 1.26 \\
\hline Sponsor Exclusivity & 6.90 & 1.81 \\
\hline Affordability & 6.87 & 1.43 \\
\hline Product/Service Utility with Sport & 6.61 & 1.58 \\
\hline Sport Property Profile & 6.54 & 1.54 \\
\hline Spectator Psychographics & 6.41 & 1.73 \\
\hline Signage & 6.41 & 1.80 \\
\hline Local Media Coverage & 6.38 & 1.47 \\
\hline Potential Presence of Current Customers & 6.13 & 1.82 \\
\hline Sponsorship of an Established Sport & 6.10 & 1.94 \\
\hline Sales/Retail Tie-in Opportunities & 6.03 & 1.76 \\
\hline Non-Attending Demographics & 6.03 & 2.02 \\
\hline Long-Term Sponsorship Opportunity & 6.03 & 2.18 \\
\hline Opportunity to be Major Sponsor & 6.03 & 1.96 \\
\hline Sponsor Clutter & 5.97 & 1.62 \\
\hline Sport Fan Loyalty & 5.97 & 1.61 \\
\hline Complementary Advertising (e.g. event program) & 5.68 & 1.99 \\
\hline Non-Attending Audience Size & 5.42 & 2.17 \\
\hline Immediate Audience Size & 5.39 & 1.72 \\
\hline Non-Attending Psychographic Profile & 5.35 & 2.17 \\
\hline Cooperation of Athletes & 5.26 & 2.22 \\
\hline National Media Coverage & 5.19 & 2.52 \\
\hline Social Media Opportunities & 5.19 & 1.89 \\
\hline Hospitality Opportunities & 4.90 & 2.28 \\
\hline Opportunity to be Title Sponsor & 4.64 & 2.44 \\
\hline Promotional Licensing & 4.64 & 2.61 \\
\hline Corporate Staff Knowledge/Interest in Sport & 4.58 & 1.87 \\
\hline Competition's Ambush Marketing Opportunities & 3.90 & 2.31 \\
\hline Competitions Interest in Sport & 3.87 & 2.22 \\
\hline
\end{tabular}


Response frequencies were also calculated to help provide further evidence to the relative importance of each selection criteria. The relative importance placed on each selection criteria were grouped into pairs. Table 4.5 reports how frequently each selection criteria was reported to be extremely important, somewhat important, somewhat not important, and not important.

Similar to the findings above, cost effectiveness, company image fit within the target market of the sport property, company product/service image fit with the image of the sport, sport property's flexibility to assist in the achievement of sponsorship objectives, and spectator demographics were reported to be the most important niche sport sponsorship selection criteria within the study sample. 
Table 4.5

Response Frequencies of Sponsorship Selection Criteria $(N=31)$

\begin{tabular}{|c|c|c|c|c|}
\hline & $\begin{array}{l}\text { Not Important } \\
\text { (1 } 1 \text { r } 2)\end{array}$ & $\begin{array}{c}\text { Somewhat } \\
\text { Not } \\
\text { Important } \\
(3 \text { or } 4)\end{array}$ & $\begin{array}{c}\text { Somewhat } \\
\text { Important } \\
\text { (5 or } 6)\end{array}$ & $\begin{array}{c}\text { Extremely } \\
\text { Important } \\
(7 \text { or } 8)\end{array}$ \\
\hline Selection Criteria & $\mathrm{N}$ & $\mathrm{n}$ & $\mathrm{n}$ & $\mathrm{n}$ \\
\hline $\begin{array}{l}\text { Cost Effectiveness (audience } \\
\text { reach) }\end{array}$ & 0 & 1 & 2 & 28 \\
\hline $\begin{array}{l}\text { Company Image Fit within } \\
\text { Target Market }\end{array}$ & 0 & 0 & 5 & 26 \\
\hline $\begin{array}{l}\text { Company Product/Service Image } \\
\text { Fit with Sport Image }\end{array}$ & 0 & 3 & 2 & 26 \\
\hline Flexibility of Sport Property & 0 & 0 & 7 & 24 \\
\hline Spectator Demographics & 0 & 2 & 5 & 24 \\
\hline Sponsor Exclusivity & 1 & 3 & 4 & 23 \\
\hline Affordability & 0 & 3 & 7 & 21 \\
\hline $\begin{array}{l}\text { Potential Presence of New } \\
\text { Customers }\end{array}$ & 0 & 1 & 9 & 21 \\
\hline Sport Property Profile & 1 & 2 & 9 & 19 \\
\hline Signage & 2 & 3 & 7 & 19 \\
\hline Local Media Coverage & 1 & 3 & 9 & 18 \\
\hline $\begin{array}{l}\text { Product/Service Utility Fit with } \\
\text { Sport }\end{array}$ & 1 & 3 & 9 & 18 \\
\hline Spectator Psychographics & 1 & 4 & 8 & 18 \\
\hline $\begin{array}{l}\text { Long-Term Sponsorship } \\
\text { Opportunity }\end{array}$ & 3 & 4 & 6 & 18 \\
\hline $\begin{array}{l}\text { Sponsorship of an Established } \\
\text { Sport }\end{array}$ & 3 & 2 & 10 & 16 \\
\hline $\begin{array}{l}\text { Potential Presence of Current } \\
\text { Customers }\end{array}$ & 1 & 4 & 10 & 16 \\
\hline Non-Attending Demographics & 2 & 4 & 9 & 16 \\
\hline $\begin{array}{l}\text { Opportunity to be the Major } \\
\text { Sponsor }\end{array}$ & 2 & 5 & 9 & 15 \\
\hline Sales/Retail Tie-in Opportunities & 1 & 5 & 11 & 14 \\
\hline Sponsor Clutter & 2 & 5 & 10 & 14 \\
\hline Sport Fan Loyalty & 1 & 4 & 13 & 13 \\
\hline National Media Coverage & 6 & 6 & 6 & 13 \\
\hline Non-Attending Audience Size & 5 & 4 & 11 & 12 \\
\hline $\begin{array}{l}\text { Non-Attending Psychographic } \\
\text { Profile }\end{array}$ & 4 & 5 & 10 & 12 \\
\hline Complimentary Advertising & 3 & 6 & 12 & 10 \\
\hline Cooperation of Athletes & 5 & 5 & 11 & 10 \\
\hline Promotional Licensing & 9 & 6 & 6 & 10 \\
\hline Immediate Audience Size & 2 & 8 & 12 & 9 \\
\hline Hospitality Opportunities & 6 & 5 & 11 & 9 \\
\hline Opportunity to be Title Sponsor & 8 & 6 & 10 & 7 \\
\hline Social Media Opportunities & 5 & 3 & 17 & 6 \\
\hline $\begin{array}{l}\text { Competition's Ambush } \\
\text { Marketing Opportunities }\end{array}$ & 10 & 10 & 5 & 6 \\
\hline $\begin{array}{l}\text { Corporate Staff } \\
\text { Knowledge/Interest in Sport }\end{array}$ & 5 & 8 & 14 & 4 \\
\hline Competitions Interest in Sport & 9 & 11 & 7 & 4 \\
\hline
\end{tabular}


Respondents also ranked and reported the top five sponsorship selection criteria they deemed most important when evaluating niche sport sponsorship opportunities. Respondents were asked to indicate which sponsorship selection criteria they considered most important, second most important, third most important, fourth most important, and fifth most important with respect to their most recent North American professional niche sport sponsorship. Due to the large number of selection criteria companies take into consideration when evaluating a sponsorship opportunity respondents were provided an open-ended text box to rank and report their top five selection criteria of the 34 provided on the survey instrument. The structure of the question caused many respondents to skip this question completely, provide incomplete answers, or include sponsorship objectives. Due to the volume of potential answers, variety of answers provided, and low response rate, results reported in Table 4.6 should be cautiously interpreted.

Respondents most frequently selected spectator demographics (3) as the single most important sponsorship selection criteria followed by cost effectiveness (2), company image fit within target market (3), and sport property profile.(3). 
Table 4.6

Top Five Ranked Sponsorship Selection Criteria

\begin{tabular}{|c|c|c|c|c|c|}
\hline Objectives & $\begin{array}{c}\text { Most } \\
\text { Important }\end{array}$ & $\begin{array}{c}\text { Second } \\
\text { Most } \\
\text { Important }\end{array}$ & $\begin{array}{c}\text { Third } \\
\text { Most } \\
\text { Important }\end{array}$ & $\begin{array}{c}\text { Fourth } \\
\text { Most } \\
\text { Important }\end{array}$ & $\begin{array}{l}\text { Fifth Most } \\
\text { Important }\end{array}$ \\
\hline Spectator Demographics & 3 & 2 & 1 & 0 & 0 \\
\hline $\begin{array}{l}\text { Cost Effectiveness } \\
\text { Company Product/Service }\end{array}$ & 2 & 1 & 2 & 2 & 0 \\
\hline $\begin{array}{l}\text { Image Fit with Sport Image } \\
\text { Company Product/Service }\end{array}$ & 2 & 1 & 1 & 1 & 0 \\
\hline Image Fit with Sport Image & 2 & 0 & 1 & 0 & 3 \\
\hline Sponsor Exclusivity & 1 & 2 & 3 & 0 & 1 \\
\hline $\begin{array}{l}\text { Promotional Licensing } \\
\text { Potential Presence of New }\end{array}$ & 1 & 0 & 3 & 0 & 0 \\
\hline $\begin{array}{l}\text { Customers } \\
\text { Opportunity to be Title }\end{array}$ & 1 & 1 & 0 & 1 & 2 \\
\hline Sponsor & 1 & 0 & 1 & 0 & 1 \\
\hline Affordability & 0 & 3 & 1 & 0 & 0 \\
\hline Signage & 0 & 1 & 1 & 1 & 0 \\
\hline $\begin{array}{l}\text { Hospitality Opportunities } \\
\text { Complementary }\end{array}$ & 0 & 1 & 1 & 0 & 0 \\
\hline $\begin{array}{l}\text { Advertising (e.g. event } \\
\text { program) } \\
\text { Flexibility of Sport }\end{array}$ & 0 & 0 & 1 & 2 & 1 \\
\hline Property & 0 & 1 & 0 & 1 & 0 \\
\hline $\begin{array}{l}\text { Spectator Psychographics } \\
\text { Long-Term Sponsorship }\end{array}$ & 0 & 1 & 0 & 0 & 0 \\
\hline $\begin{array}{l}\text { Opportunity } \\
\text { Competitions Interest in }\end{array}$ & 0 & 0 & 0 & 2 & 1 \\
\hline Sport & 0 & 0 & 0 & 1 & 1 \\
\hline
\end{tabular}

At the commencement of the sponsorship selection criteria section, respondents were provided an opportunity to indicate any additional important selection criteria not represented within the survey items. Four responses were collected from the open-ended question. Two respondents indicated their companies were only interested in sponsoring established sport properties that had values similar to the sponsoring company. One respondent indicated hospitality opportunities were very important. Finally, one respondent stated the opportunity to conduct sampling at an event to be "extremely 
important." With the exception of a sponsor wanting to conduct sampling at the event, each of the additional selection criteria captured from the open-ended question were accounted for within the current instrument.

\section{RESULTS FOR RESEARCH QUESTION TWO}

The second research question focused on uncovering the relative importance niche sport sponsors placed on each of the sponsorship objectives. Similar to the analysis presented above, descriptive statistics were implemented to assess research question two. Respondents reported the relative importance of each sponsorship objective on an eightpoint scale $(1=$ Not Important and $8=$ Extremely Important $)$. Therefore, those objectives with a mean value greater than 4.5 represent objectives respondents deemed to be closer to extremely important than not important. Likewise, those objectives with a mean value less than 4.5 represent objectives respondents deemed to be closer to not important than extremely important. According to the analysis of means respondents reported the five most important objectives as: (a) increasing their awareness within a specific target market $(M=6.81, S D=1.65),(\mathrm{b})$ increase sales/market share $(M=6.56, S D=2.17),(\mathrm{c})$ increase public awareness $(M=6.34, S D=2.16)$, (d) enhance their company image $(M=$ $6.06, S D=2.17)$, and (e) become involved in the community $(M=5.50, S D=2.12)$.

Table 4.7 provides a complete report of the analysis of means for each of the 12 sponsorship objectives. 
Table 4.7

Means and Standard Deviations of Sponsorship Objectives $(N=32)$

\begin{tabular}{lcc}
\hline Objective & Mean & Std. Deviation \\
\hline Increase Target Market Awareness & 6.81 & 1.65 \\
Increase Sales/Market Share & 6.56 & 2.17 \\
Increase Public Awareness & 6.34 & 2.16 \\
Enhance Company Image & 6.06 & 2.17 \\
Involve with the Community & 5.50 & 2.13 \\
Build Trade Goodwill & 4.25 & 2.09 \\
Build Trade Relations & 4.09 & 2.13 \\
Alter Public Perception & 4.00 & 2.54 \\
Engage in Social Responsibility & 3.72 & 2.19 \\
Engage in Corporate Philanthropy & 3.46 & 2.16 \\
Enhance Employee Relations & 3.22 & 2.04 \\
Block/Pre-empt Competition & 2.81 & 1.71 \\
\hline
\end{tabular}

Response frequencies were also calculated to help determine the relative importance of each objective. Table 4.8 reports how frequently each objective was reported to be extremely important, somewhat important, somewhat not important, and not important.

The top five most important niche sport sponsorship objectives based on the frequency of respondents indicating an objective to be extremely important included: (a) increase sales/market share, (b) increase target market awareness, (c) increase public awareness, (d) enhance company image, and (e) become involved in the community. 
Table 4.8

Response Frequencies of Sponsorship Objectives $(N=32)$

\begin{tabular}{|c|c|c|c|c|}
\hline \multirow[b]{3}{*}{ Objectives } & \multicolumn{3}{|c|}{ Somewhat } & \multirow[b]{2}{*}{$\begin{array}{l}\text { Extremely } \\
\text { Important } \\
(7 \text { or } 8)\end{array}$} \\
\hline & $\begin{array}{c}\text { Not } \\
\text { Important } \\
(\text { lor } 2) \\
\end{array}$ & $\begin{array}{c}\text { Not } \\
\text { Important } \\
(3 \text { or } 4)\end{array}$ & $\begin{array}{c}\text { Somewhat } \\
\text { Important } \\
(5 \text { or } 6)\end{array}$ & \\
\hline & $\mathrm{n}$ & $\mathrm{n}$ & $n$ & $\mathrm{n}$ \\
\hline Increase Sales/Market Share & 3 & 2 & 4 & 23 \\
\hline Increase Target Market Awareness & 1 & 2 & 9 & 20 \\
\hline Increase Public Awareness & 3 & 4 & 5 & 20 \\
\hline Enhance Company Image & 4 & 3 & 6 & 19 \\
\hline Involve with the Community & 3 & 8 & 7 & 14 \\
\hline Alter Public Perception & 13 & 5 & 7 & 7 \\
\hline Build Trade Goodwill & 7 & 11 & 8 & 6 \\
\hline Engage in Social Responsibility & 12 & 10 & 5 & 5 \\
\hline Build Trade Relations & 8 & 10 & 10 & 4 \\
\hline Enhance Employee Relations & 14 & 9 & 6 & 4 \\
\hline Engage in Corporate Philanthropy & 12 & 9 & 9 & 2 \\
\hline Block/Pre-empt Competition & 14 & 12 & 5 & 1 \\
\hline
\end{tabular}

Respondents also ranked and reported the top five sponsorship objectives they deemed most important when evaluating niche sport sponsorship opportunities. Due to the relatively small number of objectives compared to selection criteria, the structure of the ranking question changed. Respondents were asked to check the objective they considered to be most important, second most important, third most important, fourth most important, and fifth most important (See Appendix A). The structure of this question led to a much greater number of usable responses compared to the open-ended rank and report of selection criteria. Respondents most frequently selected increasing sales and market share (10) as the single most important sponsorship objective followed 
by increase target market awareness (9), and increase public awareness (8). A complete analysis of respondents top five ranked objectives are found in Table 4.9.

At the commencement of the Sponsorship Objectives section, respondents provided additional important objectives not represented within the survey items. Five comments reported the following as missing important professional niche sport sponsorship objectives: (a) distributor support for their programs, (b) tour geography, (c) revenue streams from equipment, (d) opportunity to host customers, and (e) unique experience for customers. Each of these objectives was found to be quite similar to existing objectives or selection criteria already included in the instrument.

Table 4.9

Top Five Ranked Sponsorship Objectives

\begin{tabular}{|c|c|c|c|c|c|}
\hline Objectives & $\begin{array}{c}\text { Most } \\
\text { Important }\end{array}$ & $\begin{array}{c}\text { Second } \\
\text { Most } \\
\text { Important }\end{array}$ & $\begin{array}{c}\text { Third } \\
\text { Most } \\
\text { Important }\end{array}$ & $\begin{array}{c}\text { Fourth } \\
\text { Most } \\
\text { Important }\end{array}$ & $\begin{array}{l}\text { Fifth Most } \\
\text { Important }\end{array}$ \\
\hline Increase Sales/Market & & & & & \\
\hline $\begin{array}{l}\text { Share } \\
\text { Increase Taroet Market }\end{array}$ & 10 & 7 & 5 & 2 & 2 \\
\hline $\begin{array}{l}\text { Increase Target Market } \\
\text { Awareness } \\
\text { Increase Public }\end{array}$ & 9 & 6 & 2 & 3 & 6 \\
\hline Awareness & 8 & 4 & 6 & 4 & 2 \\
\hline $\begin{array}{l}\text { Enhance Company Image } \\
\text { Involve with the }\end{array}$ & 0 & 7 & 5 & 7 & 4 \\
\hline Community & 2 & 3 & 0 & 5 & 2 \\
\hline Alter Public Perception & 0 & 0 & 5 & 4 & 2 \\
\hline $\begin{array}{l}\text { Build Trade Relations } \\
\text { Engage in Social }\end{array}$ & 0 & 1 & 2 & 2 & 5 \\
\hline Responsibility & 1 & 1 & 1 & 1 & 2 \\
\hline $\begin{array}{l}\text { Build Trade Goodwill } \\
\text { Engage in Corporate }\end{array}$ & 0 & 0 & 3 & 3 & 1 \\
\hline $\begin{array}{l}\text { Philanthropy } \\
\text { Block/Pre-empt }\end{array}$ & 1 & 1 & 0 & 1 & 0 \\
\hline $\begin{array}{l}\text { Competition } \\
\text { Enhance Employee }\end{array}$ & 0 & 1 & 1 & 0 & 3 \\
\hline Relations & 0 & 0 & 1 & 0 & 2 \\
\hline
\end{tabular}




\section{RESULTS FOR RESEARCH QUESTIONS THREE}

The third research question focused on determining how important niche sport sponsorship objectives vary by company size, scope or industry segment. As noted in

Chapter III, three separate MANOVAs were used to address this research question. Rather than including all twelve objectives, only the five most important objectives (as identified from the analysis of RQ 2) were included as dependent variables in the MANOVA analysis. Several factors influenced the decision to include only the five most important objectives and omit the other seven objectives.

First, previous analysis within the current study indicated respondents consistently placed the greatest importance on five distinct niche sport sponsorship objectives: (a) increase target market awareness, (b) increase public awareness, (c) increase sales/market share, (d) enhance company image, and (e) become involved in the community. These five objectives were found to be the most important in all three analyses conducted in the assessment of research question two. Secondly, the findings within the current study are supported by the sport sponsorship literature, specifically the sponsorship lifecycle presented by Lough and Irwin (2001). Thirdly, while significant differences may exist between different corporate demographics (company size, scope, or industry segment) for sponsorship objectives reported to be of less importance, only those objectives deemed important by sponsorship decision-makers have significant pragmatic relevance.

Differences found in objectives reported to be less important hold little practical significance as niche sport sponsors within the current study reported to rarely focus on these less important objectives. 
Furthermore, Stevens (2002) cautions researchers that as dependent variables increase, the power of the test decreases. Statistically, "power is the probability of making a correct decision" (Stevens, 2002, p. 193). Therefore, by limiting the number of dependent variables the power of the MANOVA analysis was enhanced. Power is discussed more thoroughly below. For all of the above stated reasons, only the five most important objectives were retained within the analysis of research question three.

\section{Statistical Power}

As noted previously, statistical power represents "the mathematical probability of detecting an existing effect size of a particular magnitude or strength at an established alpha level" (Parks, Shewokis, \& Costa, 1999, p. 141). Stevens (2002) cautions studies with small samples or group sizes less than 20 must be very sensitive to the possibility of poor power. Stevens (2002) noted the power of a statistical test is dependent on three factors: alpha level, sample size, and effect size.

Briefly, effect size represents the proportion of variance in the dependent variable explained by the independent variable (Parks et al., 1999). Effect size is typically reported using eta squared $\left(\eta^{2}\right)$ generally reflecting a small, moderate, or large effect size. Most pertinent to the current study, Parks et al. (1999) stated:

a study with insufficient power to detect a meaningful effect size yields a nonsignificant test statistic, the results of the study will be inconclusive; the researcher will not know if the nonsignificant test statistic was due to the fact that a difference or association did not exist in the population or to the fact the study had insufficient power to detect an existing difference or association (p. 142). 
Poor power is often determined to be analogous to Type II error. Previous researchers have determined an observed power of .80 to be the minimum acceptable level (Park et al., 1999; Stevens, 2002). The only feasible option for boosting power was to limit the number of dependent variables in each test as the use of a more liberal alpha would inflate Type I error. Effect sizes were already demonstrated to be quite large, and sample size could not feasibly be increased. Combined with the fact no MANOVAs demonstrated an observed power above the .80 threshold, each MANOVA was followed by a univariate ANOVA at the $\alpha$ $=.05$ level in an effort to balance Type I and Type II error. However, because of the relatively low power likely due to a small sample, findings within the current study must be interpreted with caution.

\section{Assumptions}

Several assumptions must be tested and met before MANOVA results can be confidently analyzed and interpreted. Specifically, Stevens (2002) indicated three assumptions must be met before conducting a MANOVA: (a) independence of observations, (b) multivariate normality on the dependent variables in each population, and (c) equality of the covariance matrices. The independence assumption was addressed and met by having each participant complete only a single survey. Multivariate normality of distribution was tested by a comparison of results against the normal distribution curve. Finally, homogeneity of covariance was tested using Box's test of equality.

The normality assumption was not met within the dependent variables (increase target market awareness, increase public awareness, increase sales/market share, enhance company image, and become involved in the community). The deviation from normality 
was a result of all the dependent variable demonstrating negative skewness, where scores are disproportionately high. However, both Keppel and Wickens (2004), and Stevens (2002) indicated the violation of this assumption should not have a significant impact on the findings of the MANOVA. Box's M test was not significant at the .05 level, indicating the homogeneity of covariance assumption was met.

\section{Company Size}

To test the effect of company size on niche sport sponsorship objectives a MANOVA was conducted. Results of the MANOVA revealed no statistically significant difference between the two Company Size groups within the five sponsorship objectives (increase target market awareness, increase public awareness, increase sales/market share, enhance company image, and become involved in the community), where $F(5,25)$ $=1.64, p=.185, \eta^{2}=.25$. According to Stevens $(2002) \eta^{2}=.25$ represents a large effect size indicating a large relationship exists between company size and niche sport sponsorship objectives. The ANOVA indicated there was a statistically significant difference in the objective Increase Target Market Awareness between the two Company Size groups $\left(F(1,29)=5.92, p=.021, \eta^{2}=.17\right)$. An analysis of Table 4.10 indicates companies within the Less than $\$ 1 \mathrm{M}-\$ 500 \mathrm{M}$ group placed significantly greater importance on increasing their target market awareness through North American professional niche sport sponsorships than companies within the $\$ 500 \mathrm{M}$ and Above group. Table 4.10 also illustrates the actual mean differences between the two Company Size groups for each of the five most important objectives. 
Table 4.10

Comparison of Sponsorship Objectives Means by Company Size $(N=31)$

\begin{tabular}{|c|c|c|}
\hline Objectives & $\begin{array}{c}\text { Less than } \$ 1 \mathrm{M}-\$ 500 \mathrm{M} \\
(n=13) \\
M(S D)\end{array}$ & $\begin{array}{c}\$ 500 \mathrm{M} \text { and Above } \\
(n=18) \\
M(S D)\end{array}$ \\
\hline \multicolumn{3}{|l|}{ Increase Public } \\
\hline Awareness & $6.77(1.59)$ & $6.33(2.22)$ \\
\hline Enhance Company Image & $5.92(1.93)$ & $6.11(2.40)$ \\
\hline Involve with the & & \\
\hline $\begin{array}{l}\text { Community } \\
\text { Increase Target Market }\end{array}$ & $5.92(1.71)$ & $5.44(2.20)$ \\
\hline $\begin{array}{l}\text { Awareness } \\
\text { Increase Sales/Market }\end{array}$ & $7.61(0.88)$ & $6.55(1.38)$ \\
\hline Share & $6.77(2.17)$ & $6.72(1.84)$ \\
\hline
\end{tabular}

\section{Company Scope}

The independent variable Company Scope measured the breadth of the respondent's business. As noted earlier this variable was transformed into a dichotomous (National Level and International Level) variable. All assumptions, with the exception of normality, were tested and met. To test the effect of company scope on niche sport sponsorship objectives a MANOVA was conducted. Results of the MANOVA revealed no statistically significant difference between the two Company Scope groups within the five sponsorship objectives (increase target market awareness, increase public awareness, increase sales/market share, enhance company image, and become involved in the community) where $F(5,25)=0.39, p=.854, \eta^{2}=.07$. Results indicated the effect size of Company Scope on sponsorship objectives to be a medium effect size (Stevens, 2002). While no inferable differences between the two groups were found, Table 4.11 illustrates a relatively large mean difference between National Level companies and International Level companies within the objectives Increase Target Market Awareness and Increase Sales/Market Share. 
Table 4.11

Comparison of Sponsorship Objectives Means by Company Scope $(N=31)$

\begin{tabular}{lcc}
\multicolumn{1}{c}{ Objectives } & $\begin{array}{c}\text { National Level } \\
(n=17) \\
M(S D)\end{array}$ & $\begin{array}{c}\text { International Level } \\
(n=14) \\
M(S D)\end{array}$ \\
\hline $\begin{array}{l}\text { Increase Public } \\
\text { Awareness }\end{array}$ & $6.41(2.09)$ & $6.64(1.86)$ \\
$\begin{array}{l}\text { Enhance Company Image } \\
\text { Involve with the }\end{array}$ & $6.00(2.21)$ & $6.07(2.27)$ \\
$\begin{array}{l}\text { Community } \\
\text { Increase Target Market }\end{array}$ & $5.53(2.06)$ & $5.79(1.97)$ \\
Awareness & $6.82(1.51)$ & $7.21(0.97)$ \\
Increase Sales/Market & $6.29(2.28)$ & $7.28(1.32)$ \\
Share &
\end{tabular}

Frequency of Product/Service Purchase

Industry Segment was divided into two groups: (a) frequently purchased goods/services, and (b) infrequently purchased goods/services. All assumptions with the exception of normality were met. To test the effect of industry segment on niche sport sponsorship objectives a MANOVA was conducted. Results of the MANOVA revealed no statistically significant difference between the two Industry Segment groups within the five sponsorship objectives, where $F(5,25)=1.23, p=.326, \eta^{2}=.19$. Results indicated the effect size of Industry Segment on sponsorship objectives to be a large effect size (Stevens, 2002). A follow-up ANOVA found a statistically significant difference between related to Target Market Awareness $\left(F(1,29)=4.24, p=.048, \eta^{2}=.13\right)$. The Frequently Purchased Products/Services group placed a statistically significant greater importance on Increasing Target Market Awareness. A complete breakdown of all mean differences between the two Industry Segments for each of the objectives is found in Table 4.12. 
Table 4.12

Comparison of Sponsorship Objectives Means by Industry Segment $(N=31)$

\begin{tabular}{|c|c|c|}
\hline Objectives & $\begin{array}{c}\text { Frequently Purchased } \\
\text { Products/Services } \\
(n=17) \\
M(S D)\end{array}$ & $\begin{array}{c}\text { Infrequently Purchased } \\
\text { Products/Services } \\
(n=14) \\
M(S D)\end{array}$ \\
\hline \multicolumn{3}{|l|}{ Increase Public } \\
\hline Awareness & $6.47(2.06)$ & $6.57(1.91)$ \\
\hline Enhance Company Image & $5.58(2.48)$ & $6.57(1.74)$ \\
\hline Involve with the & & \\
\hline Community & $5.35(1.90)$ & $6.00(2.11)$ \\
\hline Increase Target Market & & \\
\hline Awareness & $7.41(0.87)$ & $6.50(1.55)$ \\
\hline Increase Sales/Market & & \\
\hline Share & $7.12(1.45)$ & $6.28(2.39)$ \\
\hline
\end{tabular}

\section{RESULTS FOR RESEARCH QUESTION FOUR}

Research question four aimed to better understand the effects of company size, company scope and company industry segment on niche sport sponsors selection criteria. Three separate MANOVAs assessed research question four. Similar to the analysis conducted in the analysis of research question three, only the five most important selection criteria were retained as dependent variable for analysis within the three MANOVAs. The five selection criteria consistently reported to hold the highest level of importance for niche sport sponsorship decision-makers within the current study included: (a) cost effectiveness, (b) company image fit within the target market, (c) company product/service image fit with sport image, (d) spectator demographics, and (e) the flexibility of the sport property to assist in attaining sponsorship objectives. The normality assumption was not met within the dependent variables (cost effectiveness, company image fit within the target market, company product/service image fit with sport image, spectator demographics, and the flexibility of the sport property to assist in 
attaining sponsorship objectives). The deviation from normality was a result of all the dependent variables demonstrating negative skewness, where scores are disproportionately high. However, both Keppel and Wickens (2004), and Stevens (2002) indicated the violation of this assumption should not have a significant impact on the findings of the MANOVA. All independent variables used in the assessment of research question three (company size, company scope, and industry segment) were used in the assessment of research question four.

\section{Company Size}

Prior to assessing the effects of company size on selection criteria, a check of assumptions found Box's test of equality of covariance matrices was to be significant $(F(15,2671)=2.20, p<.01)$ indicating the assumption homogeneity of covariance matrices was not met. According to both Stevens (2002) and Field (2005), Box's test is very sensitive to nonnormality. Field (2005) and Stevens (2002) both noted that MANOVA is quite robust to this violation so long as group sizes are approximately equal. Relative cell size equality had previously been established. Results of the MANOVA revealed no statistically significant difference between company size within the five sponsorship selection criteria (cost effectiveness, company image fit within the target market, company product/service image fit with sport image, spectator demographics, and the flexibility of the sport property to assist in attaining sponsorship objectives), where $F(5,25)=1.87, p=.136, \eta^{2}=.27$. According to Stevens $(2002) \eta^{2}=$ .27 represents a large effect size. Although no inferable differences were found between the two Company Size groups for any of the five sponsorship selection criteria, Table 4.13 revealed relatively large actual mean differences between the two Company Size 
groups within the selection criteria: Company Image Fit within Target Market, and Spectator Demographics.

Table 4.13

Comparison of Sponsorship Selection Criteria Means by Company Size $(N=31)$

\begin{tabular}{lcc}
\hline & $\begin{array}{c}\text { Less than } \$ 1 \mathrm{M}-\$ 500 \mathrm{M} \\
(n=13) \\
\mathrm{M}(\mathrm{SD})\end{array}$ & $\begin{array}{c}\$ 500 \mathrm{M} \text { and Above } \\
(n=18) \\
\mathrm{M}(\mathrm{SD})\end{array}$ \\
$\begin{array}{l}\text { Objectives } \\
\text { Cost Effectiveness }\end{array}$ & $7.83(0.39)$ & $7.33(1.08)$ \\
Company Image Fit & & \\
within Target Market & $7.07(1.25)$ & $7.44(0.70)$ \\
$\begin{array}{l}\text { Company } \\
\text { Product/Service Image }\end{array}$ & & \\
Fit with Sport Image & & $7.06(1.30)$ \\
Flexibility of Sport & $7.31(1.11)$ & \\
Property & & $7.22(1.06)$ \\
Spectator Demographics & $7.23(1.01)$ & $6.89(1.45)$ \\
\hline
\end{tabular}

\section{Company Scope}

To test the effect of Company Scope on niche sport sponsorship selection criteria a MANOVA was conducted. The assumption of normality was the only assumption violated. Results of the MANOVA revealed no statistically significant difference between the two Company Scope groups within the five selection criteria variables, where $F(5,25)=0.66, p=.659, \eta^{2}=.16$. Results indicated the effect size to of Company Scope on sponsorship selection criteria to be a large effect (Stevens, 2002). Whereas no inferable significant differences were found, Table 4.14 illustrates the relatively large actual mean differences between the two levels of Company Scope within the selection criteria Company Product/Service Image Fit with Sport Image. 
Table 4.14

Comparison of Sponsorship Selection Criteria Means by Company Scope $(N=31)$

\begin{tabular}{lcc}
\hline Objectives & $\begin{array}{c}\text { National Level } \\
(n=17) \\
M(S D)\end{array}$ & $\begin{array}{c}\text { International Level } \\
(n=14) \\
M(S D)\end{array}$ \\
\hline $\begin{array}{l}\text { Cost Effectiveness } \\
\text { Company Image Fit } \\
\text { within Target Market }\end{array}$ & $7.47(1.07)$ & $7.64(0.63)$ \\
Company & $7.06(1.14)$ & $7.57(0.65)$ \\
$\begin{array}{l}\text { Product/Service Image } \\
\text { Fit with Sport Image }\end{array}$ & & \\
Flexibility of Sport & $6.88(1.27)$ & $7.50(1.09)$ \\
Property & & $7.28(1.14)$ \\
Spectator Demographics & $7.17(0.95)$ & $7.28(1.32)$ \\
\hline
\end{tabular}

To test the effect of Industry Segments on niche sport sponsorship selection criteria a MANOVA was conducted. However, assumption issues arose within the analysis of the effects of industry segment. Similar to the analysis of the effects of Company Size on selection criteria, Box's test of equality of covariance matrices was found to be significant $(F(15,3097)=2.73, p<.001)$ indicating a violation of the assumption of homogeneity of the covariance matrices. Field (2005) and Stevens (2002) indicated MANOVA is quite robust to this violation. Results of the MANOVA revealed no statistically significant difference between the two Industry Segment groups within the five selection criteria variables, where $F(5,25)=2.04, p=.290, \eta^{2}=.29$. Results indicated the effect size of Industry Segment on sponsorship selection criteria to be a large effect (Stevens, 2002). A follow up ANOVA $\left(F(1,29)=4.77, p=.037, \eta^{2}=.14\right)$ revealed a statistically significant difference in the reported importance placed on the flexibility of the sport property to assist in achieving sponsorship objectives between the two Industry Segment groups. Respondents within the Infrequently Purchased Products/Services group placed significantly greater importance on the Flexibility of the 
Sport Property than the respondents within the Frequently Purchased Products/Services group. Table 4.15 illustrates the actual group mean differences between the two Industry

Segment groups within each of the five most important selection criteria.

Table 4.15

Comparison of Sponsorship Selection Criteria Means by Industry Segment $(N=31)$

\begin{tabular}{lcc}
\hline & $\begin{array}{c}\text { Frequently Purchased } \\
\text { Products/Services } \\
(n=17)\end{array}$ & $\begin{array}{c}\text { Infrequently Purchased } \\
\text { Products/Services } \\
(n=14)\end{array}$ \\
Objectives & $M(S D)$ & $M(S D)$ \\
\hline Cost Effectiveness & $7.58(0.62)$ & $7.50(1.16)$ \\
Company Image Fit & & \\
within Target Market & $7.29(1.05)$ & $7.28(0.91)$ \\
Company & & \\
Product/Service Image & & $6.93(1.38)$ \\
Fit with Sport Image & $7.35(1.06)$ & \\
Flexibility of Sport & & $7.64(0.49)$ \\
Property & $6.88(1.22)$ & $7.19(1.25)$ \\
Spectator Demographics & $7.18(1.33)$ & \\
\hline
\end{tabular}

\section{SUMMARY}

Findings from the current study indicated respondents within this study consistently reported five objectives (increase sale and market share, increase public awareness, increase target market awareness, enhance company image, and become involved in the community) as the most important objectives respondents attempted to achieve through niche sport sponsorships. Similarly, five selection criteria were also consistently reported to hold the greatest importance. Respondents indicated they considered the cost effectiveness, company image fit within the target market, the flexibility of the sport property to assist in achieving sponsorship objectives, spectator demographics, and their company's product/service fit with the sport image as most important when evaluating niche sport sponsorship opportunities. No statistically significant multivariate differences were found between any of the company description 
variables and the top five objectives or selection criteria. However, due to the poor power found within the current study (all MANOVAs with an observed power below the .80 threshold) it is very important to understand the results of this study indicate no statistically significant differences were found within the current study. Univariate analysis demonstrated statistically significant differences between the two Industry Segment groups within the selection criteria Flexibility and the objective Small companies (Less than $\$ 500$ ) within the current study also placed a significantly greater importance on Increasing Target Market Awareness than their larger company counterparts $(\$ 500 \mathrm{M}+)$. Further analyses of the results are discussed in the Chapter V. 


\section{CHAPTER V}

\section{DISCUSSION}

The purpose of the current study was to (a) identify which criteria sponsors deem important when evaluating professional niche sport sponsorship opportunities, and (b) investigate the objectives sponsors seek to achieve by engaging in a sponsorship relationship with a professional niche sport. To accomplish these purposes, a survey of North American professional niche sport sponsorship decision-makers was conducted. Statistical analysis of their responses revealed several selection criteria and objectives deemed important by survey respondents. The following chapter discusses the practical and theoretical implications of these findings. Each of the four research questions used to guide the study are discussed below followed by a section on the limitations of the current study as well as future research. Finally, a summary of the study is presented.

\section{IMPORTANCE OF SELECTION CRITERIA}

The first research question investigated the relative importance of each of the sponsorship selection criteria corporations use when evaluating professional niche sport sponsorship opportunities. Respondents within the current study indicated the professional niche sport sponsorship screening process is very complex. Perhaps the most interesting finding was the fact only two of 34 selection criteria were reported to have a mean value less than 4.5 on an eight-point scale. This finding indicates sponsors within the current study reported 32 selection criteria to be closer to 'Extremely Important' than 
'Not Important'. Overall, sponsors take a lot into consideration when screening professional niche sport sponsorship opportunities. Niche sport properties should be cognizant of the complexity of the screening process in an effort to produce sponsorship proposals with the greatest likelihood of acceptance.

\section{Most Important Niche Sport Sponsorship Selection Criteria}

Although respondents indicated almost all of the selection criteria were important, five specific criteria were consistently reported to hold the greatest level of importance. An analysis of means and frequencies both found the same selection criteria to be deemed most important by the niche sport sponsors within the current study. Findings indicated Cost Effectiveness, Company Image Fit within Target Market, Flexibility of Sport Property, Spectator Demographics, and Company Product/Service Image Fit with Sport Image to be the five most important selection criteria.

Several previous researchers and analysts have anecdotally indicated niche sport properties may be able/willing to provide sponsors with selection criteria not available within most mainstream sport sponsorship opportunities. Four specific selection criteria were discussed in Chapter One as potentially unique to niche sport sponsorship opportunities. These four criteria include cost effectiveness, a more refined target market, decreased sponsor clutter, and increased sport property flexibility (Brenner, 2003; Fullerton, 2010; Greenwald \& Fernandez-Balboa, 1998; Hanas, 2007; Livingstone, 2007; Milne et al., 1996; Rovell, 2009; Stotlar, 2009; Tripodi, 2001; Williams, 2001).

A number of authors stated niche sport sponsorships provide sponsors with a cost effective alternative to mainstream professional sport sponsorships (Fullerton, 2010; Greenwald \& Fernandez-Balboa, 1998; Hanas, 2007; Williams, 2001). Findings from the 
current study indicated North American niche sport sponsors also included the cost effectiveness of niche sport sponsorships to be very important. Empirical findings from the current study reinforce previous anecdotal claims concerning niche sport sponsorship cost effectiveness. Intuitively, sponsors are likely to want all sponsorships to be cost effective. However, the findings of the current study empirically confirm this to be one of the most important selection criteria sponsors use when screening professional niche sport sponsorship opportunities.

Pragmatically, niche sport properties must emphasize the cost effectiveness they can provide within their sport sponsorship proposals. Cost effectiveness includes more than simply asking for less monetary or in-kind support. The fact niche sport sponsorships have been deemed cost effective is due to their perceived ability to achieve sponsorship objectives such as reaching a specific target audience, for a relatively low cost. A low cost sponsorship of any property is only cost effective if sponsorship objectives are achieved through the sponsorship. Sponsorships unable to achieve any sponsor objectives are not cost effective no matter the actual cost incurred by the sponsoring company.

The current economic turmoil within North America may have also contributed to respondents indicating such a high level of importance on the cost effectiveness of their niche sport sponsorships. IEG (2010) noted that 2009 represented the first year sport sponsorship spending in North America had decreased compared to the previous year's spending. Perhaps the emphasis placed on niche sport cost effectiveness was partially due to sponsors' increased scrutiny of sponsorship opportunities due to budget restrictions in response to the economic downturn. According to Livingstone (2009), some niche sport 
properties have viewed the economic collapse as an opportunity to demonstrate their ability to achieve sponsors' objectives in a cost effective manner compared to mainstream professional sports. Findings from the current study indicate North American niche sport properties would be well served to emphasize their cost effective benefits within their sport sponsorship proposals. For example, niche sport managers may be wise to emphasize their ability to help sponsors achieve their objectives at a relatively low cost. A sponsorship is only cost effective when a sponsor's objective(s) are achieved.

Niche sport properties were also considered to provide potential sponsors with a refined target market. While niche sport properties may not attract the vast number of fans found within mainstream sports, they have been found to attract a relatively homogeneous collection of fans (Stotlar, 2009). Niche sports tend to attract fans with similar demographic and psychographic profiles (Stotlar, 2009) allowing sponsors to create very targeted selling messages (Brenner, 2003; Fullerton, 2010; Greenwald \& Fernandez-Balboa, 1998; Hanas, 2007; Kojima, 2010; Lough, 1996; Miloch \& Lambrecht, 2006; Milne et al., 1996; Tripodi, 2001).

Findings of the current study indicated North American professional niche sport sponsors placed a very high level of importance on the ability of niche sport properties to provide a refined targeted demographic. Three of the five most important selection criteria within the current study were related to the target market of the sponsor. Respondents reported Company Image Fit within Target Market, Spectator Demographics, and Company Product/Service Image Fit with Sport Image as some of the most important North American professional niche sport sponsorship selection criteria. Each of these three selection criteria are associated with the target market of the niche 
sport property. These findings demonstrate the high level of importance respondents placed on understanding the niche sport property's fan base and ensuring a match existed between fans and the company's target market. Findings support the theoretical assertion that not only were niche sport properties able to provide potential sponsors with a more refined target market, but sponsors find this attribute to be very important when screening niche sport sponsorship opportunities.

Many practical implications can be gleaned from these findings. First, it is imperative niche sport managers understand the demographic composition of their fan base. Without a clear understanding of fan demographics, niche sport managers would not be able to demonstrate a match between their fans and a potential sponsor's target market. Niche sport properties would also be well served to have a strong understanding of potential sponsors target markets. Demonstrating a match between a niche sport property's fan base and a potential sponsor's target market may be the most important feature a niche sport could emphasize within a sponsorship proposal. Finally, niche sport properties may be able to increase their efficiency by focusing their efforts on soliciting sponsorship support from companies demonstrating a match between the sport property's fans and the prospect company's target market.

Professional niche sports have also claimed to provide an environment of decreased sponsor clutter (Lough, 1996; Lough \& Irwin, 2001; Shank, 2005; Tripodi, 2001). Many researchers have noted that mainstream sports are reaching a point of sponsorship saturation (Amis et al., 1999; Greenwald \& Fernandez-Balboa, 1998; Shank, 2005; Tripodi, 2001). Creating a situation where fans can no longer discern sponsors 
from non-sponsors due to the vast amount of signage and overall selling messages from such a large number of sponsors at mainstream sporting events.

Current study findings indicated Sponsor Clutter to hold a relatively moderate level of importance to North American niche sport sponsors. Surprisingly, Sponsor Clutter was reported to be approximately the 20th most important selection criteria. However, upon further review of the findings, respondents had reported Sponsor Exclusivity to have a relatively high level of importance. Findings indicated Sponsor Exclusivity to be the seventh most important selection criteria. While Sponsor Clutter and Sponsor Exclusivity are not synonymous, they are closely related. Sponsor Exclusivity can be analogous to a higher order level of decreased Sponsor Clutter. In essence, decreased Sponsor Clutter ensures there are not too many sponsors of any one sport property. However, 'not too many' sponsors is quite subjective and could hold very different meanings for sponsors compared to sport properties. Sponsor Exclusivity ensures only one sponsor will be present within each industry/category (Mullin et al., 2007). Therefore, from a theoretical perspective, the findings of the current study suggest North American professional niche sport sponsors may have replaced the importance of decreased Sponsor Clutter by placing a higher level of importance on Sponsor Exclusivity.

Pragmatically, sponsors have still relayed the message that they are looking to ensure their sponsorship and related advertising/communications message are not lost in a sea of Sponsorship Clutter. Findings also indicated North American niche sport sponsors may not be satisfied with sponsorship proposal emphasizing decreased sponsor clutter. Therefore, niche sport properties may be wise to create sponsorship exclusivity 
categories to appease potential sponsors. Some of the largest North American professional niche sports have already implemented this strategy. The WNBA ensured Lee Jeans exclusivity throughout the first three WNBA seasons (Mullin et al., 2007). Understanding the importance sponsors place on exclusivity could be the tipping factor in a property securing a sponsorship.

The final unique sponsorship attribute associated with niche sports was their flexibility to assist sponsors achieve sponsorship objectives. Niche sport properties have demonstrated their flexibility through a number of means. Sponsors have been granted access to the game field (Williams, 2001) and meet-and-greets with players (Livingstone, 2009). Sponsors within the current study reported niche sport property flexibility to be highly important. Respondents indicated this to be the third most important selection criteria. These findings revealed that the anecdotal claims were accurate and niche sport sponsors highly value the flexibility niche sport properties provide.

North American niche sports should respect the importance placed on their perceived flexibility and ensure their management structure is conducive to flexibility. Rigid sponsorship policies, such as signage restrictions or preventing sponsors from providing product trials/samples, would likely not be well received by sponsors. Niche sport properties should also highlight their flexibility within their sponsorship proposals. Furthermore, professional niche sport properties may choose to demonstrate their flexibility by providing potential sponsors with a variety of sponsorship options within the proposal, so long as they remain cognizant of the potential sponsor's target market, cost effectiveness, and company objectives. 


\section{Least Important Niche Sport Sponsorship Selection Criteria}

As discussed above, only two selection criteria were calculated to have mean scores below 4.5 on an eight-point scale. These findings indicated sponsors within the current study found these two selection criteria to be closer to 'Not Important' than 'Extremely Important'. North American professional niche sport sponsors within the current study indicated the selection criteria Competitor's Ambush Marketing Opportunities $(\mathrm{M}=3.90)$ and Competition's Interest in Sport $(\mathrm{M}=3.87)$ held relatively little importance when assessing niche sport sponsorship opportunities.

The fact sponsors within the current study placed such little importance on its competition's interest in the sport is not surprising as Shaw and Amis (2001) determined that sponsorships based on the actions of competitors can never truly reach their full potential. Findings of the current study appear to support this claim. Hence, niche sport properties may choose to refrain from soliciting sponsorship support based on the actions of potential sponsor's competitors. Corporate sponsors appear to understand not all companies within the same industry hold the same corporate objectives. Therefore, competing organizations may have vastly different corporate and subsequently sponsorship objectives. The sponsors within the current study indicated they do not focus on the sponsorship actions of their competitors and it would probably be unwise for professional niche sport properties to focus on the actions of a potential sponsor's competitors when soliciting sponsorship support.

Competitor's Ambush Marketing Opportunities was the other selection criteria deemed relatively unimportant. Perhaps, niche sport properties do not attract a large enough fan base or media attention to make ambush marketing effective. Furthermore, 
the potential backlash from relatively tight knit niche sport fan bases could also discourage ambush marketing.

\section{Summary}

Overall, findings from the analysis of research question one indicated the unique benefits of professional niche sports were supported within the current study. North American professional niche sports within the current study were found to place the highest level of importance on the four unique attributes associated with niche sports: (a) cost effectiveness, (b) more refined target market, and (c) niche sport property flexibility. The only deviation found within the current study indicated sponsors were more focused on Sponsor Exclusivity than decreased Sponsor Clutter. Conversely, North American professional niche sport sponsors reported Competitor's Interest in a Sport and Competitor's Ambush Marketing Opportunities to be of little importance.

\section{IMPORTANCE OF SPONSORSHIP OBJECTIVES}

The second research question investigated the relative importance of each of the sponsorship objectives corporations aim to achieve when engaging in professional niche sport sponsorship relationships. Whereas the previous section discussed the relative importance respondents placed on a large assortment of selection criteria, only twelve objectives were included in the Sponsorship Objectives section of the survey instrument and findings were much more polarized than the selection criteria findings. North American professional niche sport sponsors within the current study had placed a relatively high level of importance on all but two of the 34 selection criteria discussed above. The analysis of responses concerning the 12 sponsorship objectives yielded quite different results. Findings indicated a very distinct split between objectives reported to 
have relatively high importance and relatively low importance. Of the 12 objectives, five had a mean score above 4.5 on an eight-point scale indicating respondent felt they were closer to 'Extremely Important' than 'Not Important'. Conversely, the remaining seven objectives had a mean score below 4.5 indicating respondents reported these objectives to be closer to 'Not Important' than 'Extremely Important'.

Findings of the current study were compared against the sponsorship lifecycle presented by Lough and Irwin (2001). The sponsorship lifecycle argues that as sport properties mature so to do their associated sponsorship objectives. The sponsorship lifecycle begins with awareness and image-focused objectives and progresses towards more market-driven objectives such as increasing sales/market share. The sport sponsorship objectives literature has supported the sponsorship lifecycle theory. Previous researchers have demonstrated how sponsors of less mature sports, such as women's sports, placed a greater emphasis on less tangible objectives (awareness and image) than mainstream sport sponsors (Lough, 1996; Lough \& Irwin, 2001). Furthermore, the sponsorship lifecycle has also been supported by sponsors within less developed sponsorship regions. The 1984 Los Angeles Olympic Games have been dubbed the birthplace of modern sport sponsorship (Irwin \& Sutton, 1994; Mullin et al., 2007) making the United States the most mature sport sponsorship region. Other countries appear to have less mature sport sponsorship markets compared to the United States as evidenced by the findings of Lough et al. (2000), Slack and Benz (1999), and Thjomoe et al. (2002). Lough et al. (2000), and Slack and Benz (1999) both found Canadian based sport sponsors to place an elevated level of importance on awareness, image, and social responsibility focused objectives when compared to U.S. based companies. Likewise, 
Thjomoe et al. (2002) produced similar findings in their analysis of Norwegian based corporate sponsors. Hence, the sport sponsorship lifecycle appears to be credible for both immature sport properties as well as immature sport sponsorship regions compared to mainstream professional North American sport sponsor objectives. These findings suggest North American professional niche sport sponsors should place a relatively high level of importance on image and awareness-based objectives.

\section{Most Important Niche Sport Sponsorship Objectives}

According to Kuzma et al. (1993), the number one rule in selling sponsorships is exhibiting a close match between sponsors objectives and sport property characteristics. Therefore, it is imperative for all sport properties to understand the objectives potential sponsors are most likely looking to achieve through a sponsorship with their organizations. Findings from the current study indicated five objectives were consistently reported to have the greatest importance for North American professional niche sport sponsors. In all three forms of analysis (means, frequencies, and ranking) respondents indicated the most important objectives to include: (a) increase target market awareness, (b) increase sales/market share, (c) increase public awareness, (d) enhance company image, and (e) become involved with the community.

Findings clearly support the sponsorship lifecycle as four of the five most important objectives within the current study were awareness or image-focused. According to Lough and Irwin (2001) increasing sales/market share is the apex of the sponsorship lifecycle but found to be an important objective of most sport sponsors. However, the high level of importance placed on image and awareness objectives appears to be present in less mature sport properties or regions and fades in importance as sport 
properties mature. As noted earlier, Lough and Irwin (2001) determined maturity was a measure of the rapidness of sponsorship growth, in terms of support generated, within a sport property. Where mature properties grow at a relatively slow pace, properties within the growth phase grow exponentially over time.

Several sponsorship objective-focused practical implications were also derived from the findings of the current study. As discussed in the previous section on selection criteria, niche sport managers must have a thorough understanding of their fan base and how their fans match the target market of potential sponsors. Niche sport managers should also be cognizant of the relatively high level of importance sponsors placed on niche sport sponsorship's ability to increase public awareness. Both of these findings indicate niche sport properties should present potential sponsors with opportunities to have their advertising/communications messages heard. Signage at the event, title sponsorship, and jersey logos are all potentially viable inventory niche sport properties can offer to help sponsors increase awareness.

As predicted by the sponsorship lifecycle, North American professional niche sport sponsors placed a high level of importance on enhancing their image through niche sport sponsorships. As noted by Mullin et al. (2007) and Shank (2005) sponsors often associate themselves with a particular sport property in the hopes that the image of the sport property will be transferred to their company. This approach has been present within professional niche sports in the past. In an effort to solidify its reputation of being tough and rugged, Ford has sponsored the PBR. Findings of the current study demonstrated that sponsors view image enhancement as a very important part of niche sport sponsorships. Therefore, niche sport properties need to be aware of their image, and 
how their image may be attractive to potential sponsors. Niche sport properties should also be cognizant of the image potential sponsors have, or are trying to establish, so they can focus on the image intricacies of their sport property which may match the wants and needs of a potential sponsor.

Finally, niche sport sponsors within the current study reported a high level of importance on community involvement. Sport sponsorship has been projected to have more potential than any other promotional tool to have a direct impact on the community (Mullin et al., 2007). Companies engaged in the sponsorship of community-based events are often viewed as being in touch with their community and their community's needs. Often the term community is geographically bound within a particular neighborhood, city or state. However, Jarvis (2002) indicated many sponsors of the Gay Softball World Series indicated community involvement within the gay and lesbian communities as one of their primary objectives. Jarvis' (2002) findings demonstrated community was not necessarily geographically restricted. Respondents within the current study indicated community involvement was a highly important objective. Niche sport properties should be aware of their influence on several different communities. Sponsors of niche sports may be attempting to become more involved with the lacrosse community, cycling community, or youth community. These objectives have been demonstrated through Reebok's sponsorship of the NLL, Subaru's sponsorship of the International Mountain Bike Association, and Mountain Dew's sponsorship of extreme sports. For these reasons niche sport properties ought to be aware of the different communities they reach both geographically specific and beyond. Also, niche sport properties should focus on their community reach within their sponsorship proposals. Reporting the demographics and 
psychographics of each community a professional niche sport property reaches and how those communities match a potential sponsor's target market would likely be a wise business strategy.

\section{Least Important Niche Sport Sponsorship Objectives}

While seven sponsorship objectives produced a mean score less than 4.5 , only three objectives were consistently reported to be of least importance. Respondents within the current study determined the three least important North American professional niche sport sponsorship objectives to include: (a) Engage in Corporate Philanthropy, (b) Enhance Employee Relations, and (c) Block/Pre-empt Competition.

These findings are consistent with the findings of previous researchers. The literature has indicated sport sponsorships motivated by corporate philanthropy (Crompton, 2004) or competition's interests (Shaw \& Amis, 2001) are ill advised. Enhancing employee relations has been identified as a salient sponsorship objective within sport promotions and marketing textbooks (Irwin et al., 2008; Mullin et al., 2007) but most empirical research has indicated sponsors place a relatively low level of importance on enhancing employee relations (Irwin \& Sutton, 1994; Lough et al., 2000; Lough \& Irwin, 2001).

Sport sponsorship may have been considered corporate philanthropy during its infancy, however, times have changed and all sponsors aim to achieve some corporate objective out of each sponsorship relationship (Crompton, 2004). Findings from the current study, indicating corporate philanthropy as one of the least important objectives, is supported by the findings of numerous other authors in both niche (Lough et al., 2000; Lough \& Irwin, 2001) and mainstream sports (Irwin \& Sutton, 1994). Sport sponsors 
have sent a very clear message to all sport properties: sport sponsorship is a business endeavor not a philanthropic venture. Therefore, sport properties, niche and mainstream, must be able to offer a potential sponsor something of value or their proposal will likely be rejected.

Similar to the findings in the selection criteria section corporate sponsors appear not to be swayed by the actions of their competitors. Findings of the current study again demonstrated the lack of importance companies place on their competitions' interests when making sport sponsorship decisions. From this, niche sport properties should focus on each sponsorship proposal individually and avoid focusing on the actions of a potential sponsor's competition. Similarly, niche sport properties should understand that just because one company within an industry is interested in sponsoring a niche sport property other companies within the same industry may have no interest in participating in a similar relationship. Therefore, niche sport properties would be wise to focus on the objectives identified above as the most important professional niche sport sponsorship objectives rather than concerning themselves with the actions of a potential sponsor's competition.

Findings from the current study also indicated North American professional niche sport sponsors placed very little importance on enhancing employee relations through a niche sport sponsorship. From these findings, niche sport properties may want to focus hospitality opportunities on enhancing the trade relations sponsors have with their suppliers or buyers rather than their employees. Enhancing trade relations/goodwill objectives were not reported to be the most important objectives, however, sponsors within the current study placed a much greater emphasis on these objectives over 
enhancing employee relations. Hence, if a sport property wants to include hospitality focused inventory within its proposals, findings of the current study indicate this inventory may be better focused on potential sponsor business associates as opposed to potential sponsor's employees.

\section{Summary}

Findings from the current study indicated niche sport sponsors aim to achieve very specific objectives through their sponsorship relationships. Specifically, respondents indicated the most important objectives were increasing their target market awareness, increasing sales/market share, increasing public awareness, enhancing company image and becoming involved in the community. From this, niche sport properties would be well served to have a firm understanding of their fan base, the different communities they reach, and the image they portray. Also, niche sport properties must do their homework to gain knowledge of a potential sponsor's target market and desired image. From this, niche sport properties would be able to produce sport sponsorship proposals demonstrating matches between sport property fans and the company's target market as well as ways in which a sponsorship with their sport property can create or solidify a desirable corporate image.

\section{VARIANCE BY COMPANY DEMOGRAPHICS}

The focus of research question three was to understand how important sponsorship objectives of niche sport sponsors vary by company industry segment, company size, or company scope. Similarly, research question four assessed how important selection criteria varied by company industry segment, company size, or company scope. The genesis of these research questions stemmed from the work of Irwin 
and Sutton (1994) who understood sponsorship objectives and selection criteria may vary based on the industry of the sponsoring corporation. Unfortunately, Irwin and Sutton (1994) were unable to perform inferential statistical analysis due to a small sample size. Therefore, the findings of the current study are still exploratory in nature.

As noted in Chapter IV the MANOVA analysis within the current study produced no statistically significant differences between any of the independent variables and the sponsorship objectives or selection criteria. However, due to the reported poor power of the tests, likely due to a small sample size, results of insignificance should be interpreted with caution. Due to the poor power of the MANOVA, results of insignificance must be interpreted as there were no statistically significant differences found within the current sample, not that no differences exist between any of the company demographics and sponsorship objectives or selection criteria within the population.

\section{Differences in Objectives}

Three findings were produced from the analysis of research question three. First, smaller companies (Less than $\$ 500 \mathrm{M}$ ) placed a statistically greater importance on increasing their target market awareness than the larger companies within the current study. Secondly, companies within the Frequently Purchased Products/Services group also placed a statistically significantly higher level of importance on increasing their target market awareness than the companies within the Infrequently Purchased Products/Services group. Finally, although not statistically significant, International Companies placed a much greater level of importance on increasing their target market awareness and sales/market share through professional niche sport sponsorships than the National Level companies within the current study. 
The analysis of research question four produced only one statistically significant finding. Companies within the Infrequently Purchased Products/Services group placed a statistically significant greater level of importance on sport property flexibility than companies within the Frequently Purchased Products/Services group. However, three other relatively large mean differences were also found. Large Companies and International Companies each placed a relatively higher level of importance on Company Image Fit within Target Market, and Small Companies placed a relatively greater level of importance on Spectator Demographics than Larger Companies.

Corporate demographic analysis indicated sponsors within the current study had divergent views with respect to the relative importance placed on each of the selection criteria and objectives. Pragmatically, the most important finding from this section of the study was the implication that niche sport properties have to be flexible and creative when constructing sponsorship proposals. Generally, the homogeneity of companies sampled may have clouded many strong segmentations between different corporate demographics. However, findings demonstrated not all companies engaged in niche sport sponsorships for the same reasons.

\section{FUTURE STUDIES}

The exploratory nature of the current study has laid the groundwork for a variety of future studies. Many of the future studies could be designed to mitigate the limitations of the current study. Perhaps the first step in this line of research should be a backwards one. One of the most challenging obstacles within the current study was the lack of a concrete definition of professional niche sports. The entire line of niche sport research would be well served by a coherent exhaustive definition of professional niche sports. 
Stemming from the formation of a concrete definition of professional niche sports, future researchers could segment niche sports and determine what differences, if any, exist among different segments of niche sports. One of the most influential factors in the creation of the current study was the consideration all professional sports cannot be painted with the same broad brush with respect to sponsorship objectives and selection criteria. For that matter, not all professional niche sports can be painted with the same brush either.

Future researchers should try to secure a larger, more heterogeneous group of professional niche sport sponsors than the current study. To accomplish this task, future researchers may implement the use of a variety of sampling strategies. Snowball sampling could be used to gain a larger number of respondent companies. This strategy could even be implemented from the accessible population found within the current study. Other sampling strategies may include sampling sponsors of specific niche sports. This would provide a better perspective of the types of companies niche sport attract. A blending of sampling strategies may be the best solution. Sampling from a frame similar to that used in the current study provides insight into the different types of niche sports particular companies support. Alternatively, sampling all sponsors from a set variety of niche sports provides better insight into the different types of companies involved in niche sport sponsorship. However, this strategy limits the number and types of niche sports represented. Therefore, a blending of the two sampling strategies may produce the most holistic sample of niche sports and the companies sponsoring niche sports.

One of the limitations of the current study indicated the results reflect a snapshot in time. Future research may take a longitudinal approach. A longitudinal professional 
niche sport sponsorship study could address several issues. First, a longitudinal study focused on niche sports could validate the sponsorship lifecycle. According to the sponsorship lifecycle, as niche sports mature, sponsors' objectives should move from awareness and image-focused objectives towards more market-driven objectives. A longitudinal study of niche sports may be able to track a sport as it progresses into a mainstream sport. Secondly, a longitudinal approach may reflect the effects economic change has on sponsorship selection criteria and objectives. The current study is reflective of North American professional niche sport sponsors opinions during a recessionary time. However, these opinions may change as the economy shifts. Furthermore, distinct social or political occurrences may influence the importance sponsors place on specific objectives and selection criteria. A longitudinal study may be able to capture these influences.

The current study focused on North American professional niche sports. However, niche sports and the subsequent sponsor objectives and selection criteria may differ based on regionality. Future research may compare and contrast the sponsorship objectives and selection criteria for sports in different regions of the United States. Moreover, international studies could illuminate the sponsorship objectives and selection criteria from a variety of areas.

Finally, possibly the most logical extension of the current study would include conducting a study to understand what niche sports currently focus on within their sponsorship proposals. Niche sport sponsors have indicated they attempt to achieve very specific objectives through niche sports. In addition, niche sport sponsors indicated they use a variety of very important selection criteria when screening niche sport sponsorship 
opportunities. However, if niche sport properties are unaware of these objectives and selection criteria they may be creating proposals destined for failure.

\section{SUMMARY OF THE STUDY}

The current sport sponsorship literature indicated sport organizations face tremendous pressure to secure sponsorship support (Copland et al., 1996). Professional niche sports, defined in the current study as any North American professional sport not including the: NFL, NHL, MLB, NBA, NASCAR or PGA TOUR, face even greater pressure as sponsorship support often determines whether an event can take place (Sutton, 2009). Kuzma et al. (1993) state the number one principle in selling sponsorships is establishing a close match between sponsor objectives and event characteristics. Therefore, the purpose of the current study was to investigate the objectives sponsors aim to achieve through niche sport sponsorship as well as understand the selection criteria used to screen niche sport sponsorship opportunities.

A survey of 352 sport sponsorship decision-makers, yielding a response rate of 25.3\% with 32 usable professional niche sport sponsor responses, revealed many interesting findings. Respondents indicated the most important objectives they aim to achieve through niche sport sponsorship include: (a) increase target market awareness, (b) increase sales/market share, (c) increase public awareness, (d) enhance company image, and (e) become involved in the community. Respondents also revealed enhancing employee relations and blocking competition to be the least important niche sport sponsorship objectives.

Niche sport sponsorship decision-makers also reported the most important selection criteria used to screen niche sport sponsorship opportunities include: (a) cost 
effectiveness, (b) company image fit within the target market of the sport property, (c)

flexibility of the sport property, (d) spectator demographics, and (e) company

product/service image fit with the sport image.

Finally, findings suggested that different companies engaged in niche sport sponsorships for different reasons. Some companies placed a greater importance on target market awareness than others, while some were more concerned with spectator demographics. Overall, the sponsorship decision-making process was reported to be very complex as sponsors take many selection criteria into consideration when evaluating niche sport sponsorship opportunities. However, the most consistent finding indicated that sponsors are looking for a good fit between their target market, and image and the sport property they choose to sponsor. In summary, niche sport properties must be well aware of their fan base and community reach and how these factors match the target market of potential sponsors. 


\section{REFERENCES}

A futile search. (2008, January 14). Sport Business Journal. Retrieved from http://www.sportsbusinessjournal.com/article/57769

Abratt, R., Clayton, B. C., \& Pitt, L. F. (1987). Corporate objectives in sports sponsorship. International Journal of Advertising, 6, 299-311.

Aguilar-Manjarrez, R., Thwaites, D., \& Maule, J. (1997). Modelling sport sponsorship selection decisions. Asia-Australia Marketing Journal, 5(1), 9-20.

Amis, J., Slack, T., \& Berrett, T. (1999). Sport sponsorship as distinctive competence. European Journal of Marketing, 33(3/4), 250-272.

Apostolopoulou, A., \& Papadimitriou, D. (2004), “Welcome home”: Motivations and objectives of the 2004 Grand National Olympic Sponsors. Sport Marketing Quarterly, 13, 190-192.

Baldauf, A., Reisinger, H., \& Moncrief, W. C. (1999). Miscellany. Journal of the Market Research Society, 4I(3), 345-353.

Bennett, G., \& Henson, R. K. (2003). Perceived status of the action sports segment among college students. International Sports Journal, Winter, 124-138.

Bennett, G., Ferreira, M., Lee, J., \& Polite, F. (2009). The role of involvement in sports and sport spectatorship in sponsor's brand use: The case of Mountain Dew and action sports sponsorship. Sport Marketing Quarterly, 18, 14-24. 
Bennett, G., Henson, R., \& Zhang, J. (2002). Action sports sponsorship recognition. Sport Marketing Quarterly, 11(3), 174-185.

Bennett, G., Sagas, M., \& Dees, W. (2006). Media preferences of action sports consumers: Differences between Generation X and Y. Sport Marketing Quarterly, $15,40-49$.

Berrett, T., \& Slack, T. (1999). An analysis of the influence of competitive and institutional pressures on corporate sponsorship decisions. Journal of Sport Management, 13, 114-138.

Bradish, C., \& Lathrop, A. H. (2001). Girl power: Examining the female pre-teen and teen as a distinct sement of the sports marketplace. Sport Marketing Quarterly, IO(1), 19-24.

Brenner, S. (2003, September 15). Emerging sports sponsors find value below the radar. SportsBusiness Journal. Retrieved from: http://www.sportsbusinessjournal.com/ index. $\mathrm{cfm}$ ?fuseaction=article.preview \&articleID=33191

Chadwick, S., \& Thwaites, D. (2004). Advances in the management of sport sponsorship: Fact or fiction ? Evidence from English professional soccer. Journal of General Management, 30(1), 39-60.

Copeland, R., Frisby, W., \& McCarville, R. (1996). Understanding the sport sponsorship process from a corporate perspective. Journal of Sport Management, 10(1), 32-48.

Cornwell, T. B., Roy, D. P., \& Steinard, E. A. (2001). Exploring managers’ perceptions of the impact of sponsorship on brand equity. Journal of Advertising, 30(2), 4151. 
Cousens, L., \& Slack, T. (1996). Using sport sponsorship to penetrate local markets: The case of the fast food industry. Journal of Sport Management, 10, 169-187.

Cresswell, J. W. (2002). Educational research: Planning, conducting, and evaluating quantitative and qualitative research.. Upper Saddle River, NJ: Pearson Education.

Crowley, M. (1991). Prioritising the sponsorship audience. European Journal of Marketing, 25(11), 11-21.

Crompton, J. L. (2004). Conceptualization and alternate operationalizations of the measurement of sponsorship effectiveness in sport. Leisure Studies, 23(3), 267281.

Daniels, M., Baker, R., Backman, K., \& Backman, S. (2007). What sponsors want. International Journal of Sport Management, 8, 131-146.

Dees, W., Bennett, G., \& Villegas, J. (2008). Measuring the effectiveness of sponsorship of an elite intercollegiate football program. Sport Marketing Quarterly, 17(2), 7989.

DeVellis, R. F. (2003). Scale development: Theory and applications. ( $2^{\text {nd }}$ ed.). Thousand Oaks, CA: Sage Publications.

Dillman, D. A. (2007). Mail and interned surveys: The tailored design method. (2 ${ }^{\text {nd }}$ ed.). Hobeken, NJ: John Wiley \& Sons.

Doherty, A., \& Murray, M. (2007). The strategic sponsorship process in a non-profit sport organization. Sport Marketing Quarterly, 16, 49-59. 
Ferreira, M., Hall, T. K., \& Bennett, G. (2008). Exploring brand positioning in a sponsorship context: A correspondence analysis of the Dew Action Sports Tour. Journal of Sport Management, 22, 734-761.

Field, A. (2005). Discovering statistics using SPSS (2 ${ }^{\text {nd }} E d$.). Thousand Oaks, CA: Sage. Frankel, J. R., \& Wallen, N. E. (1996). How to design and evaluate research in education ( $3^{\text {rd }}$ ed.). New York, NY: McGraw-Hill.

Fullerton, S. (2010). Sports marketing (2nd Ed.). New York; NY: McGraw-Hill Irwin.

Garson, G.D. (2010). "Reliability Analysis”, from Statnotes: Topics in multivariate analysis. Retrieved from http://faculty.chass.ncsu.edu/garson/PA765/reliab.htm.

Greenwald, L., \& Fernandez-Balboa, J. (1998). Trends in the sport marketing industry and in the demographics of the United States: Their effect on the strategic role of grassroots sport sponsorship in corporate America. Sport Marketing Quarterly, 7(4), 35-47.

Hagar, M. A., Wilson, S., Pollack, T. H., \& Rooney, P. M. (2003). Response rates for mail surveys of nonprofit organizations: A review and empirical test. Nonprofit and Voluntary Sector Quarterly, 32(2), 252-267.

Hanas, J. (2007). Going pro: What's with all these second-tier sports? Advertising Age, 78(5), S3.

Hochman, P. (1999). Street lugers, stunt bikers, and - Colgate-Palmolive! Fortune, 140(10), 60 .

IEG. (2010). Sponsorship spending recedes for first time; better day seen ahead.

Retrieved from: http://www.sponsorship.com/IEG-Insights/SponsorshipSpending-Recedes-For-First-Time;-Bette.aspx 
Ilivea, J., Baron, S., \& Healey, N. M. (2002). Online survey in marketing research: Pros and cons. International Journal of Market Research, 44, 361-376.

Irwin, R. L., \& Sutton, W. A. (1994). Sport sponsorship objectives: An analysis of their relative importance for major corporate sponsor. European Journal of Sport Management,1(2), 93-101.

Irwin, R. L., Assimakopoulos, M. K., \& Sutton, W. A. (1994). A model for screening sport sponsorship opportunities. Journal of Promotion Management, 2(3/4), 5369.

Irwin, R. L., Sutton, W. A., \& McCarthy, L. M. (2008). Sport promotion and sales management. Champaign, IL: Human Kinetics.

Jarvis, N. (2002). Sponsorship and gay sport: A case study of the 2000 Gay Softball World Series. International Journal of Sports Marketing \& Sponsorship, September/October, 205-230.

Johnston, M., Paulsen, N. (2007, December). The relative importance of sponsorship selection criteria: A choice -based conjoint study using hierarchical Bayes analysis. ANZMAC Annual Conference. Dunedin, New Zealand.

Jones, R. (2008). Advertise creatively with offbeat sports. Entrepreneur.com. Retrieved from http://www.entrepreneur.com/article/printhis/193762.html

Jowdy, E., \& McDonald, M. (2002). The FUTURES Golf Tour case study: Sponsorship sales and eduselling. Sport Marketing Quarterly, 11(4), 248-251.

Keppel, G., \& Wickens, T. D. (2004). Design and analysis: A researcher's handbook $\left(4^{\text {th }}\right.$ Ed.). Upper Saddle River, NJ: Pearson Prentice Hall. 
Kojima, S. (2010, January 22). NLL seeks new sponsorship, Reebok deal expires in 2010. Retrieved from http://www.nllinsider.com/2010/01/22/nll-seeks-newsponsorships-reebok-deal-expires-in-2010/

Kuzma, J. R., Shanklin, W.L., \& McCally, J.F. (1993). Number one principle for sporting events seeking corporate sponsors: Meet benefactor's objective. Sport Marketing Quarterly, 2(3), 27-32.

Lamont, M., \& Dowell, R. (2007). A process model of small and medium enterprise sponsorship of regional sport tourism events. Journal of Vacation Marketing, 14(3), 253-266.

Livingstone, S. (2009). PBR stays in saddle. USA Today. Retrieved from http://usatoday.com/sports/2009-01-14-tough-economy-impact_N.htm

Lough, N. L. (1996). Factors affecting corporate sponsorship of women's sport. Sport Marketing Quarterly, 5(2), 11-19.

Lough, N. L., \& Irwin, R. L. (2001). A comparative analysis of sponsorship objectives for U.S. women's sport and traditional sport sponsorship. Sport Marketing Quarterly, 10(4), 202-211.

Lough, N. L., Irwin, R. L., \& Short, G. (2000). Corporate sponsorship motives among North American companies: A contemporary analysis. International Journal of Sport Management, 1, 283-295.

Ludwig, S., \& Karabetsos, J. D. (1999). Objectives and evaluation processes utilized by sponsors of the 1996 Olympic Games. Sport Marketing Quarterly, 8(1), 11-19. 
Mack, R. W. (1999). Event sponsorship: An exploratory study of small business objectives, practices and perceptions. Journal of Small Business Management, July, 25-30.

Masteralexis, L. P. (2009). Professional sport. In L. P. Masteralexis, C. A. Barr, \& M. A. Hums (Eds.), Principles and practice of sport management (pp. 205-232).

Sudbury, MA: Jones and Bartlett.

Maxwell, H., \& Lough, N. (2009). Signage vs. no signage: An analysis of sponsorship recognition in women's college basketball. Sport Marketing Quarterly, 18, 188198.

Mc Cook, K., Turco, D., \& Riley, R. (1997). A look at the corporate sponsorship decision-making process. Cyber-Journal of Sport Marketing. Retrieved from http://fulltext.ausport.gov.au /fulltext/1997/cjsm/v1n2/mcook.htm.

McCarthy, L. M., \& Irwin, R. (2000). An examination of the rationale and motives for corporate purchase of stadia and arena naming rights. Cyber Journal of Sport Marketing, 4(3).

McCarthy, M. (2006, April 17). Bull riding set to piggyback on high viewership of NFL. USA Today. Retrieved from http://www.usatoday.com/sports/2006-04-16-bullriding-tv_x.htm

McCarville, R. E., \& Copeland, R. P. (1994). Understanding sport sponsorship through exchange theory. Journal of Sport Management, 8, 102-114.

Meenaghan, T. (1991). The role of sponsorship in the marketing communications mix. International Journal of Advertising, 10, 35-47. 
Mickle, T. (2010, January 25). Sponsorsh have more flexibility at X Games. SportsBusiness Journal, 27.

Miloch, K. S., \& Lambrecht, K. W. (2006). Consumer awareness of sponsorship at grassroots sport events. Sport Marketing Quarterly, 15(3) 147-154.

Milne, G. R., McDonald, M. A., Sutton, W. A., \& Kashyap, R. (1996). A niche-based evaluation of sport participation patterns. Journal of Sport Management, 10, 417434.

Milne, G. R., Sutton, W. A., \& McDonald, M. A. (1996). Niche analysis: A strategic measurement tool for sport managers. Sport Marketing Quarterly, 5(3), 15-22.

Moorman, A. M., \& Greenwell, T. C. (2005). Consumer attitudes of deception and the legality of ambush marketing practices. Journal of Legal Aspects of Sport, 15(2), 183-211.

Mueller, T., \& Roberts, M. S. (2008). The effective communication of attributes in sportsponsorship branding. International Journal of Sport Communication, 1, 155-172.

Mullin, B.J., Hardy, S., \& Sutton, W.A. (2007). Sport marketing (3rd ed.). Champaign, IL: Human Kinetics.

Papadimitriou, D., Apostolopoulou, A., \& Theofanis, D. (2008). Event sponsorship as a value creating strategy for brands. Journal of Product \& Brand Management, $17(4), 212-222$.

Parks, J. B., Shewokis, P. A., \& Costa, C. A. (1999). Using statistical power analysis in sport management research. Journal of Sport Management, 13(2), 139-147.

Rosner, S., \& Shropshire, K. L. (Eds). (2004). The business of sports. Sudbury, MA: Jones \& Bartlett Publishers. 
Rovell, D. (2009). NFL teams selling space on practice jerseys. Retrieved from www.cnbc.com/id/31082521/

Sam, M. P., Batty, R., \& Dean, R. G. K. (2005). A transactional cost approach to sport sponsorship. Sport Management Review, 8, 1-17.

Scott, D. R., \& Suchard, H. T. (1992). Motivations for Australian expenditure on sponsorship - An analysis. International Journal of Advertising, 11, 325-332.

Seguin, B., Teed, K. C., \& O'Reilly, N. J. (2005). National sports organizations and sponsorship: An identification of best practices. International Journal Sport Management and Marketing, 1 (1/2), 69-92.

Shani, D., \& Sandler, D. (1996, August 26). Climbing the sports event pyramid. SportsMarketing, 6.

Shank, M. (2005). Sports marketing: A strategic perspective. Upper Saddle River, NJ: Pearson Prentice Hall.

Sharma, A., \& Lambert, D. M. (1994). Segmentation of markets based on customer service. International Journal of Physical Distribution \& Logistics, 24(1). 50-59.

Shaw, S., \& Amis, J. (2001). Image and investment: Sponsorship and women's sport. Journal of Sport Management, 15, 219-246.

Siebert, D. C. (2006). Maximizing response rates in survey research: Issues and methods. Advances in Social Work, 7(2), 1-11.

Slack, T., \& Benz, L. (1996). The involvement of small businesses in sport sponsorship. Managing Leisure, 1, 175-184.

Stevens, J. (2002). Applied multivariate statistics for the social sciences. $\left(4^{\text {th }} \mathrm{ed}.\right)$. Mahawah, NJ: Lawrence Erlbaum Associates. 
Stotlar, D. K. (2009). Developing successful sport sponsorship plans. ( ${ }^{\text {rd }}$ ed.). Morgantown, WV: Fitness Information Technology.

Tedesco, R. (2009, February). Second string: 'Smaller' sports are scoring in tough times. Promo Magazine, 22-24.

Teddlie, C., \& Tashakkori, A. (2009). Foundations of mixed methods research. Thousand Oaks, CA: Sage Publications.

Thjomoe, H. M., Olson, E. L., \& Bronn, P. S. (2002). Decision-making processes surrounding sponsorship activities. Journal of Advertising Research, November/December, 6-15.

Thwaites, D., Aguilar-Manjarrez, R., \& Kidd, C. (1998). Sports sponsorship development in leading Canadian companies: Issues \& trends. International Journal of Advertising, 17(1), 29-49.

Tomasini, N., Frye, C., Stotlar, D. (2004). National collegiate athletic association corporate sponsor objectives: Are there differences between divisions I-A, I-AA, and I-AAA? Sport Marketing Quarterly, 13, 216-226.

Tripodi, J. A. (2001). Sponsorship - A confirmed weapon in the promotional armory. International Journal of Sports Marketing \& Sponsorship, March/April, 1-20.

Wartella, J. (2009). Sponsorship of interscholastic athletics: An examination of state high school athletic/activity association sponsors (Unpublished doctoral dissertation). University of Nevada, Las Vegas, Las Vegas, NV.

Williams, P. (2001, January 15). Minor leagues play major competitive role. SportsBusiness Journal. Retrieved from http://www.sportsbusinessjournal.com /index.cfm? fuseaction=article.preview\&articleID $=8964$ 
Witcher, B. Craigen, J. G., Culligan, D., \& Harvey, A. (1991). The links between objectives and function organizational sponsorship. International Journal of Advertising, 10, 13-33. 


\title{
APPENDICES
}

\section{Appendix A}

\section{North American Professional Niche Sport Sponsorship Questionnaire}

\author{
1. Professional North American Sport Sponsorship \\ Sport Sponsorship Objectives and Selection Criteria
}

\section{Dear Executive:}

You are being invited to participate in a research study about sport sponsorship objectives and selection criteria. The results of this study should provide sport properties with valuable information to enhance their sponsorship proposals. Hence, your participation in this very brief survey (approximately 5 minutes) could potentially save you from having to read through poorly constructed proposals in the future.

This research study serves, in part, to the completion of the researchers Ph.D. in Sport Administration. Your willingness to assist in this effort is greatly appreciated.

There are no known risks for your participation in this research study. The information collected may not benefit you directly. The information learned in this study may be helpful to others. Your completed survey will be at the University of Louisville in the Department of Health and Sport Sciences.

Individuals from the Department of Health and Sport Sciences, the Institutional Review Board (IRB), the Human Subjects Protection Program Office (HSPPO), and other regulatory agencies may inspect these records. In all other respects, however, the data will be held in confidence to the extent permitted by law. Should the data be published, your identity will not be disclosed.

Taking part in this study is voluntary. By completing this survey you agree to take part in this research study. You do not have to answer any questions that make you uncomfortable. You may choose not to take part at all. If you decide to be in this study 
you may stop taking part at any lime. If you decide not to be in this study or if you stop taking part at any time, you will not lose any benefits for which you may qualify.

If you have any questions, concerns, or complaints about the research study, please contact: Dr. T. Christopher Greenwell at tcgreenwell@ louisville.edu or (502) 852-0555.

If you have any questions about your rights as a research subject, you may call the Human Subjects Protection Program Office at (502) 852-5188. You can discuss any questions about your rights as a research subject, in private, with a member of the Institutional Review Board (IRB). You may also call this number if you have other questions about the research, and you cannot reach the study doctor, or want to talk to someone else. The IRB is an independent committee made up of people from the University community, staff of the institutions, as well as people from the community not connected with these institutions. The IRB has reviewed this research study.

If you have concerns or complaints about the research or research staff and you do not wish to give your name, you may call 1-877-852-1167. This is a 24 hour hot line answered by people who do not work at the University of Louisville.

Sincerely,

Dr. T. Christopher Greenwell \&

Greg Greenhalgh

\section{Professional North American Sport Sponsorship}

The following questionnaire aims to better understand why corporations choose to sponsor professional North American sports and what criteria they use when evaluating professional North American sport sponsorship opportunities.

\section{Has your company engaged in a sponsorship relationship with a North American Professional Niche Sport Property?}

For the purpose of this study, professional niche sports will be defined as any professional sport within North America which is NOT one of the following: NFL

MLB

NBA

NHL

NASCAR

PGA TOUR

Yes

No 


\section{Professional Niche Sport Sponsorship}

$*$

1. Please Identify the MOST RECENT North American based Professional NICHE Sport your company has sponsored.

*For the purpose of this study, professional niche sports will be defined as any professional sport within North America which is NOT one of the following: NFL, MLB, NBA, NHL, NASCAR, or the PGA TOUR.*

2. Please indicate the level of sponsorship for the above sport property.

League

Tour

Team

Event

Individual Athlete

Other (please

specify)

3. List and explain 3 to 5 reasons your company chose to sponsor this North American professional NICHE sport? (i.e. the sport property identified earlier)

\section{Professional Mainstream Sport Sponsorship}

$*$

1. Please Identify the MOST RECENT North American based Professional MAINSTREAM Sport your company has sponsored.

*For the purpose of this study, professional mainstream sports will be defined as one of the following: NFL, MLB, NBA, NHL, NASCAR, or the PGA TOUR.*

NFL MLB

NBA NASCAR

NHL PGA 
TOUR

2. Please indicate the level of sponsorship for the above sport property.

League

Tour

Team

Event

Individual Athlete

Other (please

specify)

3. List and explain 3 to 5 reasons your company has NOT chosen to sponsor any North American professional NICHE sports? (i.e. Professional sports not including: NFL, NBA, MLB, NHL, NASCAR, PGA TOUR)

\section{Part II: Sport Sponsorship Objectives}

All Subsequent Questions Should Be Answered With Respect To the MOST RECENT North American based Professional Sport your company sponsored. (the sport property identified earlier)

\section{How was the sponsorship support provided?}

Financial Support

Value In-kind

Combination of Financial Support and Value In-kind

I would prefer not to answer this question

What was the approximate dollar value of the sponsorship agreement? If a combination, please indicate the percentage of value provided in Financial Support and percentage of value provided in Value In-kind

$*$

2. When your company assessed your MOST RECENT sport sponsorship opportunity (as identified earlier) each of the following objectives were: 


\section{$1=$ NOT IMPORTANT $\ldots \ldots \ldots \ldots \ldots \ldots \ldots . . . . .8$ = EXTREMELY IMPORTANT}

$\begin{array}{llllllll}\text { Not } & 2 & 3 & 4 & 5 & 6 & 7 & \text { Extremely } \\ \text { Important } & & & & & & & \text { Important } 8 \\ 1\end{array}$

1. Increase

public

awareness

2. Enhance

general

company image.

3. Alter public perception.

4. Involve with the community.

5. Build trade relations

6. Build trade goodwill

7. Enhance employee relations

8. Increase target market awareness.

9. Increase sales/market share

10. Engage in corporate philanthropy

11. Block/preempt

competition

12. Engage in social responsibility 
3. Please identify any other objectives your company considered when entering into your most recent sponsorship (as indicated above) and indicate its level of importance ( 1 = NOT IMPORTANT and 8 = EXTREMELY IMPORTANT)

*

4. Please rank the five most important objectives your company aimed to achieve through your most recent sponsorship opportunity.

$\begin{array}{lllll}\text { Most } & \text { Second } & \text { Third Most } & \text { Fourth Most } & \text { Fifth Most } \\ \text { Important } & \begin{array}{l}\text { Most } \\ \text { Important }\end{array} & \text { Important } & \text { Important } & \text { Important } \\ & & & \end{array}$

1. Increase public awareness

2. Enhance

general company

image

3. Alter public

perception

4. Increase

community

involvement

5. Build Trade

Relations

6. Build Trade

Goodwill

7. Enhance

employee

relations

8. Increase target

market awareness.

9. Increase

sales/market share

10. Engage in

corporate

philanthropy

11. Block/pre-

empt competition

12. Engage in

social 
responsibility

Other (please specify)

\section{Part III: Sport Sponsorship Selection Criteria}

When screening a sport sponsorship opportunity several criteria must be evaluated. Please rate the level importance of the following criteria were to your company when entering into your most recent North American Professional Sport Sponsorship Relationship (identified earlier) by reporting the importance of each of the following criteria ( $1=$ NOT IMPORTANT and $8=$ EXTREMELY IMPORTANT)

When assessing your latest sport sponsorship opportunity (as identified earlier) each of the following selection criteria were deemed to be:

$1=$ NOT IMPORTANT $8=$ EXTREMELY IMPORTANT

$*$

\section{Budget Considerations}

$\begin{array}{llllllll}\text { Not } & 2 & 3 & 4 & 5 & 6 & 7 & \begin{array}{l}\text { Extremely } \\ \text { Important 8 }\end{array} \\ 1 & & & & & & & \end{array}$

Affordability

Cost

effectiveness

(eg. Audience

reach)

$*$

\section{Management Issues}

$\begin{array}{llllllll}\text { Not } & 2 & 3 & 4 & 5 & 6 & 7 & \begin{array}{l}\text { Extremely } \\ \text { Important }\end{array} \\ \text { Important } & & & & & & & 8\end{array}$

Profile of the team/league/athlete.

Cooperation of participating athletes.

Flexibility of sport 
property to achieve

corporate

sponsorship

objectives.

$*$

\section{Positioning/Image}

$\begin{array}{llllllll}\text { Not } & 2 & 3 & 4 & 5 & 6 & 7 & \begin{array}{l}\text { Extremely } \\ \text { Important } \\ 1\end{array} \\ \text { Important } & & & & & & & 8\end{array}$

Fit of your

company

product/service

with image of

sport.

Fit of your

company

product/service

utility with sport.

Fit of your

company

image/with target

market.

\section{Targeting of Market}

$\begin{array}{llllllll}\text { Not } & 2 & 3 & 4 & 5 & 6 & 7 & \begin{array}{l}\text { Extremely } \\ \text { Important }\end{array} \\ 1 & & & & & & & 8\end{array}$

Demographic

profile of

spectators.

Psychographic

profile of

spectators

Size of immediate audience.

Sport

property/league

fan loyalty. 
National media

coverage

Local media

coverage

Social Media

Opportunities

(Facebook,

Twitter,

YouTube)

7.

When screening a sport sponsorship opportunity several criteria must be evaluated. Please rate the level importance of the following criteria were to your company when entering into your most recent North American Professional Sport Sponsorship Relationship (identified earlier) by reporting the importance of each of the following criteria ( $1=$ NOT IMPORTANT and $8=$ EXTREMELY IMPORTANT)

When assessing your latest sport sponsorship opportunity (as identified earlier) each of the following selection criteria were deemed to be:

$1=$ NOT IMPORTANT ....................8 = EXTREMELY IMPORTANT

1. Non-Attending Audience Profile (TV, Radio, Internet, Smart Phone Audience)
$\begin{array}{llllllllll}\text { Not } & 2 & 3 & 4 & 5 & 6 & 7 & \text { Extremely } \\ \text { Important } & & & & & & & \text { Important } \\ 1 & & & & & & 8\end{array}$

Non-attending

demographic

profile

Non-attending

psychographic

(personality

traits)profile.

Size of non-

attending 
audience.

*

\section{Public Relations}

$\begin{array}{llllllll}\text { Not } & 2 & 3 & 4 & 5 & 6 & 7 & \text { Extremely } \\ \text { Important } & & & & & & & \\ 1 & & & & & & & \\ 1\end{array}$

Hospitality

accommodations

available.

Potential presence

of current

customers.

Corporate staff

knowledge/interest

in sponsored

activity/sport.

Opportunity for event sales/retail tie-in.

Potential presence of new customers.

\section{Promotional Opportunities}

$\begin{array}{llllllll}\text { Not } & 2 & 3 & 4 & 5 & 6 & 7 & \begin{array}{l}\text { Extremely } \\ \text { Important }\end{array} \\ 1 & & & & & & \end{array}$

Opportunity for

promotional

licensing

Complementary advertising (e.g.

event program)

Signage

opportunities

$*$

\section{Competitional Considerations}

$\begin{array}{llllllll}\text { Not } & 2 & 3 & 4 & 5 & 6 & 7 & \text { Extremely }\end{array}$


Competition's

interest in

proposed

agreement

Competition's

ambush

marketing

opportunities

*

\section{Sponsorship Status}

$\begin{array}{llllllll}\text { Not } & 2 & 3 & 4 & 5 & 6 & 7 & \text { Extremely } \\ \text { Important } & & & & & & & \text { Important } \\ 1 & & & & & & \end{array}$

Opportunity to be the title sponsor

Opportunity to be the major sponsor

Opportunity for sponsor exclusivity

Amount of sponsor clutter

Opportunity to sponsor an established sport property/league

Opportunity to secure a long-term relationship

6. Please identify any other selection criteria your company considered when entering into your most recent sponsorship (as identified earlier) and indicate its level of importance $(1=$ NOT IMPORTANT and $8=$ EXTREMELY IMPORTANT)

*

7. Please rank the five most important selection criteria (as identified earlier)which affected your decision to support your most recent sponsorship opportunity. 
8. Do you think the current economic situation (economic recession) has affected the sponsorship objectives and selection criteria over the past two years?

Yes

NO

If yes, please briefly explain

how

\section{PART IV Company Profile}

The following questions are intended to provide background information, which will be used in the analysis of earlier sections in the questionnaire. Please respond to each question to the best of your knowledge.

1. Please check the primary industry in which your company operates.

Airline

Auto Dealer

Banking/Credit

Beverage

Cable

Communication/Technology

Entertainment

Gaming/Gambling

Other (please specify)
Government

Health Care

Insurance/Finance

Print Media

Retail trade

Sporting Goods

Consumer

Electronics

Apparel

2. What level(s) of sports does and/or has your company been involved in sponsorship agreements with? (Check all that apply)

Mainstream Professional Sports (NFL, NBA, Interscholastic (High School) 
Professional Niche Sports

Youth Sports (little league, instructional leagues, etc.)

Intercollegiate Sports

This is our first sponsorship endeavor

3. How would you describe the current scope of your company?

Local Company

Statewide Company

Regional Company

National Company

International Company

4. Approximately how many full-time employees does you company employ nationally?

Less than $25 \quad 76-100 \quad 500+$

$26-50 \quad 101-150$

$51-75 \quad 151-500$

5. Please indicate your approximate gross annual revenues.

$\begin{array}{lll}\text { Less than } & \$ 11 \mathrm{M}-\$ 20 \mathrm{M} & \begin{array}{l}\$ 101 \mathrm{M}- \\ \$ 250 \mathrm{M}\end{array} \\ \$ 1 \text { Million } & & \\ & \$ 21 \mathrm{M}-\$ 50 \mathrm{M} & \\ \$ 1 \mathrm{M}-\$ 4 \mathrm{M} & & \$ 251 \mathrm{M}- \\ & \$ 51 \mathrm{M}- & \$ 500 \mathrm{M} \\ \$ 5 \mathrm{M}-\$ 10 \mathrm{M} & \$ 100 \mathrm{M} & \\ & & \$ 500 \mathrm{M}+\end{array}$

6. In general, how many sponsorship requests/proposals does your company receive annually? 


$$
\begin{array}{lll}
0-10 & 151-200 & 601-700 \\
10-50 & 201-250 & 701- \\
& & 1000 \\
51-100 & 251-500 & \\
& & 1000+ \\
101-150 & 501-600 &
\end{array}
$$

7. What percentage of these requests/proposals comes from North American professional niche sports properties? 


\section{CURRICULUM VITAE}

\section{Greg P. Greenhalgh, Ph.D.}

\section{Home}

4304 S. $3^{\text {rd }}$ Street Apt. 1

Louisville, KY, 40214

Tel:(989)-400-6505

gpgree01@louisville.edu
Office

University of Louisville

100 HPES Building

Dept. of HPES

Louisville, KY, 40292

\section{EDUCATION}

University of Louisville

Ph.D.

Louisville, Kentucky

Major: Educational Leadership \& Organizational Development

Specialization: Sport Administration

Dissertation: An Examination of Professional Niche Sport Sponsorship:

Sponsors' Objectives and Selection Criteria.

Chair: Dr. T. Christopher Greenwell

Central Michigan University

M.A. Sport Administration

2007

Brock University

Bachelor of Sport Management
Mount Pleasant, Michigan

St. Catharines, Ontario

2003 


\section{TEACHING EXPERIENCE}

\section{University of Louisville}

\section{Courses Taught}

$\diamond$ Prepared course syllabi, class lectures, Power Point presentations, class assignments, and created and maintained Blackboard modules for each class.

- SPAD 530: Sport Promotion \& Publicity (Fall 2010)

- SPAD 383: Sport Marketing (Fall 2010, 2 Sections)

- SPAD 402: Internship in Sport Administration (Spring 2010)

- SPAD 381: Principles of Sport Administration (Fall 2009)

- SPAD 384: Current Trends in Sport (Fall 2008)

$\diamond$ Taught a variety of activity classes (Golf, Volleyball, Weight Training, Fitness Walking, and Basketball). Solely responsible for all aspects of development, implementation and grading of classes.

\section{Guest Lectures}

- SPAD 384 Current Trends in Sport. (Spring 2010)

- Invited by Dr. Thorn to speak about violence in contemporary sport.

- SPAD 381 Principles of Sport Administration. (Spring 2010)

- Invited by Dr. Thorn to speak about the proper use of APA referencing and writing format, and management functions in sport management.

- SPAD 384 Current Trends in Sport. (Fall 2008 \& Spring 2009)

- Invited by Professor Sime-McJury to speak about the Canadian Sport System

- SPAD 561 International Sport. (Spring 2008 \& Spring 2010)

- Invited by Dr. Mary A. Hums to speak about the Canadian Sport System

\section{Teaching Assistant}

- SPAD 381: Principles of Sport Administration (Spring \& Fall 2009; Spring 2010)

- Teaching Assistant for Dr. Mary A. Hums, \& Dr. Dustin Thorn

- Assisted in redesigning class, creating and modifying course assignments and group activities to accommodate a large lecture section of 80 students.

- Prepared and delivered two guest lectures each term on Sport and the Environment, and Sport Marketing 
- Assisted in grading Resumes, APA Assignments, Career Exploration Papers, Mid-Term and Final Exams for 80 students

- Maintained grade records and Blackboard class module

\title{
Central Michigan University
}

\author{
Guest Lectures
}

- PES 320 Foundations of Sport Management(Fall 2005 \& Fall 2006)

- Invited by Professor Albrecht to speak about the artificial turf industry and my career within the artificial turf industry, specifically with FieldTurf Tarkett

\section{INDUSTRY EXPERIENCE}

FieldTurf Tarkett, Montreal, Quebec

$2004-2007$

Company Representative

- Presented the benefits of the FieldTurf Tarkett turf system and company philosophy to potential customers throughout Ontario

- Represented company at high profile events such as Super Bowl XL and the NCAA 2006 Annual Convention

- Represented company for troubleshooting purposes at Ford Field in Detroit, Michigan on five occasions

\section{Professional Hockey Players' Association, St. Catharines, Ontario}

Intern

- Assisted the Marketing, Licensing, and Communications Department with daily functions and updated website information continuously

- Conducted several interviews with American Hockey League and East Coast Hockey Alumni

Gatter's Pro Shop, St. Catharines, Ontario

$1998-2005$

Assistant Manager

- Trained 6-10 new employees on effective sales and customer service techniques

- Enhanced corporate image and public relations through several marketing and sponsorship campaigns

- Managed day-to-day operations including: staffing, sales, promotions and inventory control 


\section{RESEARCH}

\section{Peer Reviewed Presentations}

Hambrick, M., Simmons, J., Greenhalgh, G., \& Greenwell, T. C. Understanding athletes' use of Twitter: A content analysis of athlete Tweets. North American Society for Sport Management 2010 Annual Conference in Tampa, FL.

(To be presented June 1-5, 2010).

Tokuyama, S., \& Greenhalgh, G. Segmenting Recreational Soccer Participants based on General Demographic Variables: Who is more Committed to Watching Professional Soccer Games? North American Society for Sport Management 2010 Annual Conference in Tampa, FL.

(To be presented June 1-5, 2010).

Moorman, A., Greenhalgh, G., Hambrick, M., \& Simmons, J. (2010, March). "Run 'til Somebody Quits": An Examination of Procedural and Governance Repercussions Following the Death of a Kentucky High School Football Player. Sport and Recreation Law Association 2010 Annual Conference in Albuquerque, NM.

Greenhalgh, G., Simmons, J. M., Hambrick, M. E., Greenwell, T. C., Tubbs, T. E., \& Short, K. J. (2009, October). Finding their niche: Predicting spectator support for non-mainstream sports. Presented at the annual meeting of the Sport Marketing Association, Cleveland, $\mathrm{OH}$.

Hambrick, M., Brownlee, E., Simmons, J. \& Greenhalgh, G. (2009, March). Grading the alcohol policies of professional sports leagues: A practical application of dram shop statutes. Presented at the annual meeting of the Sport and Recreation Law Association, San Antonio, TX.

\section{Book Chapters}

Greenhalgh, G. (Under Contract). Return on sponsorship investment. In L. E. Swayne, \& G. J. Golson (Eds.). Encyclopedia of Sports Management and Marketing. Thousand Oaks, CA: SAGE Publications.

Greenhalgh, G. (Under Contract). Marketing through sports. In L. E. Swayne, \& G. J. Golson (Eds.). Encyclopedia of Sports Management and Marketing. Thousand Oaks, CA: SAGE Publications. 


\section{Works in Progress}

Greenhalgh, G., Simmons, J., Hambrick, M., Tubbs, T., Short, K., \& Greenwell, T.C. (In Review). Spectator Support: Examining the Attributes Which Differentiate Niche from Mainstream Sport. Sport Marketing Quarterly.

Hambrick, M. E., Simmons, J. M., Greenhalgh, G., \& Greenwell, T. C. (In Review). Understanding athletes' use of Twitter: A content analysis of athlete tweets. International Journal of Sport Communication.

Greenhalgh, G., Moorman, A., Hambrick, M., Simmons, J. An examination of the critical factors within the foundational criminal trial following the death of a Kentucky high school football player.

Hambrick, M., Simmons, M., Greenhalgh, G., \& Moorman, A. Procedural and governance repercussions within interscholastic sports following the death of a Kentucky high school football player.

Greenhalgh, G. Economic Crisis: Tenable Defenses for Sponsors' Breach of Contract. (To be submitted to The Journal of Legal Aspects of Sport).

Stover, N. E., Greenhalgh, G., \& Sime-McJury, K. A multi-stakeholder analysis of the sport administration internship experience: Investigating the use of interns within a newly established franchise.

(To be submitted to the Sport Management Education Journal)

\section{Unpublished Works}

Greenhalgh, G. (2007). An investigation of the purchasing considerations and satisfaction levels of Michigan high school athletic directors and head football coaches competing on synthetic infilled turf playing fields. Unpublished Masters research project, Central Michigan University.

Greenhalgh, G. (2010). An Examination of Professional Niche Sport Sponsorship: Sponsors' Objectives and Selection Criteria. Unpublished Doctoral Dissertation, University of Louisville. 


\section{SERVICE, PROFESSIONAL ACTIVITY, \& MEMBERSHIPS}

\section{Departmental/Program Service}

\section{University of Louisville}

Sport Administration Program

2007 - Present

- Assist in undergraduate student advising and meet with prospective undergraduate students and their parents

- Participate in doctoral student professional development workshops

- Attend faculty candidate functions, guest faculty lectures, and required doctoral student meetings

- Meet with prospective Master's and Doctoral students

Sport Administration Club

$2009-2010$

Assistant to the Faculty Advisor

- Assist in the development of undergraduate/graduate student executive board

- Provide guidance and assistance to the general membership

- Assisted in organizing group trip to visit Charlotte Bobcats and Charlotte Sports Commission

- Assisted in organizing trip to 2009 Winter Baseball Meetings in Indianapolis, $\mathrm{N}$

Vice-President

$2007-2008$

- Organized thirteen member trip to $15^{\text {th }}$ Annual Georgia Southern University Sport Management Conference securing $\$ 1,950$ from the University of Louisville Graduate Student Council Travel Administrator and Recognized Student Organizations' Club Programming Committee for graduate and undergraduate students

- Secured approximately $\$ 2000$ in funding for Club activities/functions

- Organized executive committee and general membership monthly meetings

- Assisted in obtaining Recognized Student Organization status

\section{Professional Memberships}

$\checkmark \quad$ North American Society of Sport Management

- Attended 2009 Annual meeting, Columbia, SC

- Sport Marketing Association

- Attended 2009 Annual meeting, Cleveland, $\mathrm{OH}$

$\checkmark$ Coaching Association of Canada 
Community Service

\author{
Louisville Courier Journal \\ November 2008 \\ Newspaper Interview \\ - Interviewed by Beth Burwinkel of the Courier-Journal concerning a \\ story on the history of sport in North America.
}

Bellarmine University

Invited Sports Information Assistant

Spring 2008

- Supervised time keeping at NCAA DI Lacrosse games

- Supervised accurate statistical record keeping at NCAA DI Lacrosse games

Central Michigan University

$2006-2007$

Assistant Men's Club Lacrosse Coach

- Developed and implemented team offensive system

- Organized and implemented specific game and practice plans

- Developed player skill sets at a variety of levels

Central Michigan University

$2006-2007$

M.A. in Sport Administration Marketing Plan

- Created and implemented marketing plan directed at increasing the quality and quantity of applicants to the M.A. in Sport Administration Program

- Organized and hosted an informational session directed at Central Michigan undergraduates

- Redeveloped the M.A. in Sport Administration website 